\title{
From Uncivil War to Civil Peace: Algerian Women's Voices [Arabic]
}

Leila Hessini

Follow this and additional works at: https://knowledgecommons.popcouncil.org/departments_sbsr-pgy How does access to this work benefit you? Let us know!

\section{Recommended Citation}

Hessini, Leila. 1998. "From Uncivil War to Civil Peace: Algerian Women's Voices [in Arabic]." Cairo: Population Council. 


$$
\begin{aligned}
& \text { مجلس السكان الدولي } \\
& \text { المكتب الاقليمي لمنطقة غرب آسيا و شمال أفريقيا }
\end{aligned}
$$

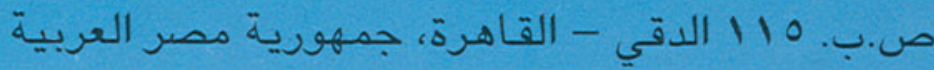

$$
\begin{aligned}
& \text { تليفون : r.r)0Y0097r: }
\end{aligned}
$$




\title{
من الحرب الهمجية إلى السلام المدنى: آراء نساء جزائريات
}

\author{
ليلى حسينى
}




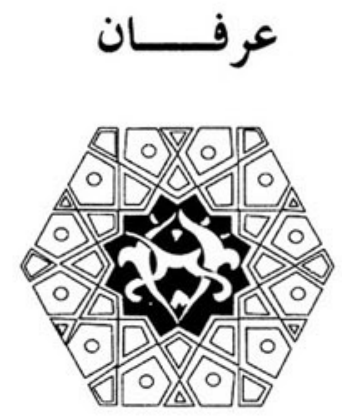

تدين هذه الكراسة بالكثير للتعليقات البناءة لكل من: لويزا آيت - هـامو، كريستيان آراندل، لاكيتش ديراس، نعمت

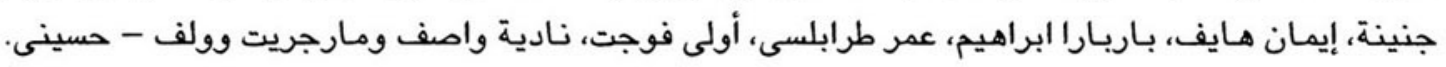

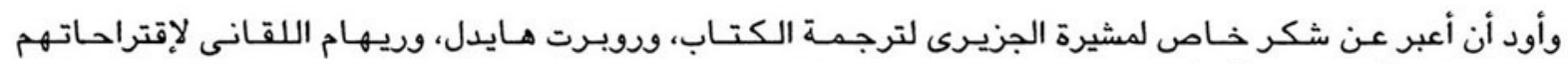

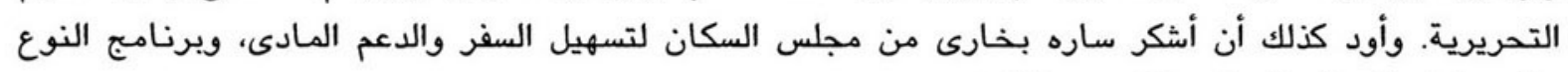

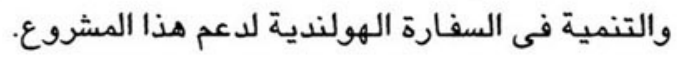

ومالم تسمح النساء اللاتى اجريت لقاءات معهن باستخدام أسماءهن الحقيقية، فقد أعطيت لهن أسماء مستعارة حماية لسلامتهن.

$$
\text { ليلى حسينى }
$$

القاهرة، مايو 1991 
"هناك ماهو أسوأ فى هذه الحياة من الموت: الموت هباءَّ" 


\section{إن \\ ฏृ?}

9

Ir

10

IV

rV

rr

rv

$\varepsilon q$

or

00

09

Tr
ملخص

تقديم

أولاً: خلفية المشروع وملاحظات تمهيدية

ثانياً: العوامل المؤدية الى الأزمة الحالية في الجزائر

ثالثاً: العنف فى الجزائر

رابعاً: النشاط النسائى فى التاريخ الجزائرى

خامساً: خصائص وأنواع التنظيمات النسائية

سادسأ: مـا الذى يمكن عمله ؟

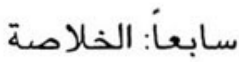

ثامنأ: المراجع

ملحق رقم ا: أفكار برامجية

ملحق رقم Y: ماذا تفعل بعض المنظمات لمساعدة الجمعيات الأهلية الجزائرية؟ 


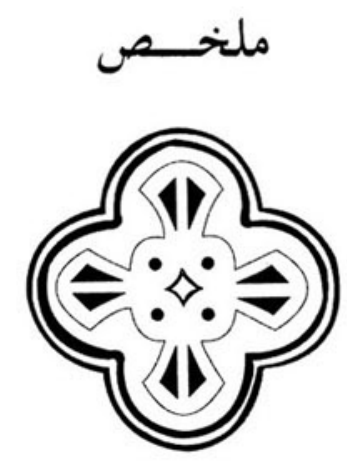

"هناك نوعان من الوقت: وقت للانتظار ووقت للأمل": جاك بريل.

نالت الجزائر استقلالها في عام 1971 بعد سبع سنوات من الحرب مات خلالها جزائرى واحد من بين كل سبعة جزائريين.

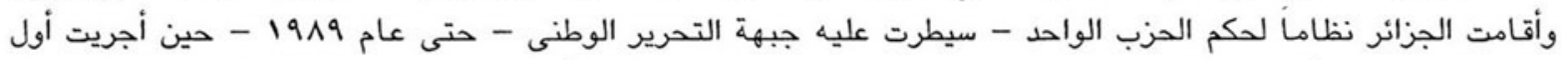

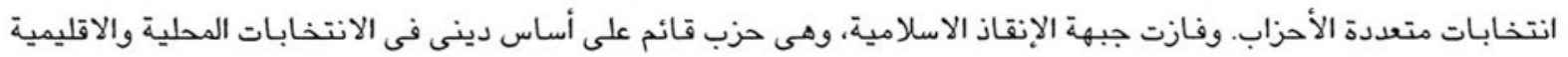

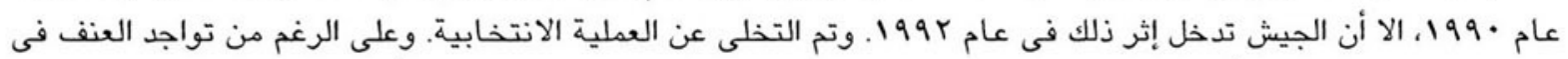

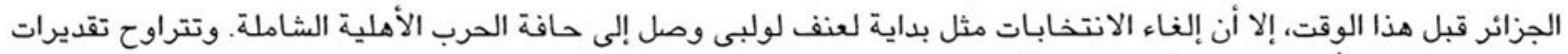

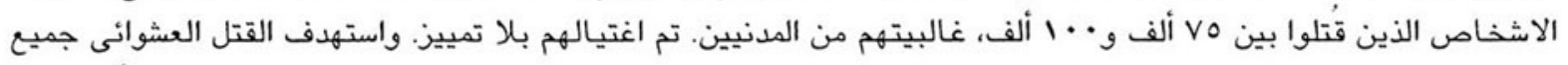

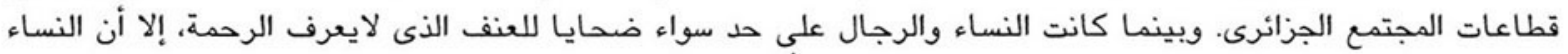

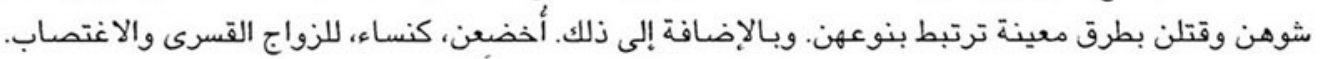

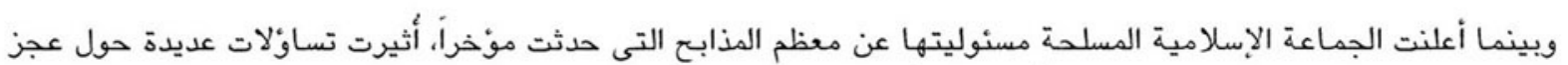

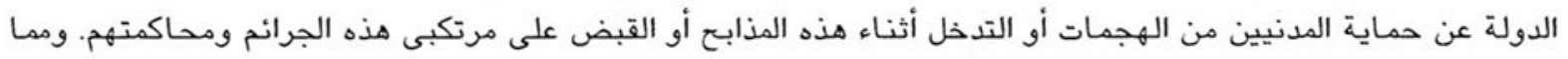

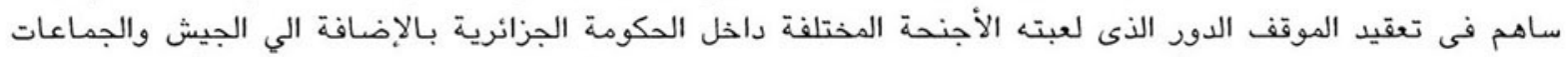
الاسلامية المسلحة. وقد عبرت أحدى الجزائريات ببلاغة عن هذا الوضع بقولها "إن الشعب الجزائرى شعب من الألرفية الأيتام”.

وأضافت الطبيعة المبهمة لنظام الحكم فى الجزائر إلى هذا الإحساس بعدم الأمان والرعب. لقد وصفت الجزائر بأنها بلد

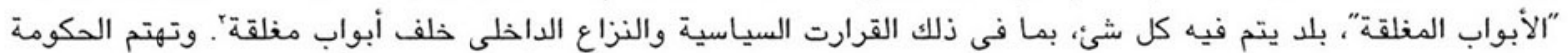

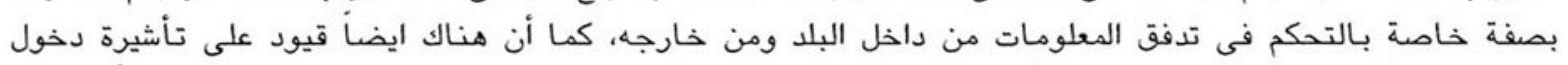

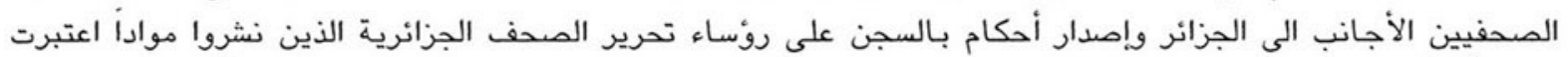

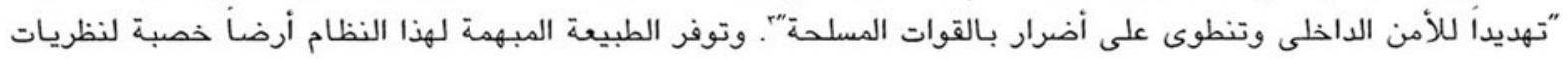

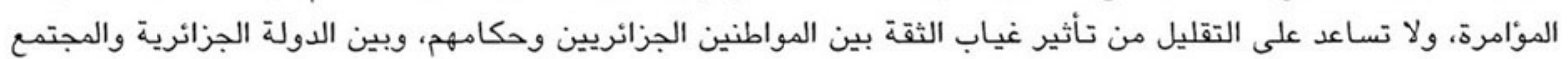

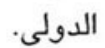

ولم تساعد التغطية الاعلامية الدولية للجزائر فى تسليط الضوء على الوضع الحالى، وتنحصر الصورة الوحيدة التى تقدمها في الإني

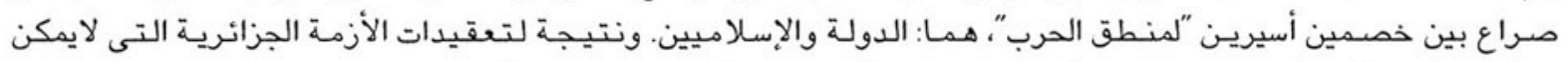

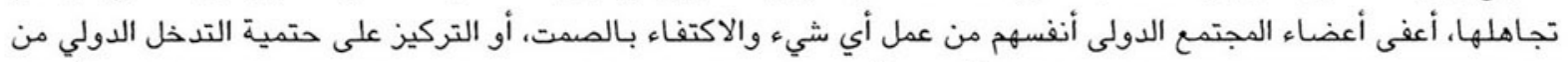
جانب واحد كحل. وتعارض الدولة الجناء الجزائرية "التدخل" الدولي بشدة ويتساءل كثير من الجزائريين عن فعالية التهية هذه الأعمال ونتيجتها الملموسة. 
بالاضافة إلى ذلك، هناك حقائق جزائرية أخرى - لاتغطيها الصحافة الدولية. فالأفراد والمجموعات فى الجزائر أسرى "منطق

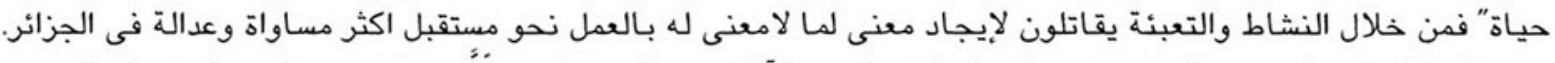

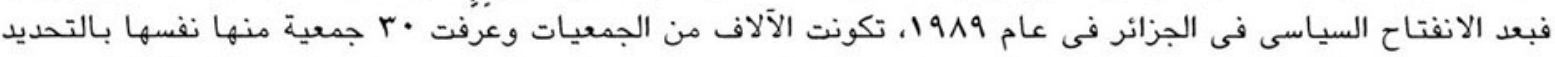

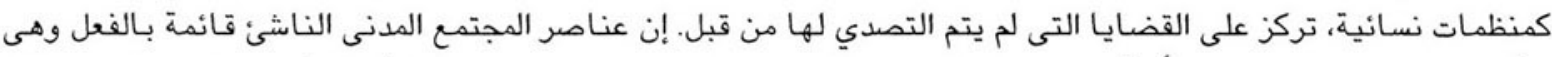

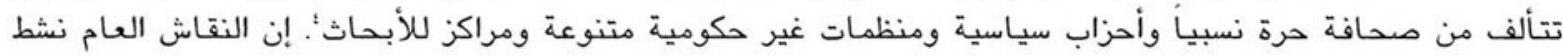

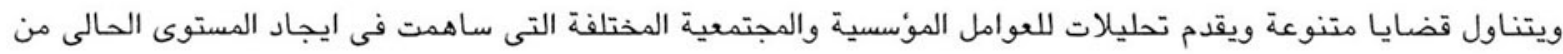

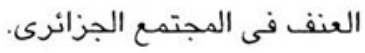

ومنذ إنشائها، ركزت معظم التنظيمات النسائية على حقوق النساء، وتحقيق المواطنة الكاملة لهن، وتصحيح الوضع المتدنيي

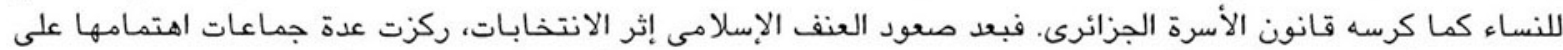

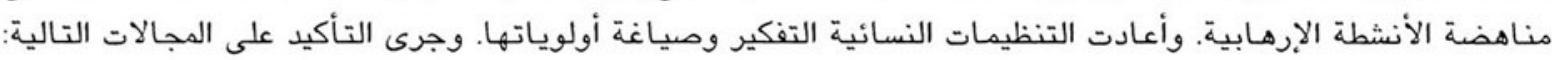

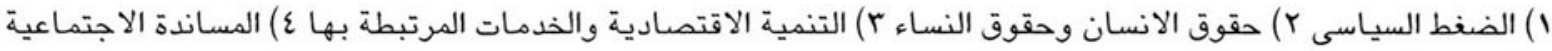

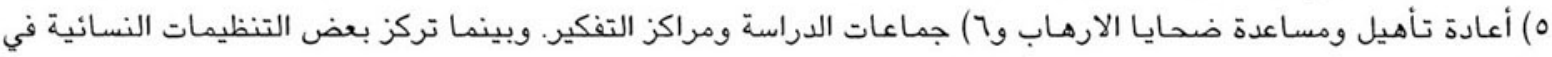

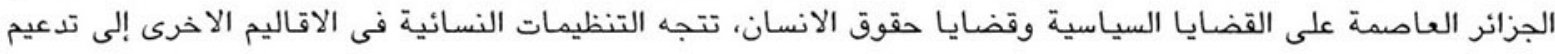
استقلالية النساء من خلال تنمية وتطوير مشروعات لتوليد الدخل وإنشاء مراكز لرعاية الاطفال ويرامج لمحو الامية.

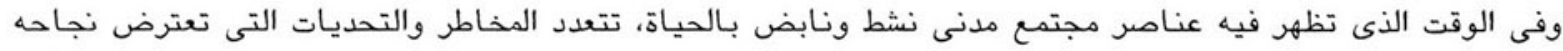
وتطوره. وبينما تستخدم بعض التنظيمات النسائية المجال العام لتعزيز الاختيارات الديموقراطية، يستخدم البعض التضات الآخر

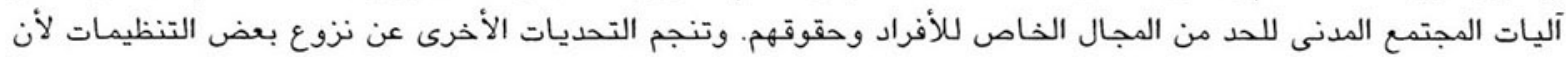

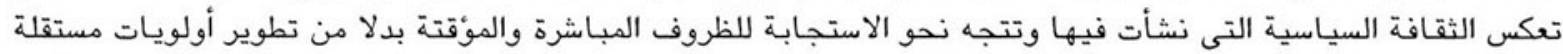

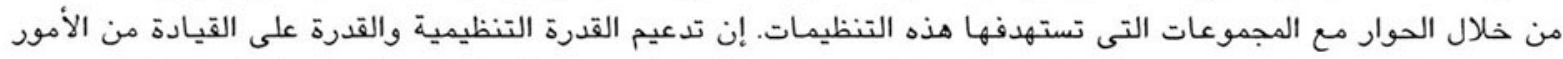

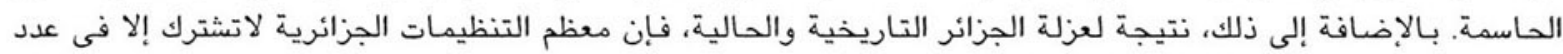
قليل، إن وجد، من شبكات المنظمات الإقليمية أو الدولية.

لقد حان الوقت للتأمل التحليلى والاستراتيجى فيما يمكن أن يكون الدور الأكثر فعالية ومسئولية الذى يمكن أن يلعبه المجتمع الداني

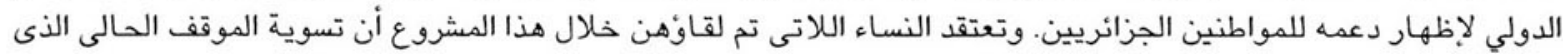

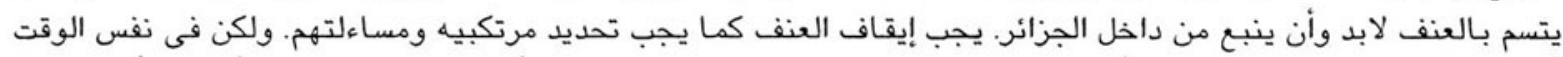

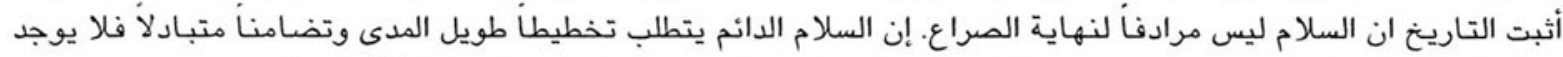

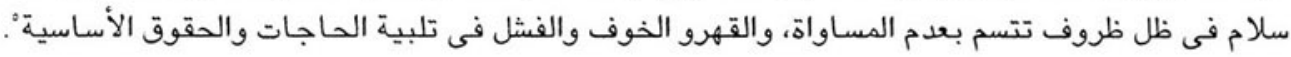

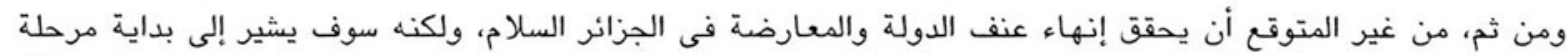

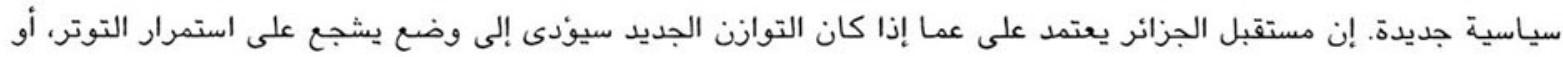

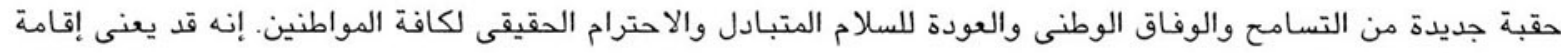

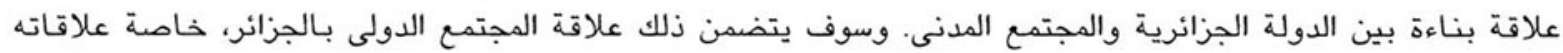

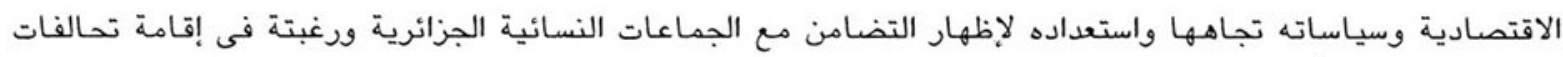

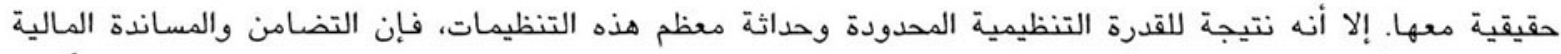
المرتقبة يجب أن تكون قائمة على أساس سليم حتى لاتساهم في تفتيت المجتمع المدنى الجزائرى الذى لايزال غير مستقراً.

ع إن المجتمع المدنى جزء أساسى في أى ديمقراطية ويشير الى خليط من الجمعيات والنوادى والنقابات والإتحادات والأحزاب والمجموعات التى تجمعت هeاً

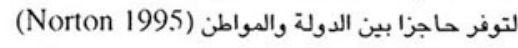

Heyzer, Noelee. "The Worst Victims of War: The Highest Stakeholders of Peace.” In Looking at Peace Through 。 Women's Eyes. Ed. Joy Mutero. Nairobi: Regal Press Kenya Limited, 1996:9. 
ومن أجل البناء على نقاط القوة فى الحركة النسائية الجزائرية والتغلب على بعض التحدئ التحفيات التى تواجهها، إقترح هذا التقرير

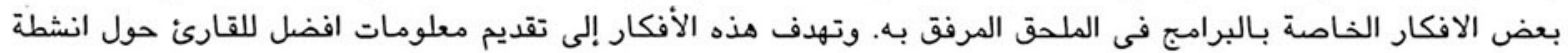

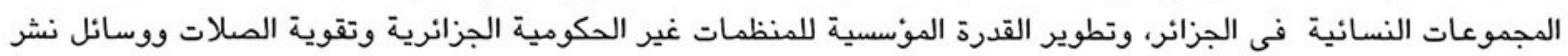

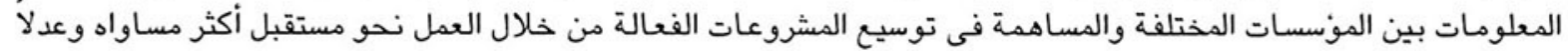
في الجزانر.

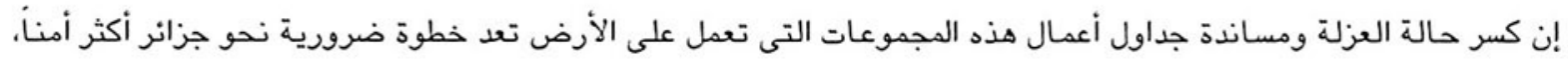

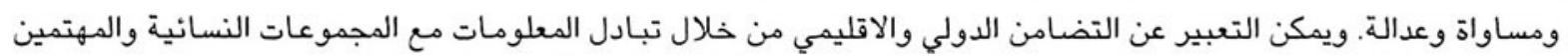

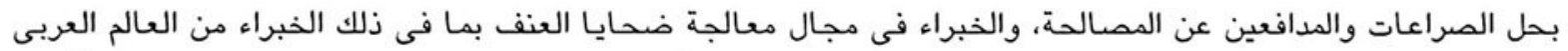

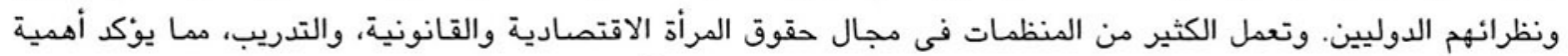

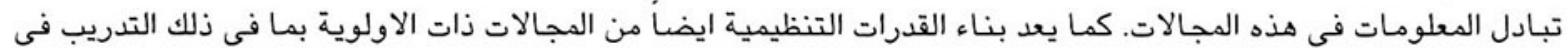

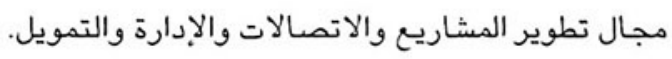

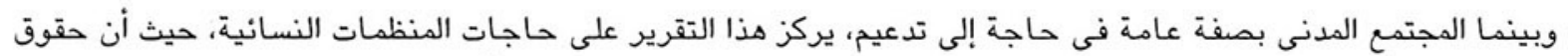

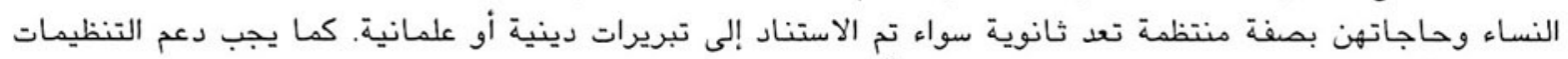

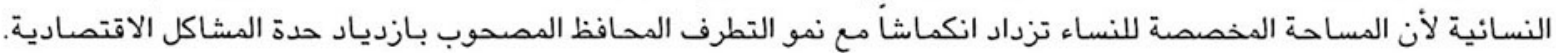
وبالتالى، فإن مساعدة النساء الجزائريات فى جهودهن نحو تحقيق المساواه والمشاركة والمواطنة الكاملة من الامور الحيوية.

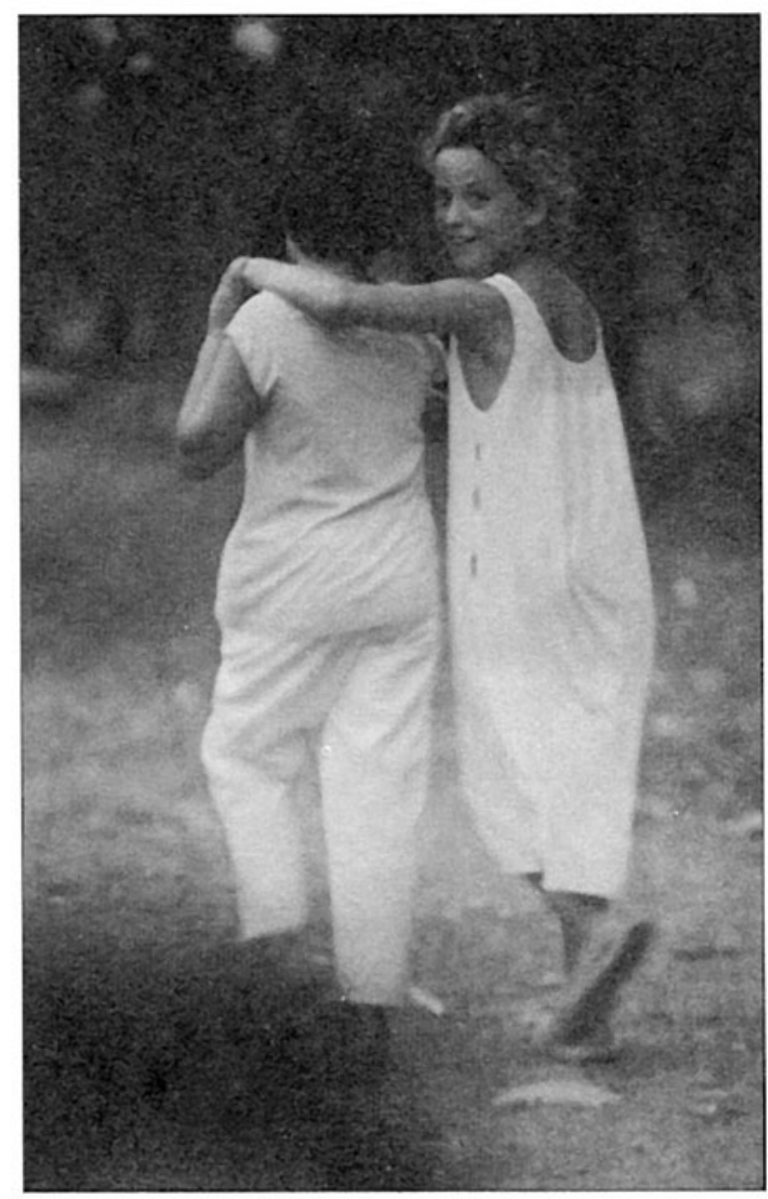

أمدقاء صنار من الجزانر 


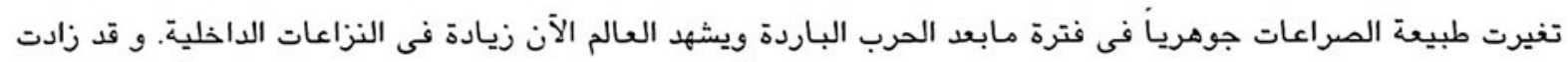

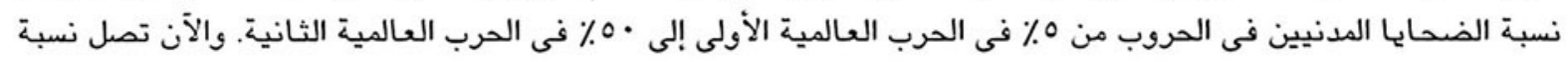

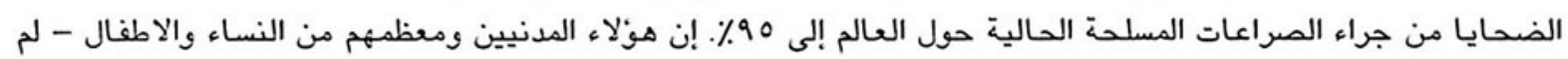

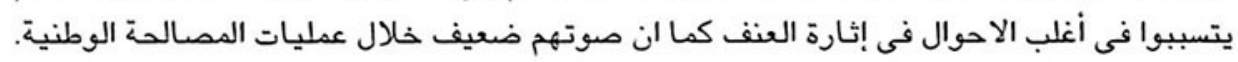

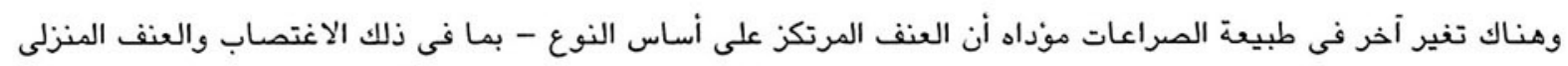

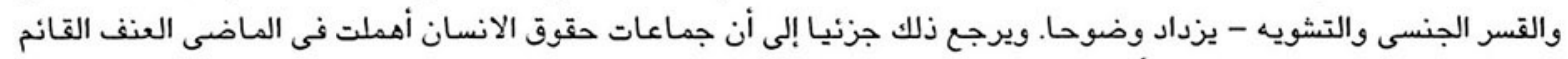

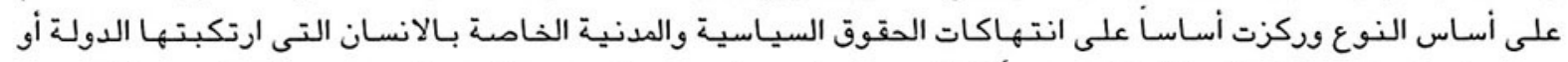

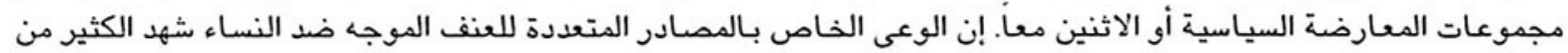

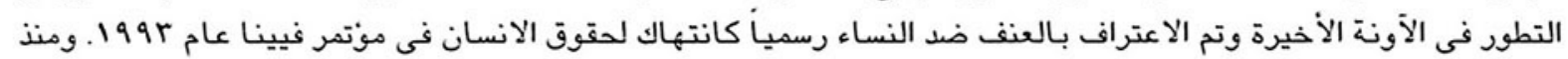

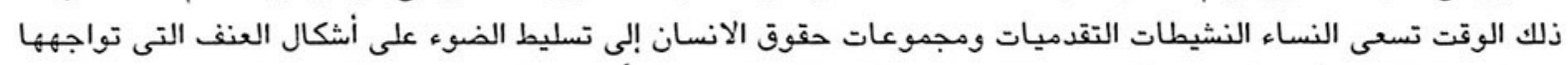

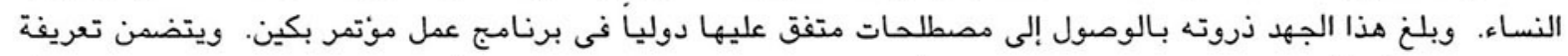

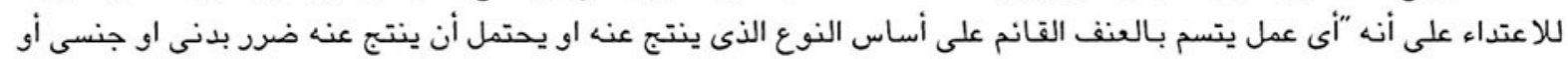

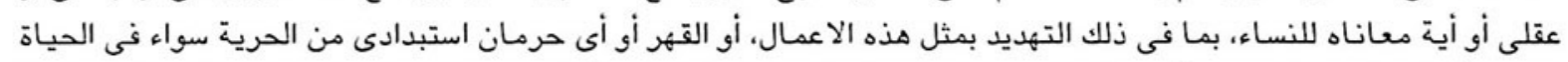

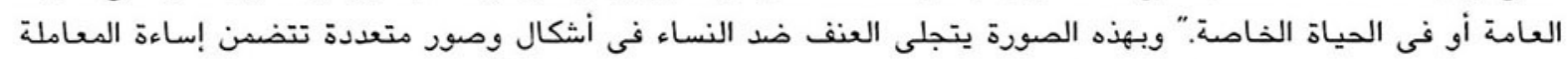

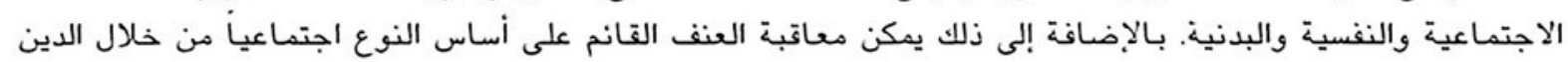
والتقاليد وايضا عن طريق سياسات الدولة والتشريعات.

استجاب صندوق الأمم المتحدة للنساء للصراعات المعاصرة التى تتميز بأنها تستهدف على نحو متزايد المدنيين بصفة عامة النهاء

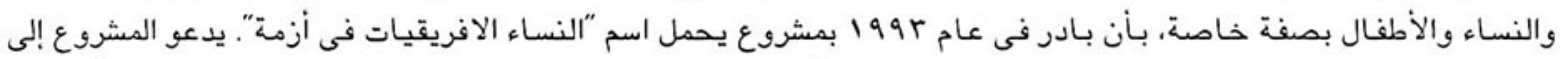

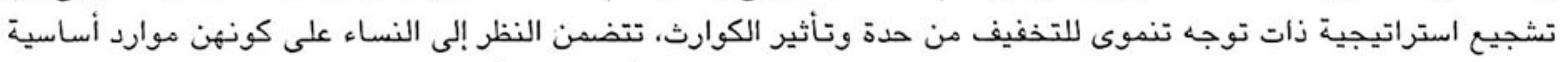

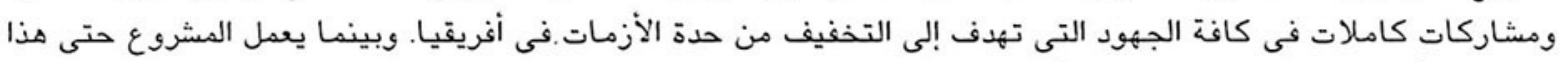

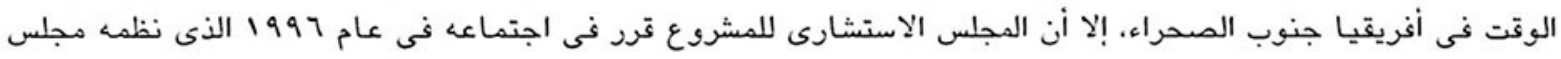

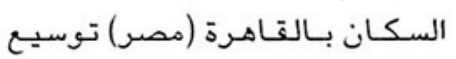
دانـرة مشروع "النساء الاغريقيات فئات

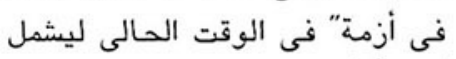

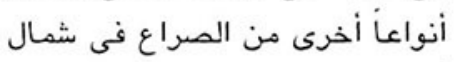

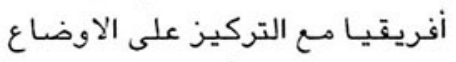

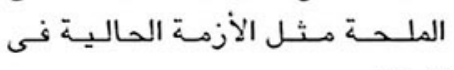
الجزانر.

وكخطوة أولى أصدر مجلس السكان الدولى بالتعاون مع مشروع ألى "النساء الاغريقيات فى أزمة" كراساً عنوانه

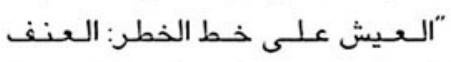

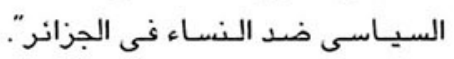

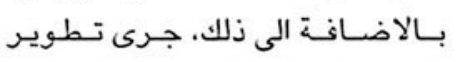

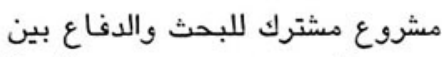
مشروع "النساء الاغريقيات في أزمة مدئ

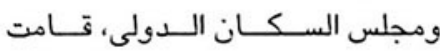

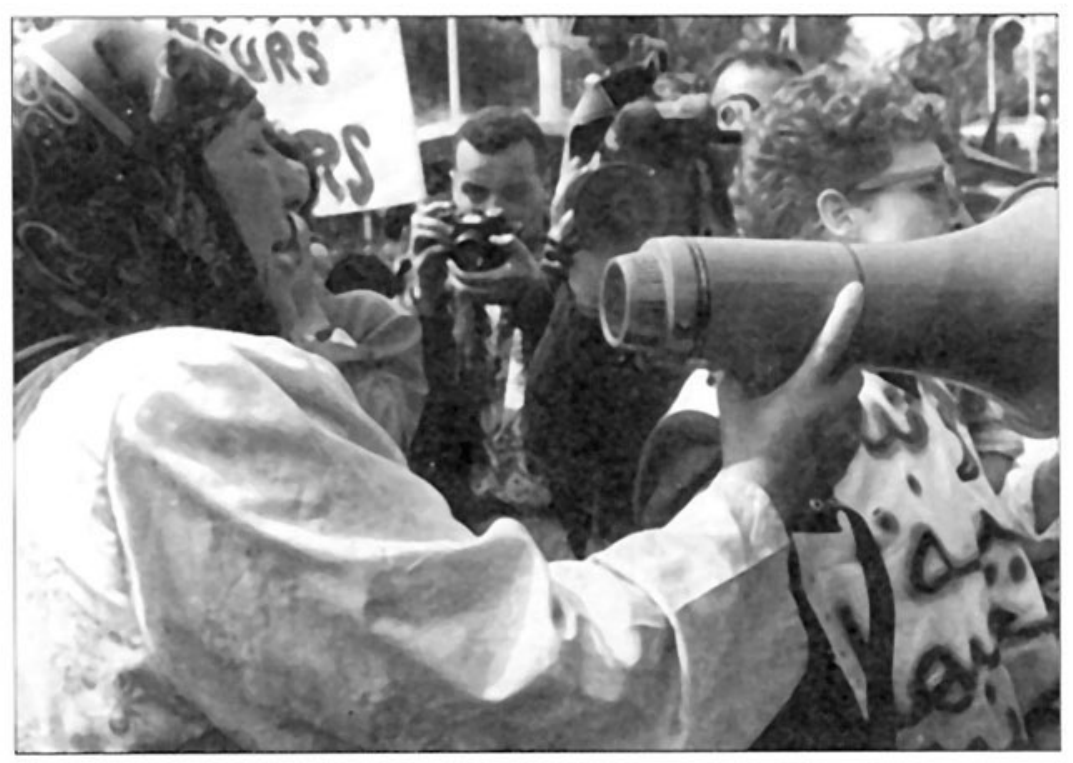

مظلاهرذ نسـانبة نى الجزانر

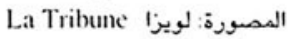




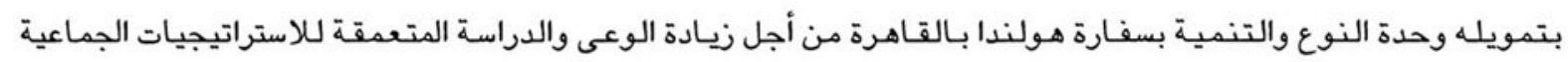

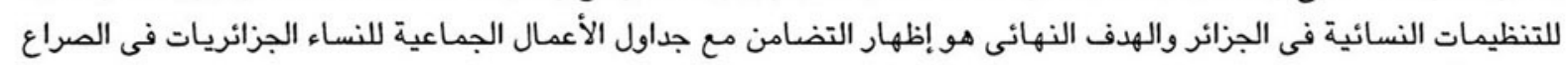

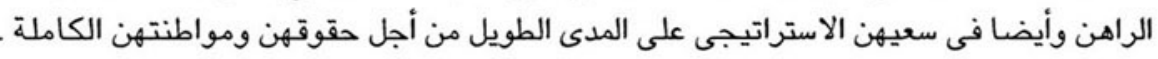

وتضمنت المرحلة الأولى من المشروع مسحاً وتقريراً حول الوضع الحالى بما فى ذلك رسم خريطة للتنظيمات النسائية

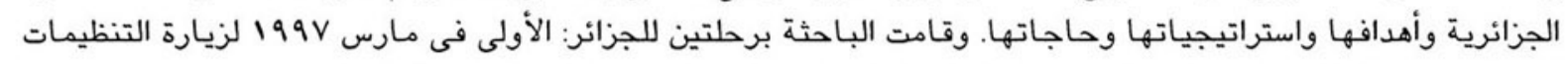

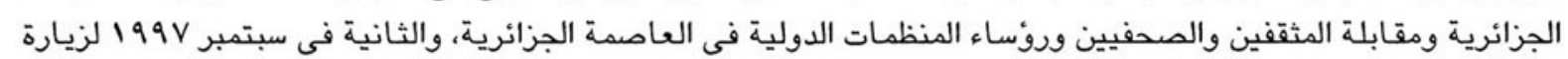

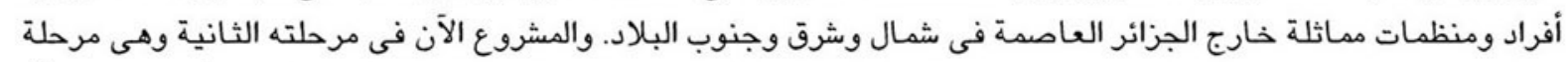

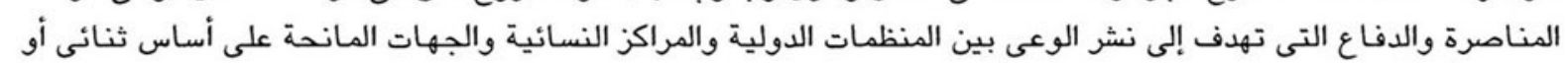

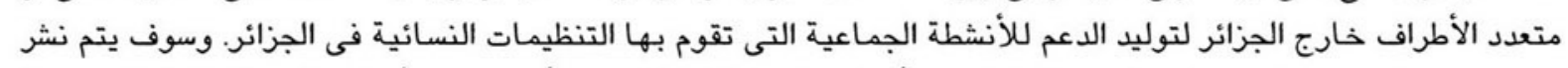

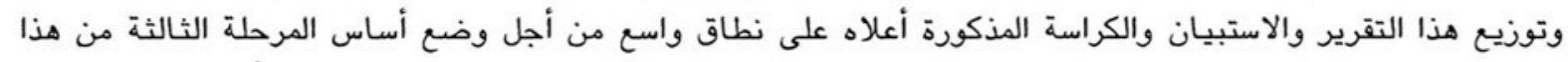

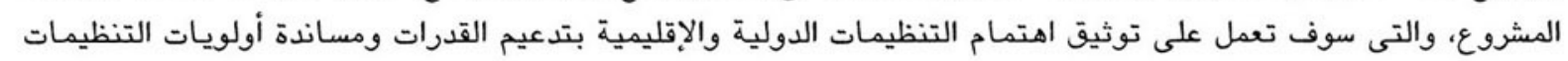
الجزائرية، وتبادل هذه المعلومات داخل تعل الجزائر. 


\title{
أولا: خلفية المشروع وملاحظات تمهيدية
}

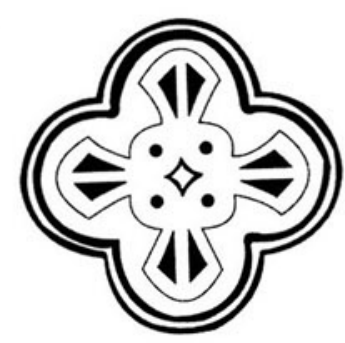

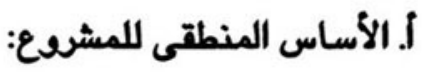

\author{
"كيف يمكن إنهاء حرياً يشنها الإنسان ضد نفسه؟
}

كان الدافع وارء هذا المشروع هو الوضع الملح في الجزائر الذي اتسم بتزايد أعداد الموتى والمصابين على نحو مونى مثير، واستخدام

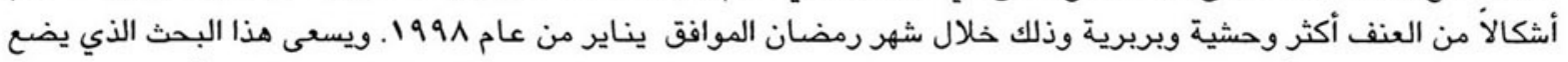

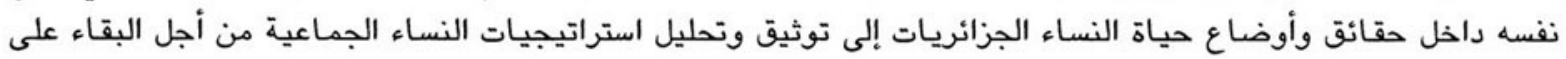

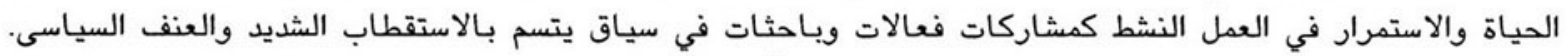

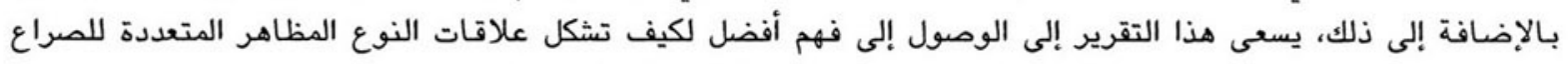

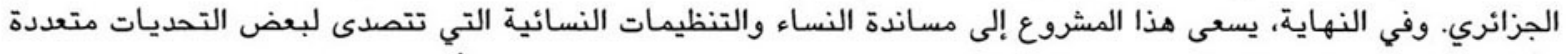

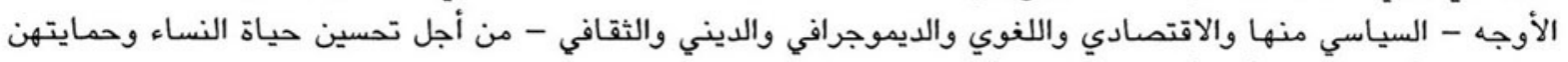
والعمل من أجل مستقبل أكثر أمنا في المقام الأخير.

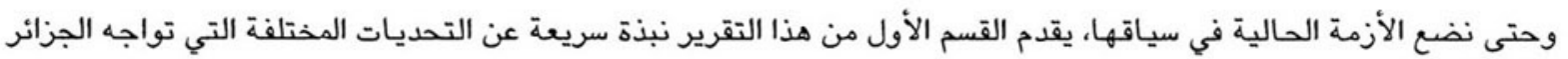

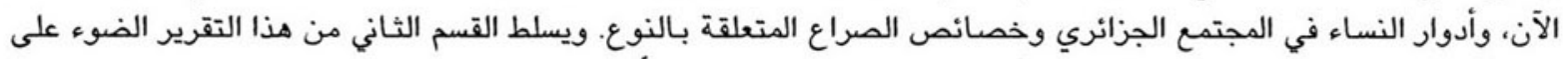

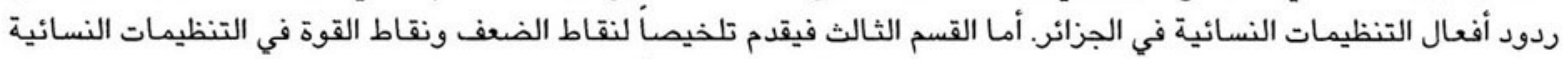

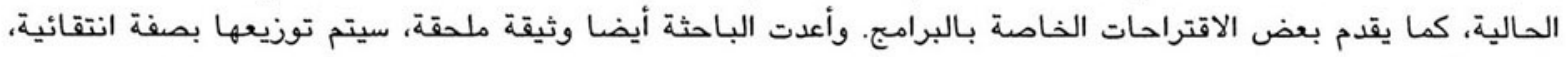

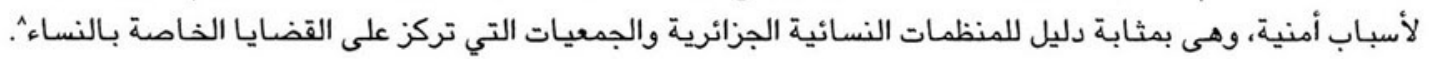

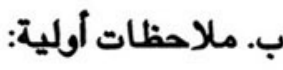

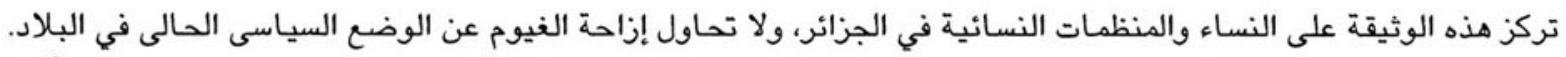

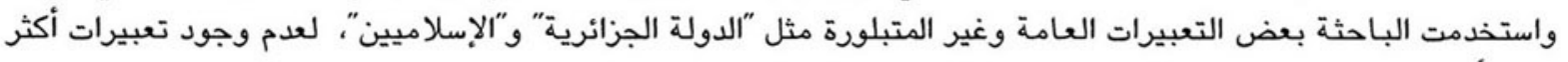

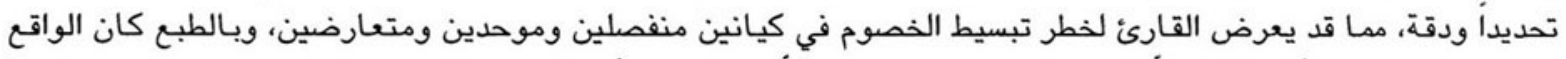

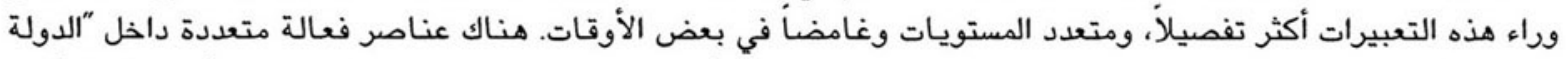

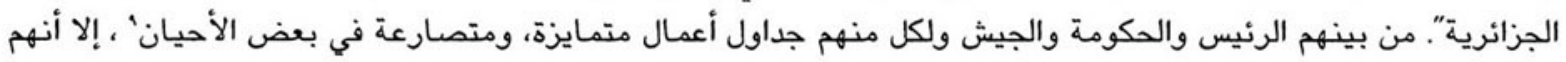
يشتركون جميعا في رغبتهم في الحفاظ على الوضع القائم والنظام الحالي للحكم.

ويشير تعبير "الإسلاميين" إلى ألوان مختلفة من الأحزاب السياسية وجماعات المعارضة في الجزائر تتراوح بين أحزائ أحزاب

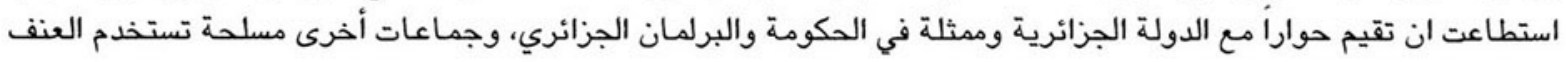

V ل لطيفة، متخصصة علم نفس. V ^ تللك هى المحاولة الأولى لجمع مثل هذا الدليل وإن كانت لم تكتمل بعد. وتأهل الباحثة فى استخدام هذه البيانات كقاعدة لمزيد من التوسع.

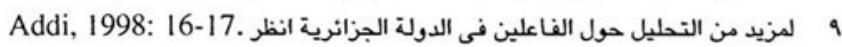


للوصول إلى أهدافها. وبينما تختلف تكتيكات الجماعات الإسلامية جذرياً، إلا انها تشترك جميعا في نسقها المرجعى ورغبتها في إقامة الجمهورية الجزائرية الإسلامية. على القارئ إذن أن يتذكر أن التعبيرات المستخدمة في هذا التقرير تعكس واتعاً معقدأ.

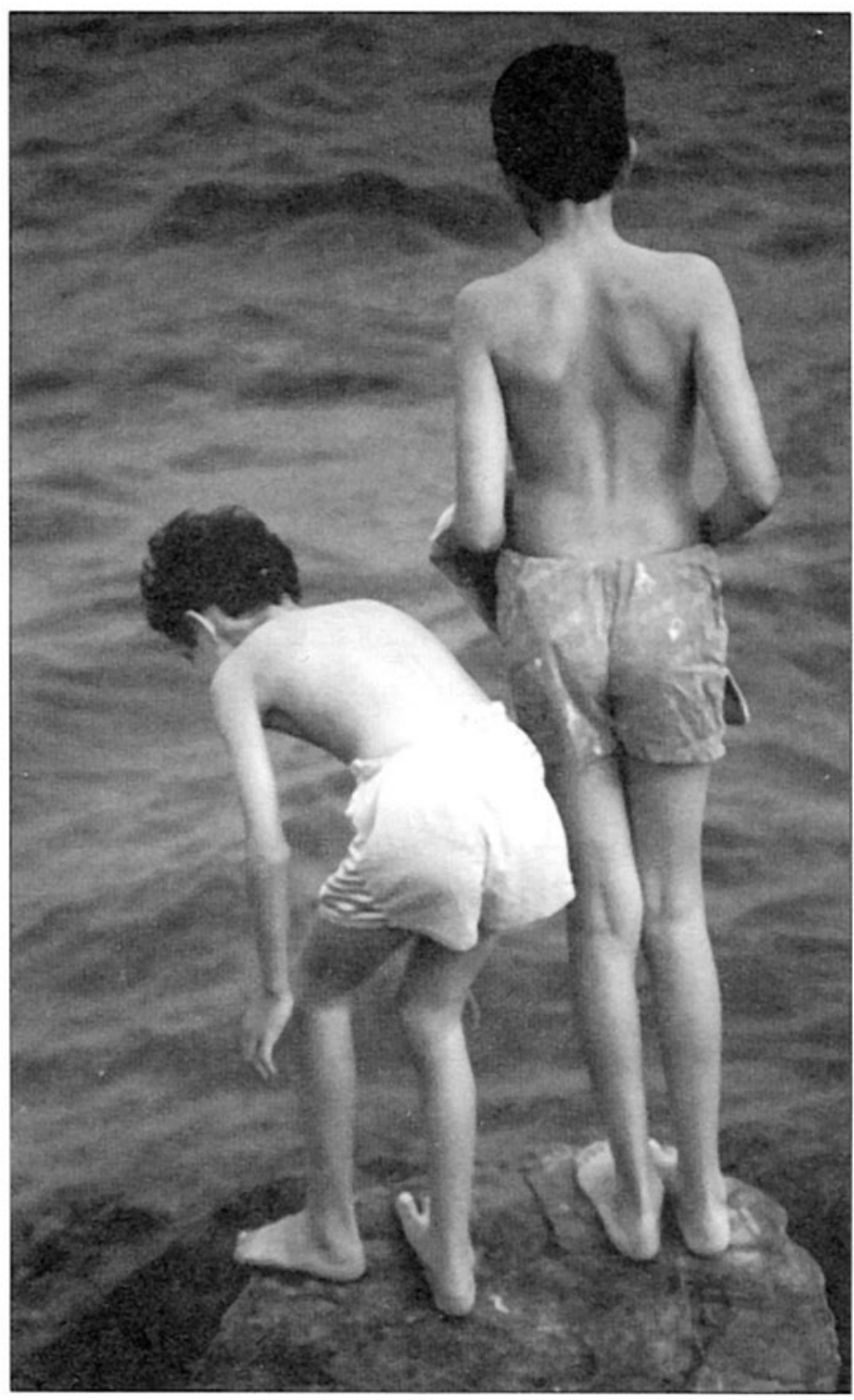

طلغان جزانريان يلهوان على شاطىء البحر الأبيض 


\section{ثانيا: العو امل المؤدية إلى الأزمة الحالية فى الجز ائر}

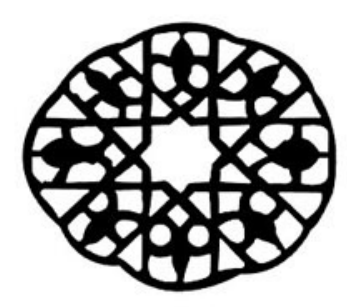

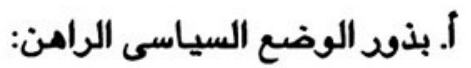

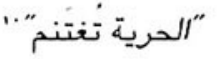

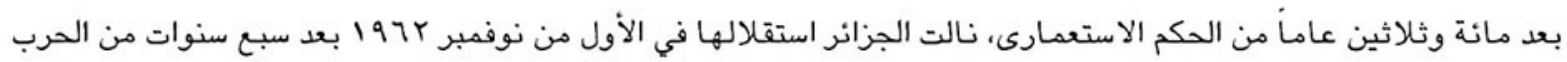

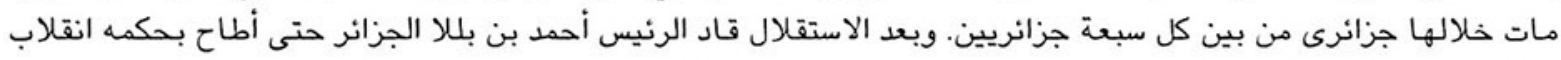

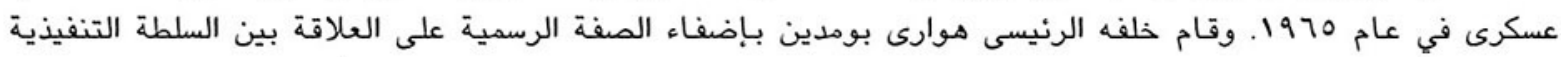

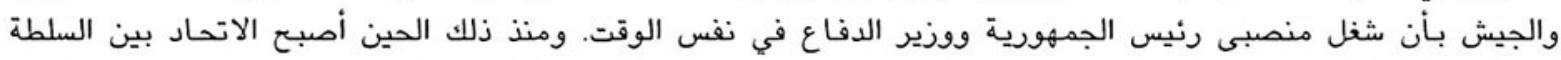

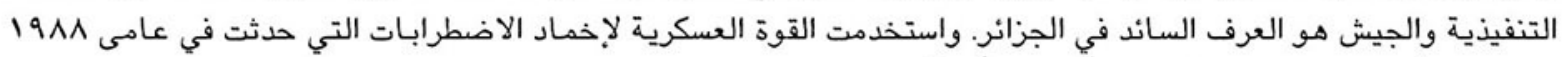

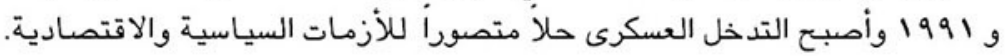

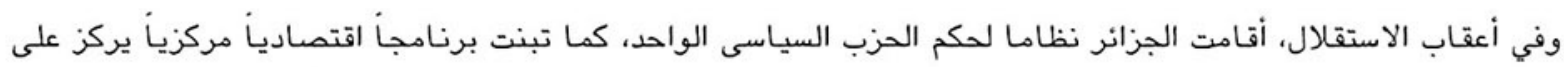

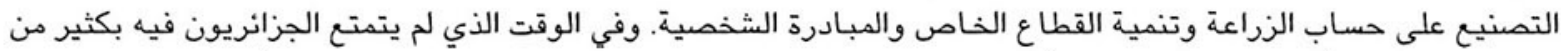

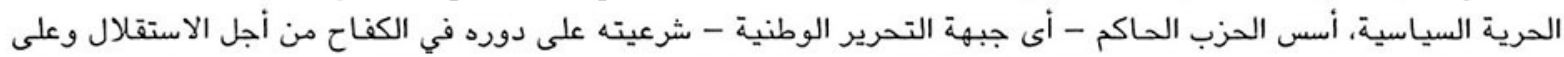

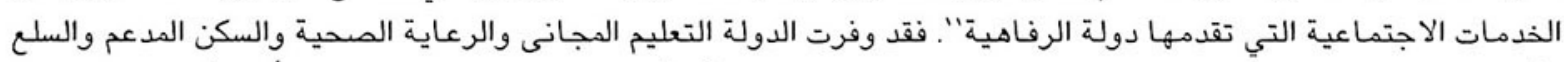

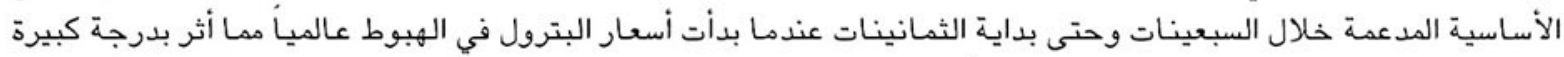

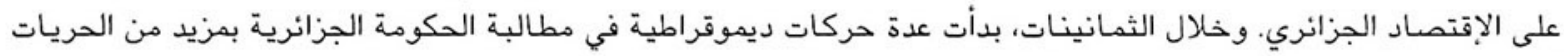

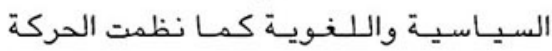

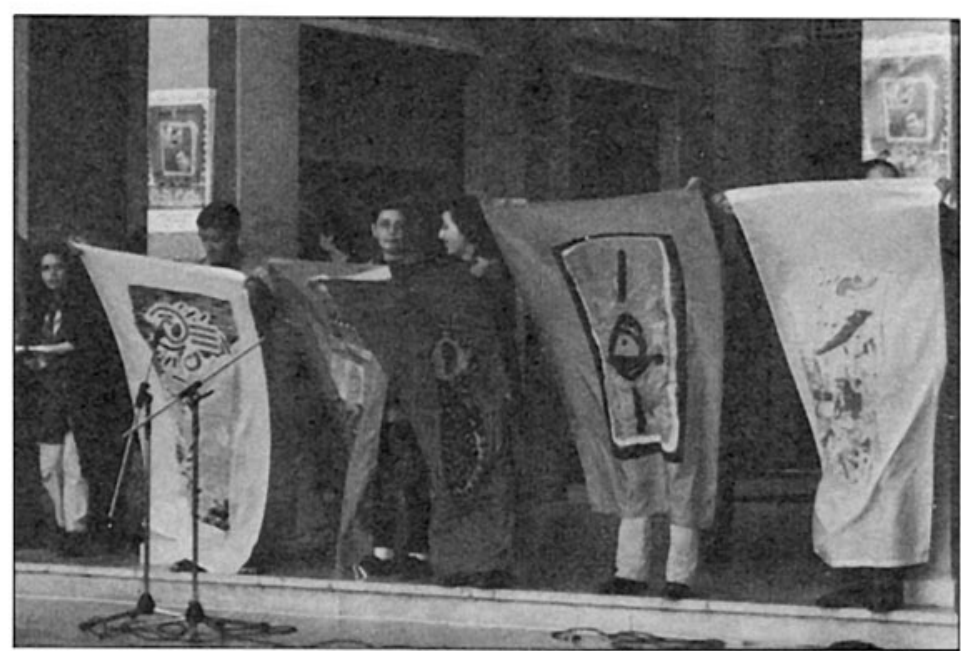

الدسابقة السنوية "علم النساهع"

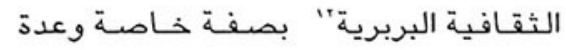

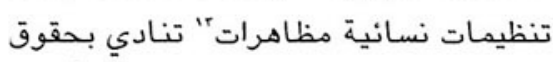
لـنــويـة وتــنـاهض سـن قـانـون الأسـرة

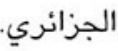

وفي عام 1911 إندلعت مظاهرات حاشدت

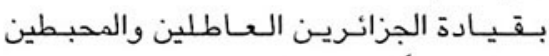

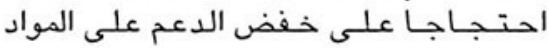
الغذائية الأساسية. وردت السلطات بـالعنف

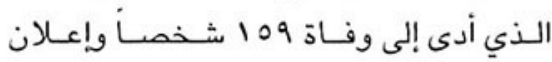
حالة الطوارئ وتطبيق الأحكام العرفية.

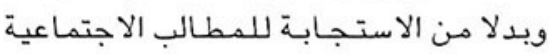
والاقـتصـاديـة، قـامت الحكومـة بـــعديـل 
الدستور الجزائري وتحرير مؤسسات الدولة بالسماح بتكوين الجمعيات، وإضفاء الشرعية على الأحزاب المعارضة في سياق

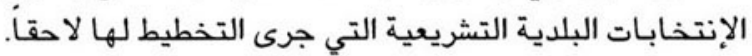

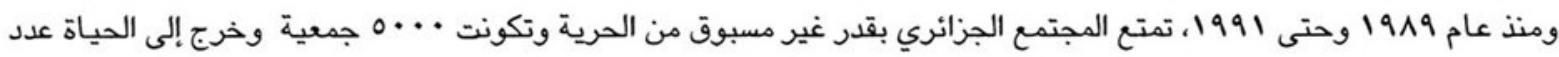

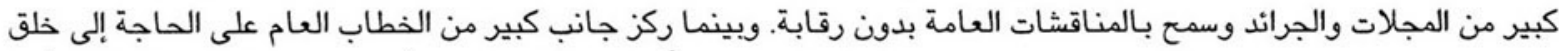

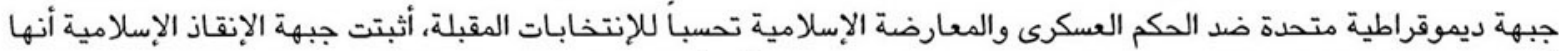
أكثر مهارة في إستثمار حالة عدم الرضا الإجتماعى السائدة، وسريعاً ما أصبحت القارة الإدة السياسية الأولى في البلاد.

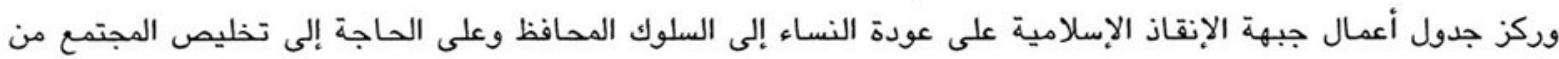

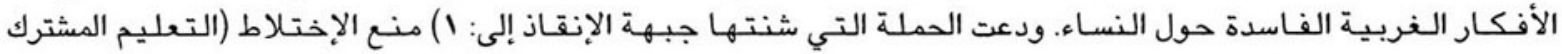

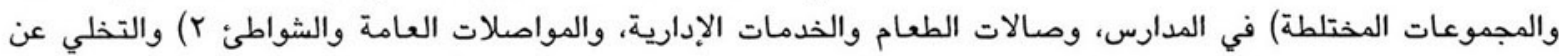

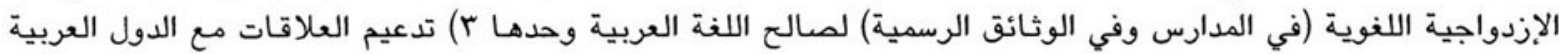

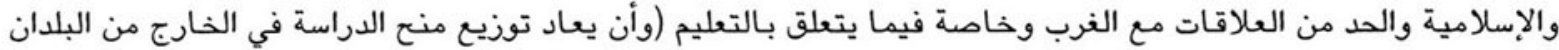

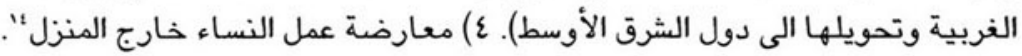

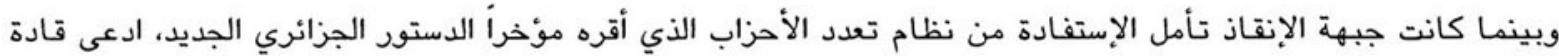

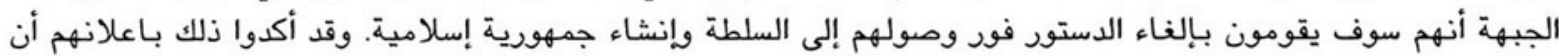

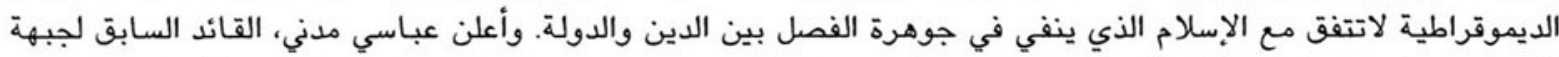

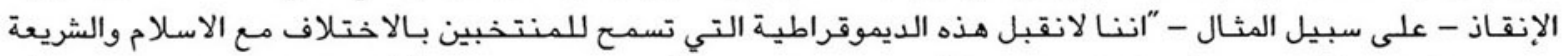

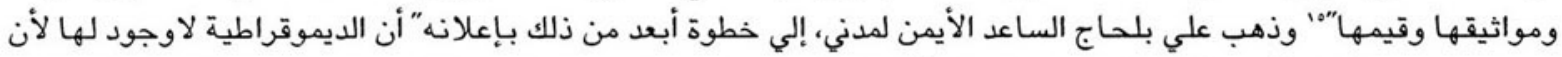

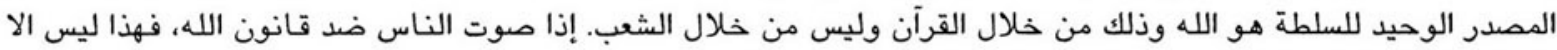

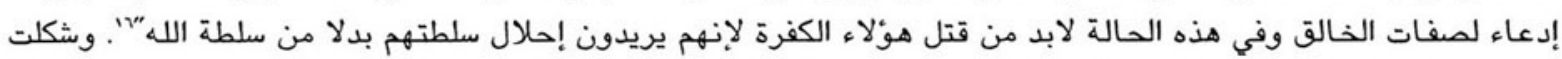

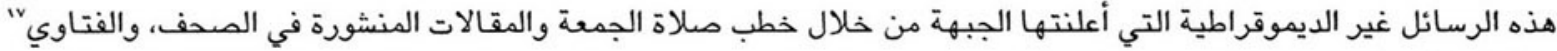
والخطب العامة مصدر خوف للجماعات العلمانية.

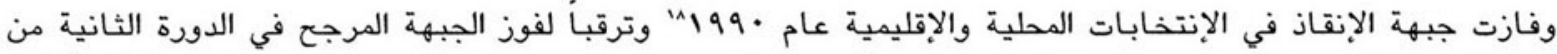

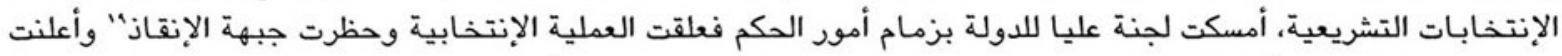

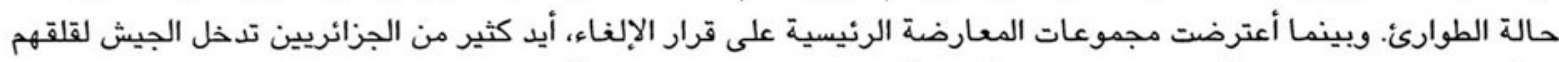

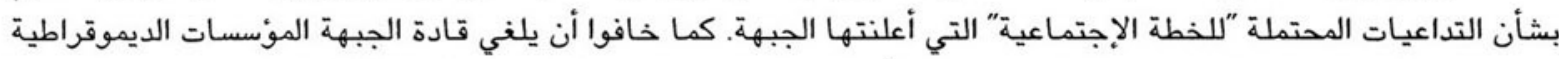

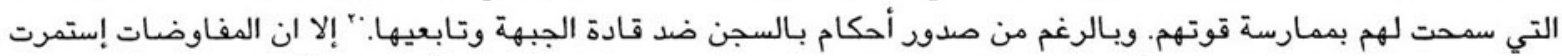

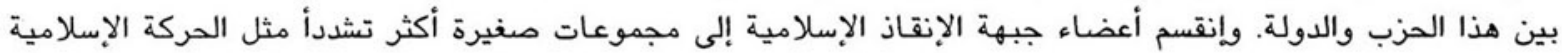
المسلحة والجماعة الإسلامية المسلحة" . ولم تكن إستراتيجية هذه الجماعات تكمن في الحصول على الإلى المساندة العامة بل في الإدي

Hessini, Leila. Living on a Fault Line: Political Violence Against Women in Algeria. Cairo: is Population Council and UNIFEM. 1996, P. 13. L'Algérie Actualité. December 24, 1989. 10 Horizon, February 29, 1989. I1

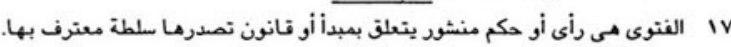

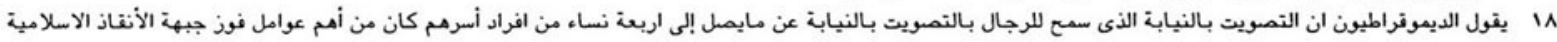

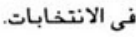
9 إل حظى قيام جبهة الإنقان الاسلامية نتيجة لاخلالها بنص القانون الذى يمنع قيام الاحزاب على أساس دينى. إلا أن الاحزاب السياسية الاخرى القانمة على أساس دينى لم تحظر

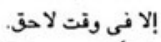

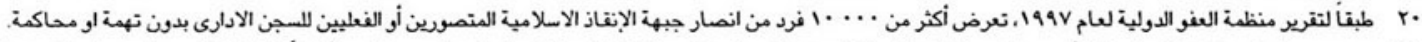

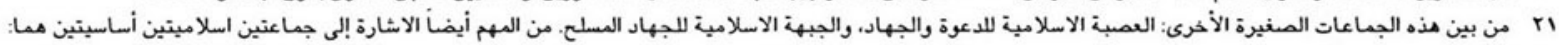

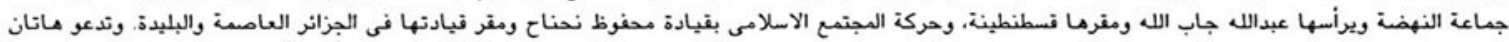

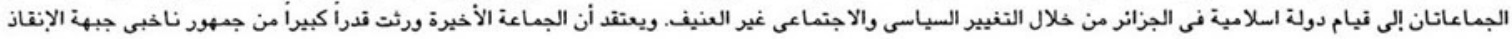


مزاولة الضغط - عن طريق نشاطهم المسلح - على نظام الحكم، للرجوع عن قراره بحظر جبهة الإنقاذ وتنفيذ برامجهم لإقامة

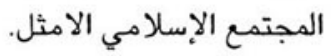

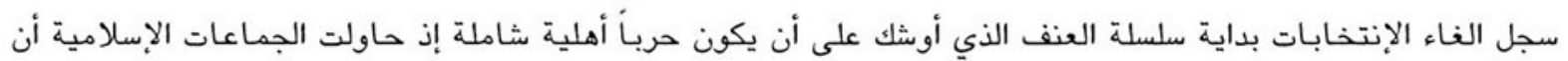

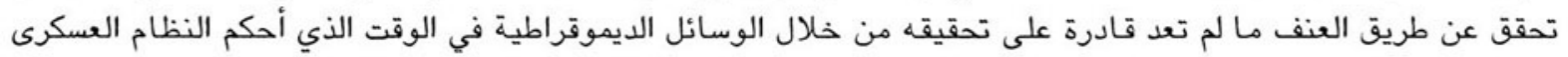

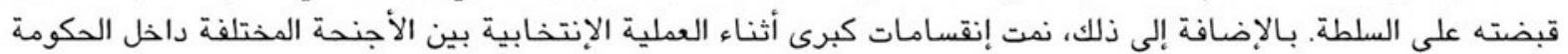

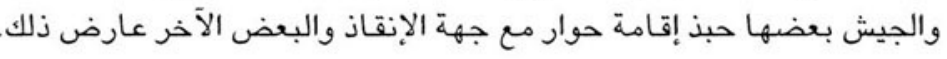

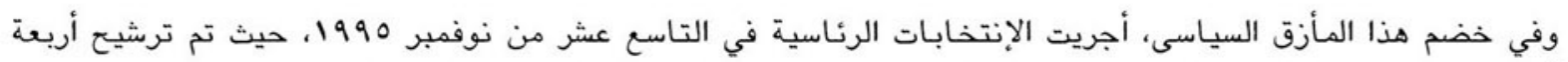

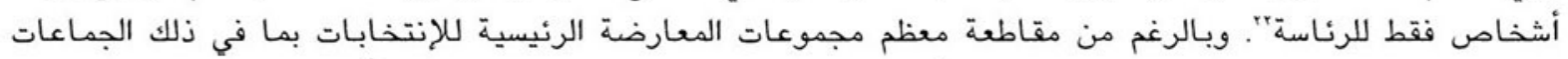

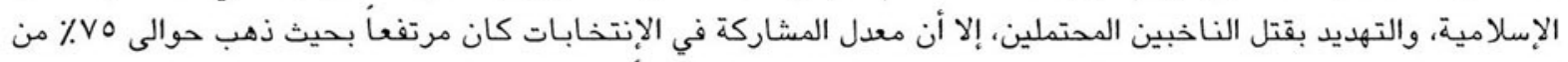

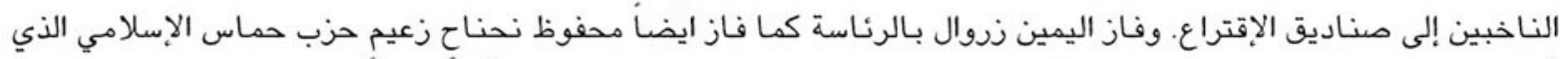

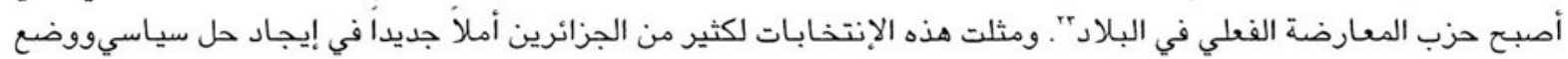
نهاية للعنف.

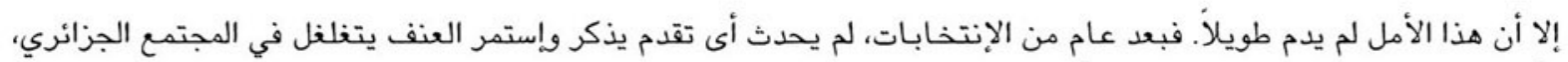

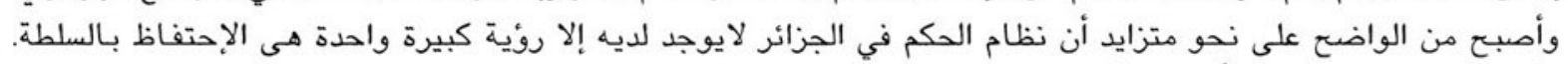

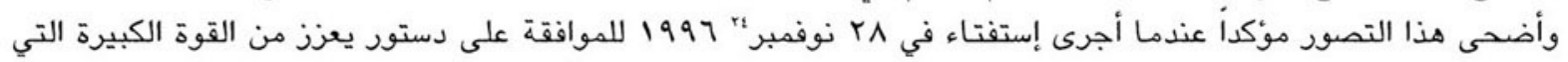

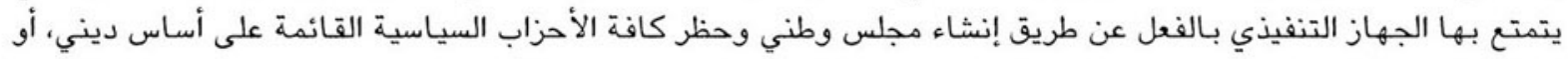
لنوي أو عرقي أو إقليمي.

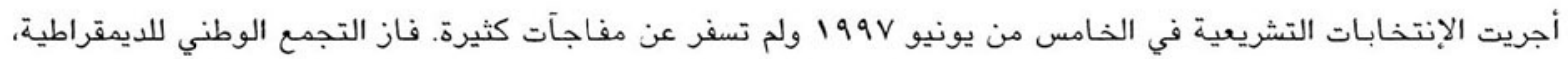

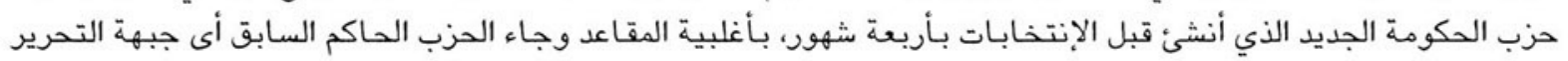

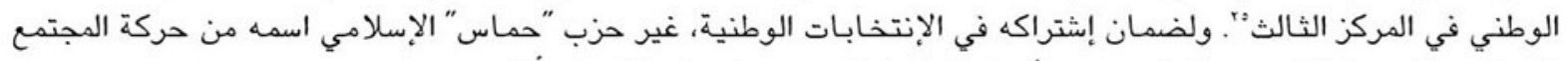

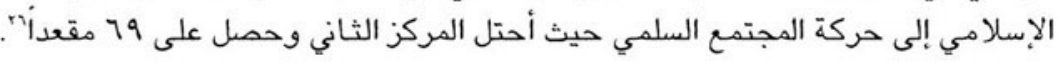

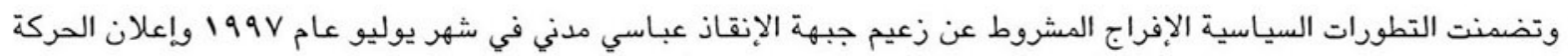

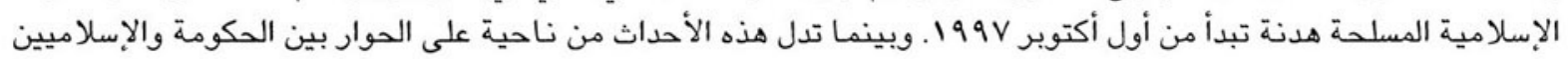

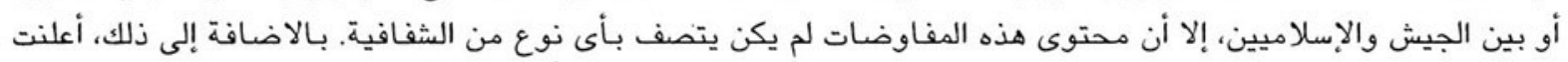

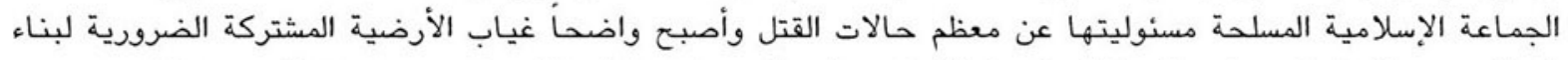

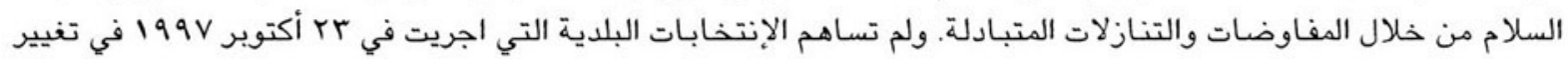

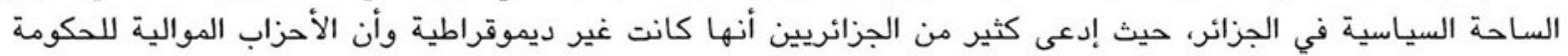
إحتفظت بغالبية المقاعد في المجالس.

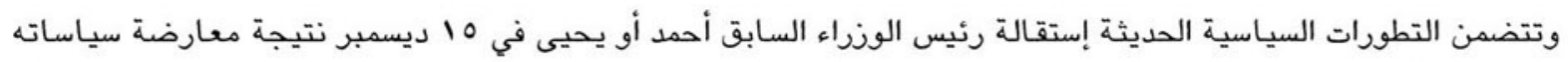

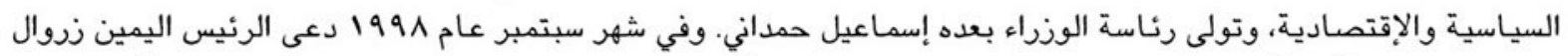

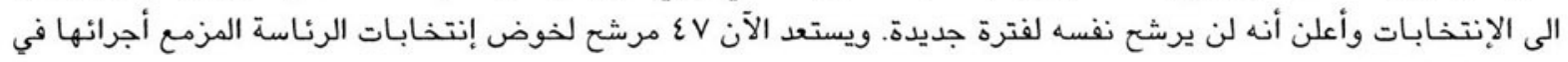

10

r r اليمين زروال - الرئيس الحالى للجزائر، ومحفوظ نحناح زعيم حزب حماس (حركة المجتمع الاسلامى) السابق، وسعد سعدى (التجمع من أجل الثقافة

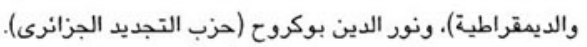

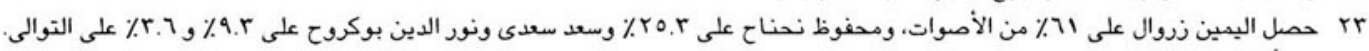

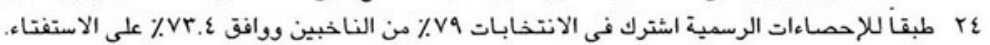

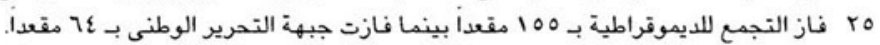

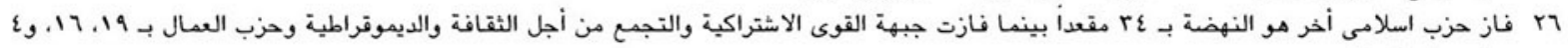
مقاعد على التوالى. 
تبنت الجزائر بعد حصولها على الإستقلال نموذجاً إقتصاديا يقوم على أساس التخطيط المركزى والتصنيع الثقيل على حساب تصاب

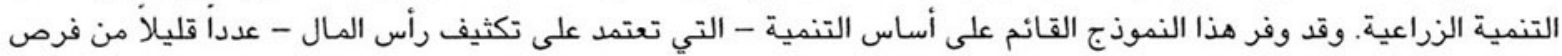

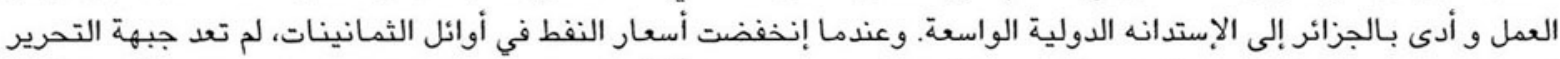

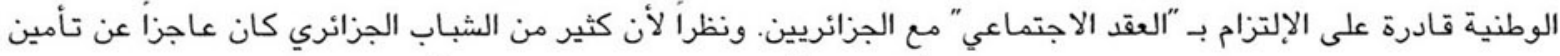

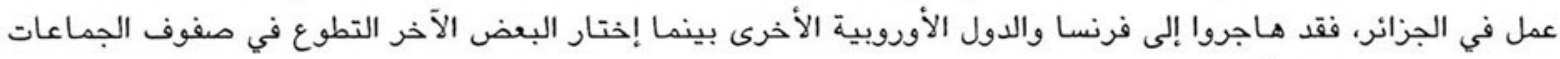
الإسلامية المتمردة في أفغانستان لمحاربة الكفار.

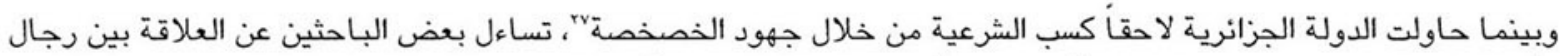

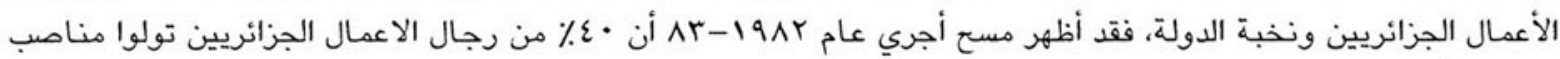

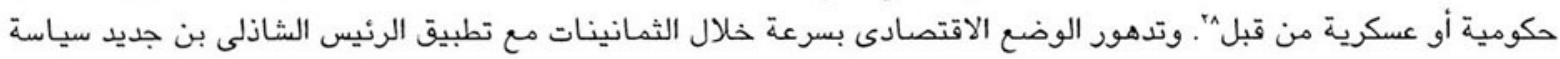

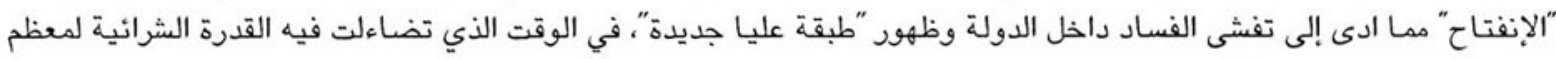

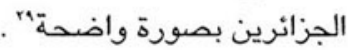

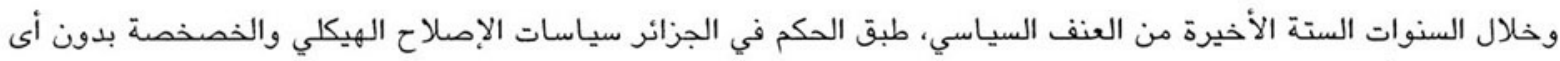

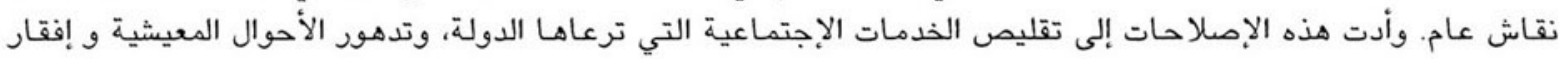

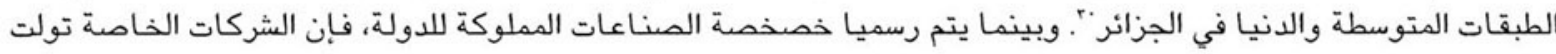

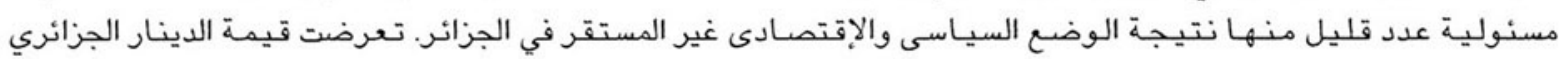

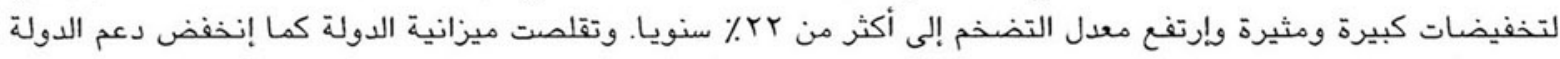

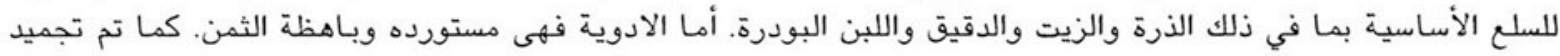

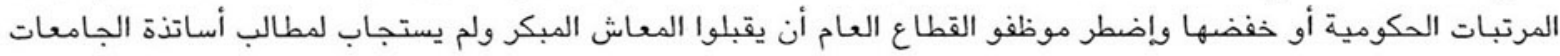

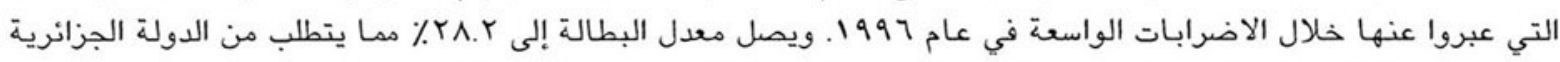

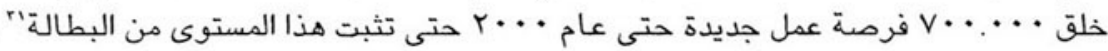

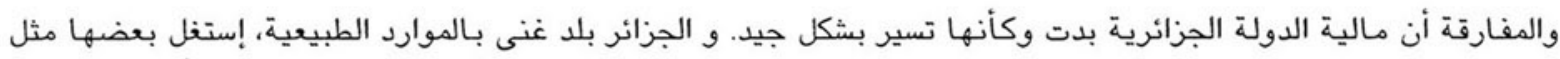

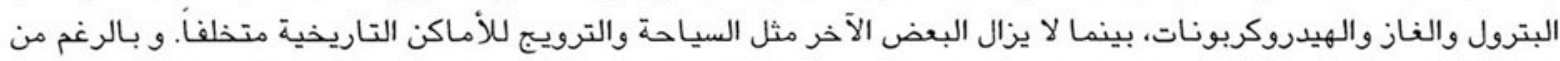

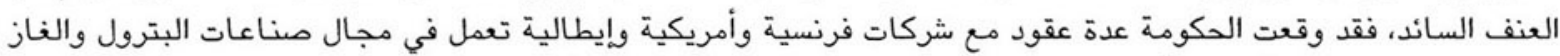

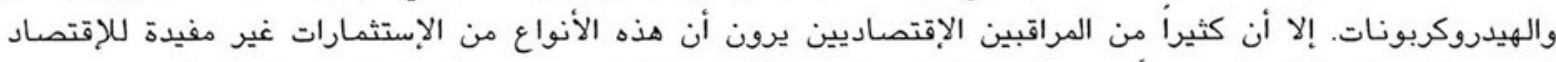

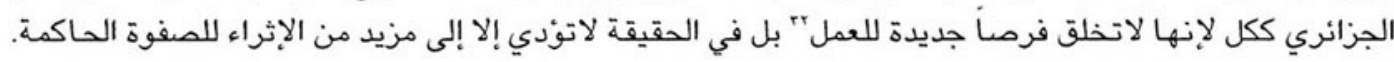

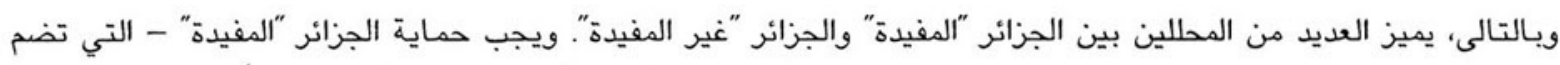

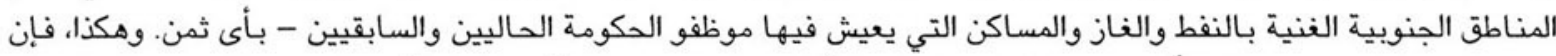

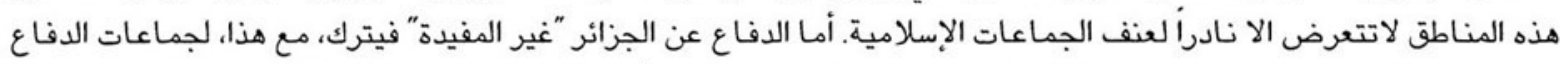

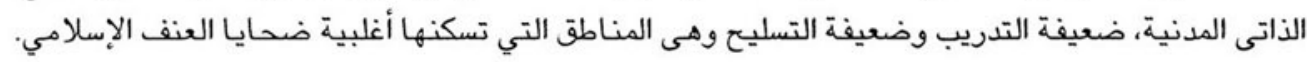

rV خصخصة القطاع الصناعى بـالأساس. PV Tlemcani, Rachid, "Chadli's Petestroika." MERIP. 1990, p. 14. rA

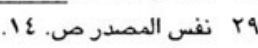
•r طبقأ لقول همثل المجلس الادارى الأوروبى أنه من بين الدول التى تطبق اجراءات التكيف الهيكلى لم تتبع دولة التوصيات بهذه الدقة مثلما فعلت الجزانر. Tuquoi, Jean Pierre. "Un pays en mal de croissance economique“. Le Monde Diplomatique, November 1995. Algérie Informations: Revue de presse. May - June 1994; No. 247. Paris, P. 26. rI rr. نفس المصدر ص. rr 


\begin{tabular}{|c|c|}
\hline \multicolumn{2}{|c|}{ الاحماءات العامة في الجزاتر: مؤشرات إتتمادية } \\
\hline$\%$ r.o & معدل النمو الحقيقى للناتج المحلى الاجمالى \\
\hline 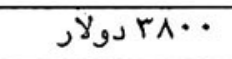 & نصيب الفرد من الناتج المحلى الاجمالى \\
\hline & توزيع الناتج المحلى الإجمالى حسب القطاع \\
\hline$\%$ & الزراعة \\
\hline$\% 0$ & الصناعة \\
\hline$\%$ rᄉ & 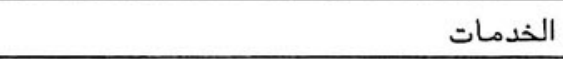 \\
\hline \multirow[t]{2}{*}{$\%$ \% } & معدل التضخم \\
\hline & حسب القطاع: \\
\hline r. T مليون عامل & 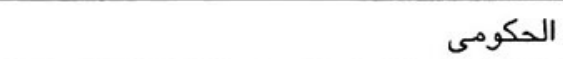 \\
\hline$\%$ \% & الزراعى \\
\hline$\% r r$ & المقاولات والأشغال العامة \\
\hline \% I.r & الصناعة \\
\hline$\%$ \%r.o & التجارة والخدمات \\
\hline$\% 0 . r$ & النقل والمواصلات \\
\hline$\%$ YA. 0 & معدل البطالة \\
\hline
\end{tabular}

المصدر: The World Fact Book, 1997

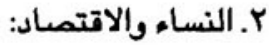

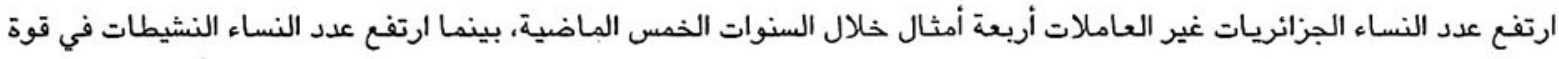

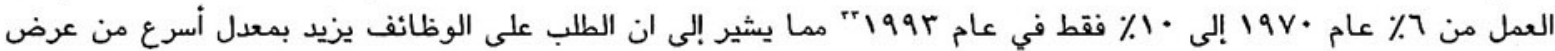

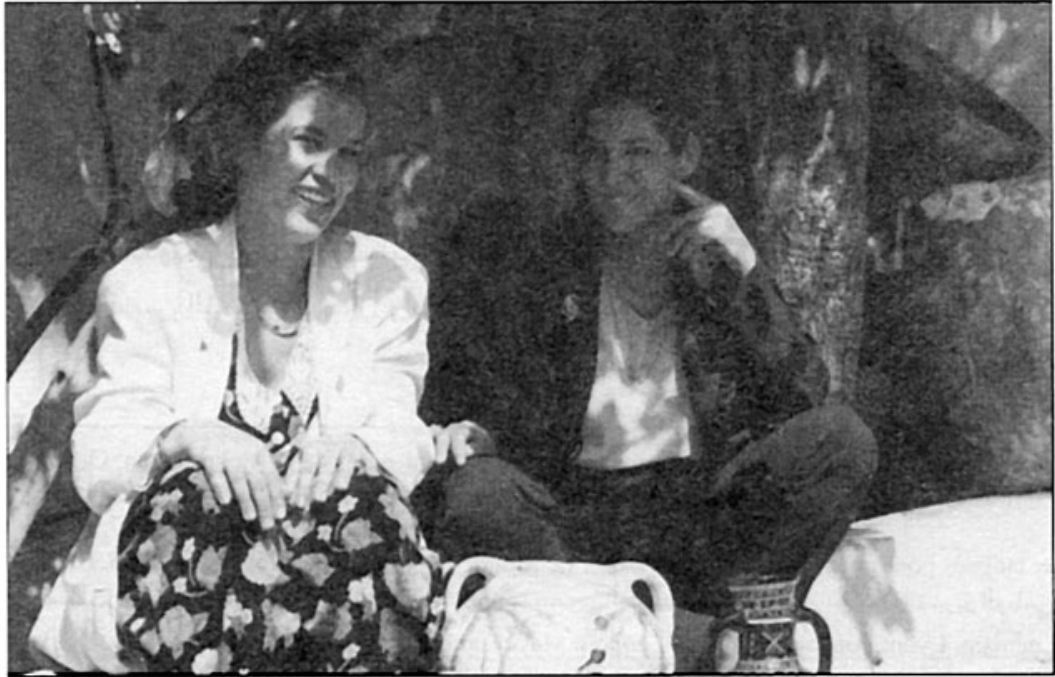

فنانات حرفيات من الجزانر

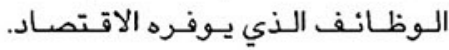

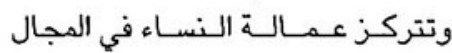

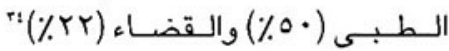

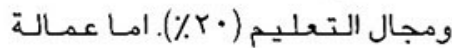
الذكور فهى موزعة بالتساوى بين

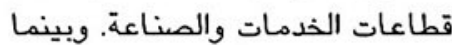

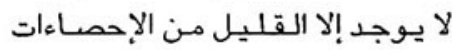
حسول اشتراك النسـاء في القطباعـات الإسات غير الرسمية، اظهر البحث الأولى أن فئن

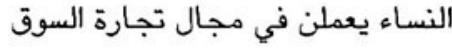

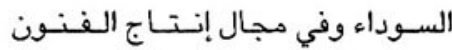

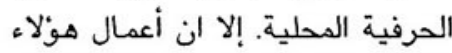

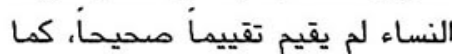
أنهن يعتمدن على التجار والسماسرة لبيع منتجاتهن. 
وتصف دوريـة شريـفاتي تضمين النساء العاملات في مجال العمل الرسمي على أنه خلق "لهوية جديدة، غامضة، ومخلقة

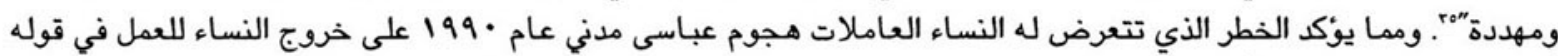

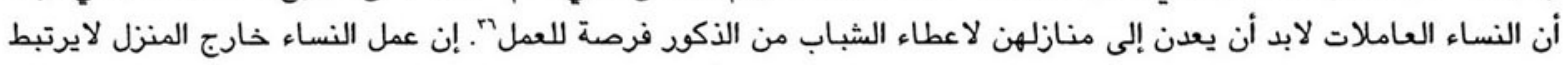

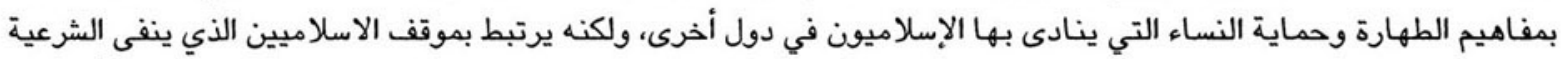

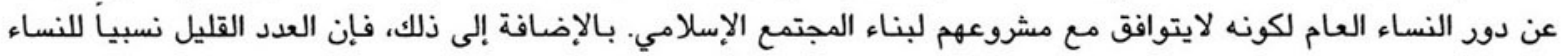

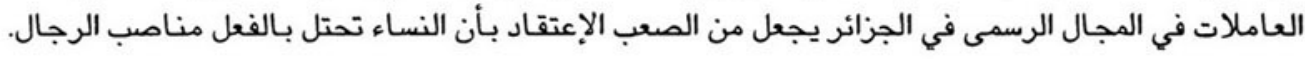

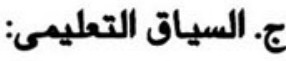

$$
\text { "لايمكن ان تعلو شجرة نحو السماء بدون ان يكون لها جذور ضارية في الارض". }
$$

يتألف النسيج اللغوى في المجتمع الجزائري من ثلاث لغات أساسية هى: العربية والبربرية والفرنسية والأخيرة هى لغة

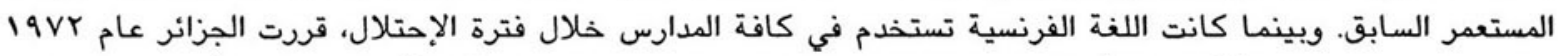

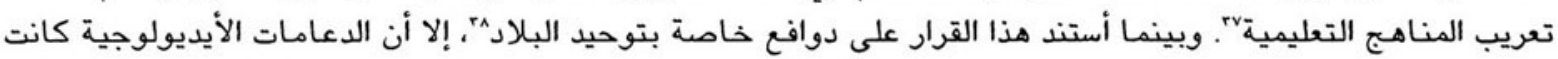

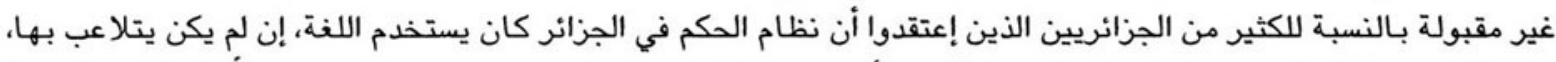

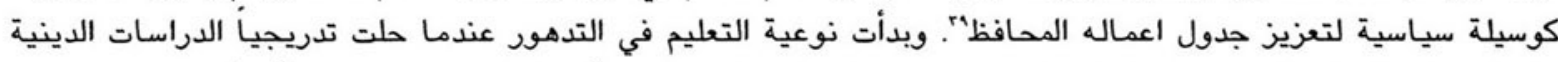

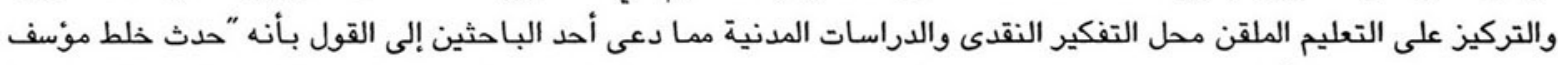

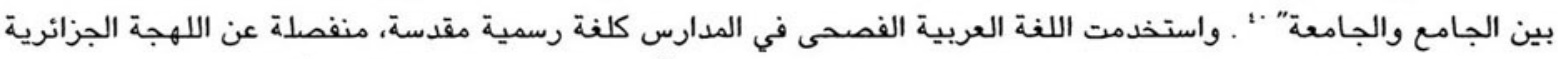

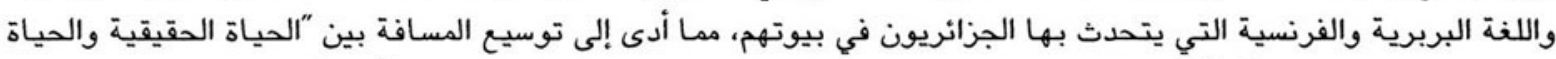

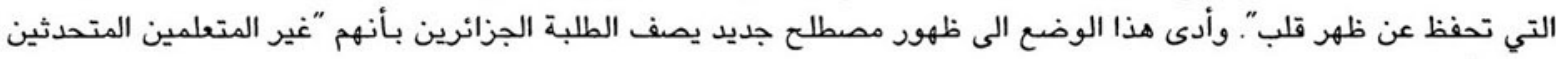

وفي الوقت نفسه، وبالرغم من التغيرات العنيفة في الأساليب التعليمية، لايزال تعليم الشباب من أهم أولويات الجزائريين كما

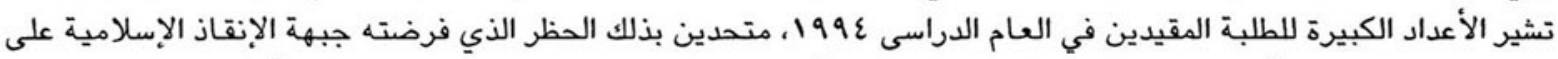

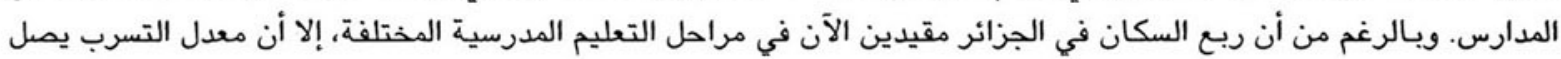

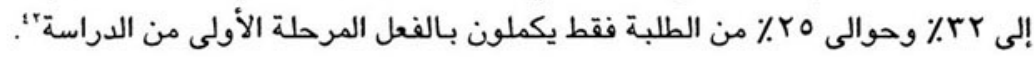

Y. النساء والتعليم:

يرى بعض المهتمين بمجال التعليم أن البرامج التعليمية الحالية تعزز اللامساواه بين البنين والبنات من خلال تركيزها على

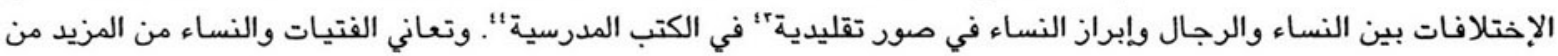

Cherifati, Doria. "Femmes - travailleuses: une identité dans la tourmente". Femmes et Developpment Actes de L'Atelier: Oran: Centre ro de Recherche en Anthropologie Sociale et Culturelle. 1995, P. 289-294 Algérie Informations, No. 247, P. 18. r7 Habib, Ali. "Deux langues pour une identité controversée". Le Monde Diplomatique. November 1995, P. 17. rv A P إستند شرعية النظام الجزائرى بعد الاستقلال إلى مصدرين أساسيين هما النضال من أجل التحرير الوطنى والدفاع عن الاسلام. أنظر: Algéric tisser la paix: Huit defis pour demain. Lyon: Fondation Charles Leopold Mayer pour le progrés de l'homme. 1996, P. 23. 
التفرقة لأنهن أول من يرغمن على ترك المدرسة على الرغم من أن الإحصاءات أظهرت أن الفتيات اللاتى يقدر لهن الإستمرار في الدراسة أكثر تفوقاً من زملانهن من من البن ترك البنينه

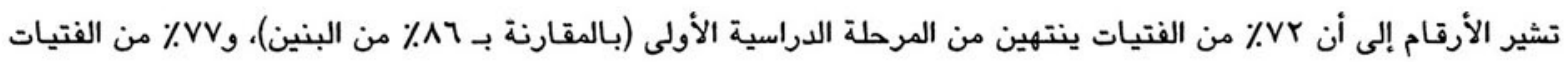

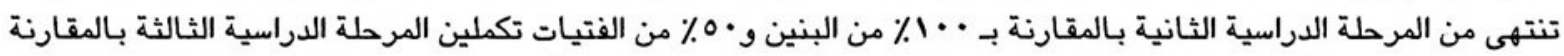

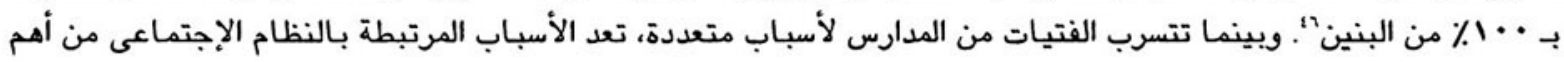

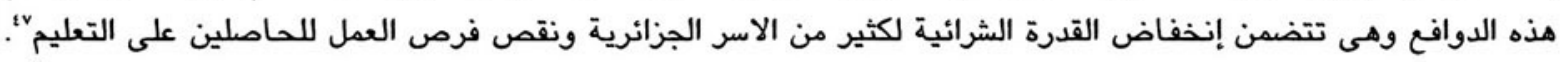

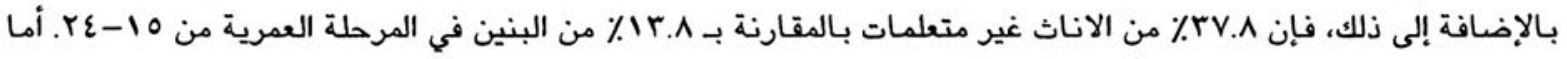

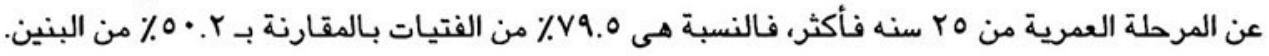

د. السياق الديموجرافى:

"إن وظيفة المرأة هى إنجاب المسلمين. وإذا تخلت عن هذا الدور، فإنها تخالف النظام الذي فرضه الله وتنضب مصدر

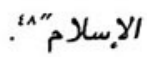

\begin{tabular}{|c|c|}
\hline \multicolumn{2}{|c|}{ الإحماءات العامة في الجزانر: السكان والمحة } \\
\hline 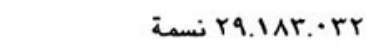 & - عدد الشباب \\
\hline$\% r . r$ & - عدل نمو الشباب \\
\hline 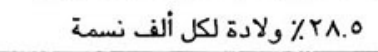 & - عدل المواليد \\
\hline \% \% ٪ حالة وفاة لكل ألف نسمة & 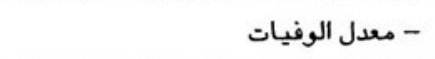 \\
\hline 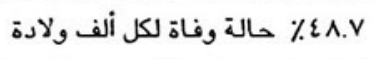 & - - معدل وفيات الأطفال \\
\hline \multirow[t]{2}{*}{ 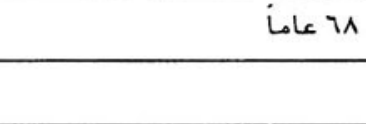 } & - العمر المتوقع للحياة عند الولادة \\
\hline & 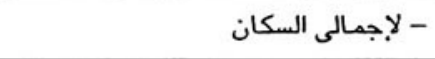 \\
\hline 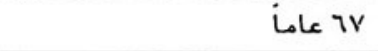 & 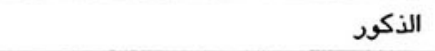 \\
\hline - 79 عامأ & الإناث \\
\hline \multirow[t]{3}{*}{ 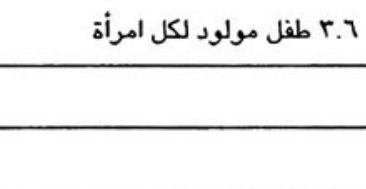 } & - معدل الخصوية الإجمالى \\
\hline & - معدل التعليم لمن تزيد أعمارهم \\
\hline & عن 10 عامأ (يستطيع القراءة والكتابة) \\
\hline ז r & 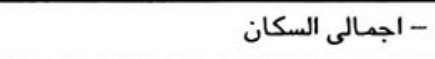 \\
\hline$\% \vee \varepsilon$ & 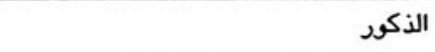 \\
\hline$\% \varepsilon 9$ & الإناث \\
\hline
\end{tabular}

المصدر: The World Fact Book, 1997

Ladjel, Khadidja. "Statut Social et Femmes en Difficulté". In "Femmes et Developpement. Actes de l'Atelier. Oran: Centre de $\varepsilon 0$ Recherche en Anthropologie Social et Culturelle.1995, P. 212

Algérie Informations, No. 247, P. 34. \&7

r \& ن Ali Belhadj in La Moitié du Ciel d'Allah 1996 \&A 


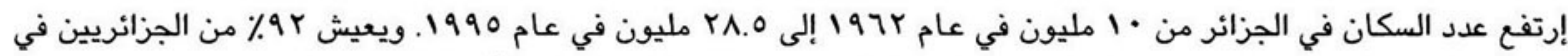

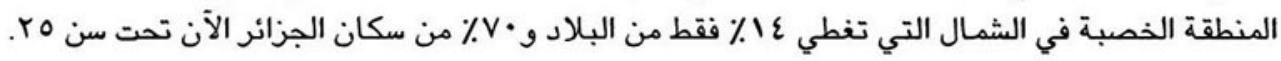

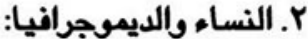

لم تعلن الجزائر بعد حصولها على الإستقلال عن سياسة للتخطيط السكانى على عكس جيرانها في تونس والمغرب. ولكنها

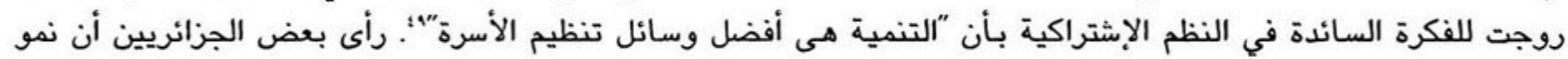

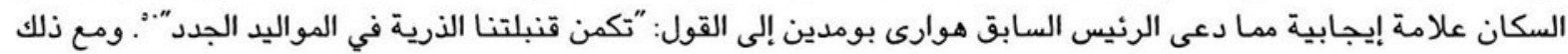

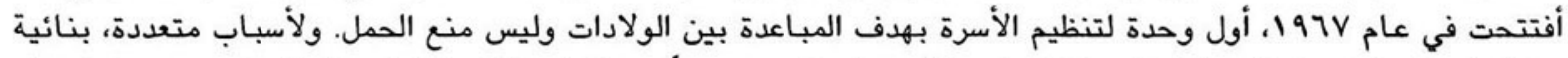

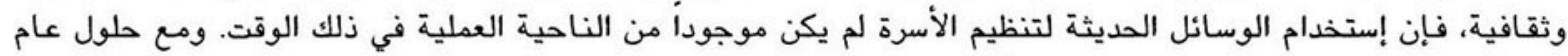

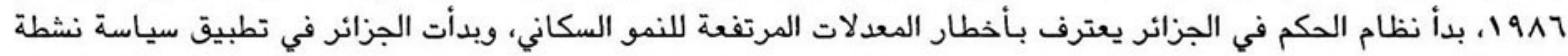

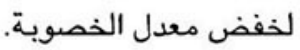

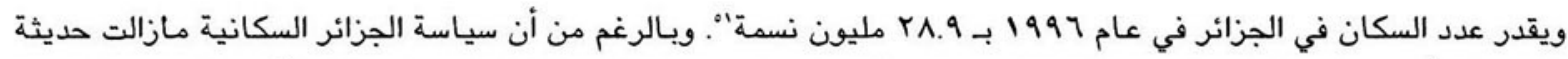

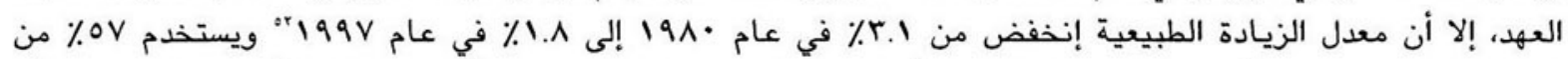

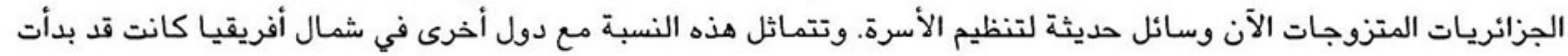

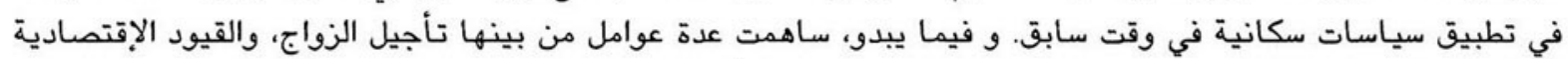
وأزمة الإسكان الحادة في القبول السريع لإستخدام وسائل تنظيم الأسرة بين الجزائرين عيد عامين.

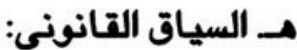

"إنه أمر مستحيل، أنه وضع غير عادل لايمكن إحتماله. لابد من تغيير قانون الأسرة، أو الرجوع عنه أو تعديله. لابد لهذا

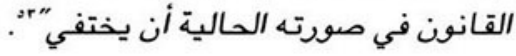

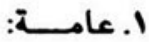

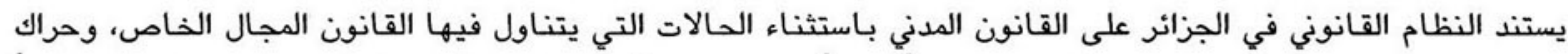

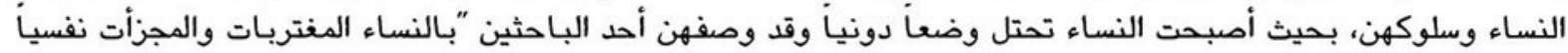

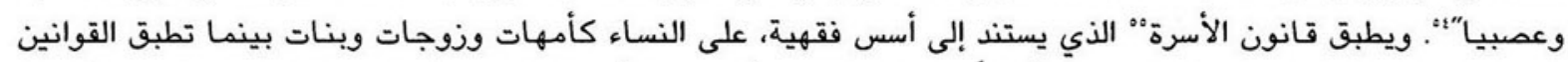

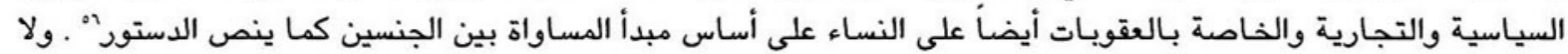

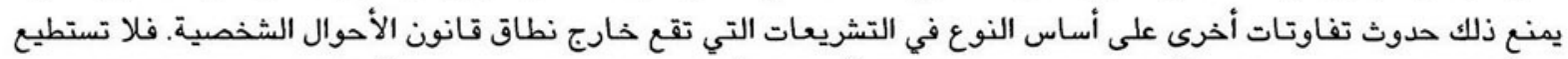

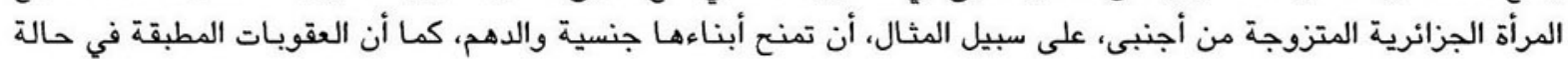
إرتكاب الزنا تختلف جوهريا بين النساء والرجال.

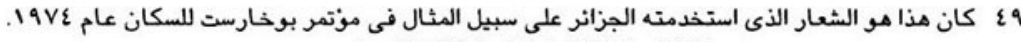

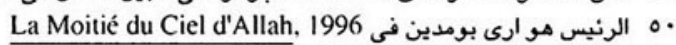

Algérie Informations, No. 247, P.27. O1 or

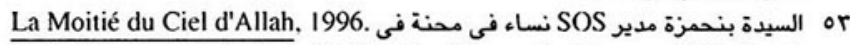
Noureddine Saadi. La Femme et la Loi en Algérie. Casablanca: Le Fennec. 1991, P. 14. of

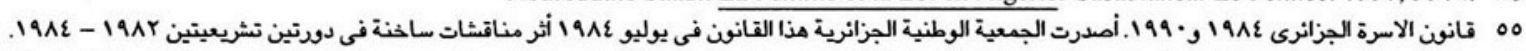
Ait - Zai, Nadia “ Les droits des femmes dans la famille". Femmes. Famille et Societé. Algiers: Organization Nationale des Droits de or L'Homme 1997, P. I. 


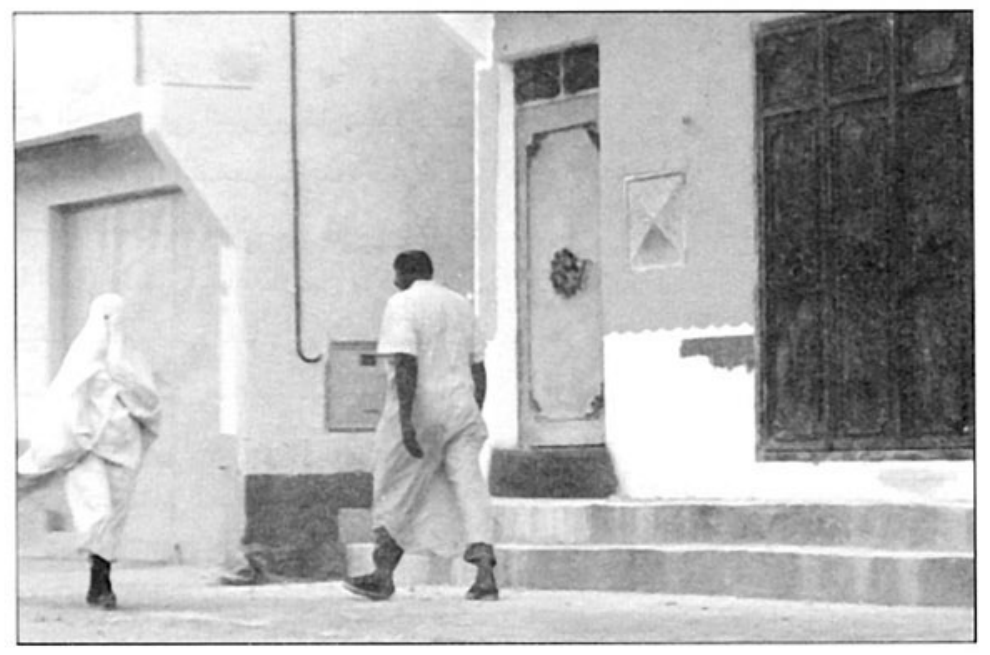

صورة: شارع نى جورديا

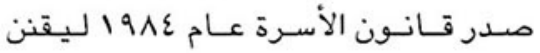

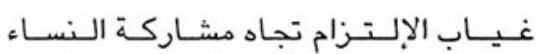
المتسـاوية والكاملة كمواطنين جزانرين

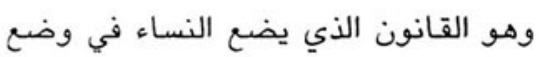
القصر مدى الحياة. والزواج ماهو إلا عقد الند

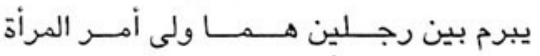

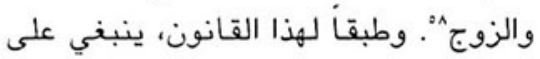

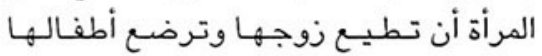

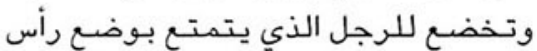
الأسـرة وعليهـا أن تحترم والديه وأقتاربه.

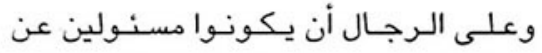

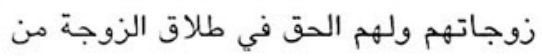

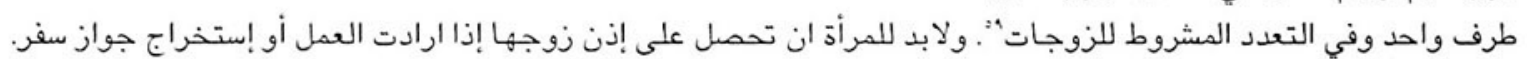
ولايتساوى الرجال والنساء في الإرث ويرث الرجل ضعف نصيب الأنثى. وللنساء في حالة الطلاق، حق حضانة الأطفال القصر

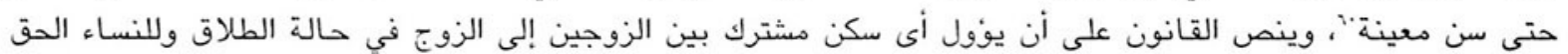

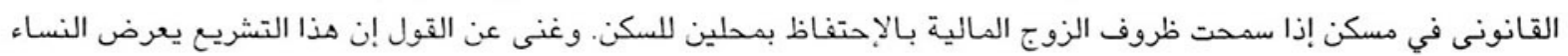
لمحن وضغوط شديدة.

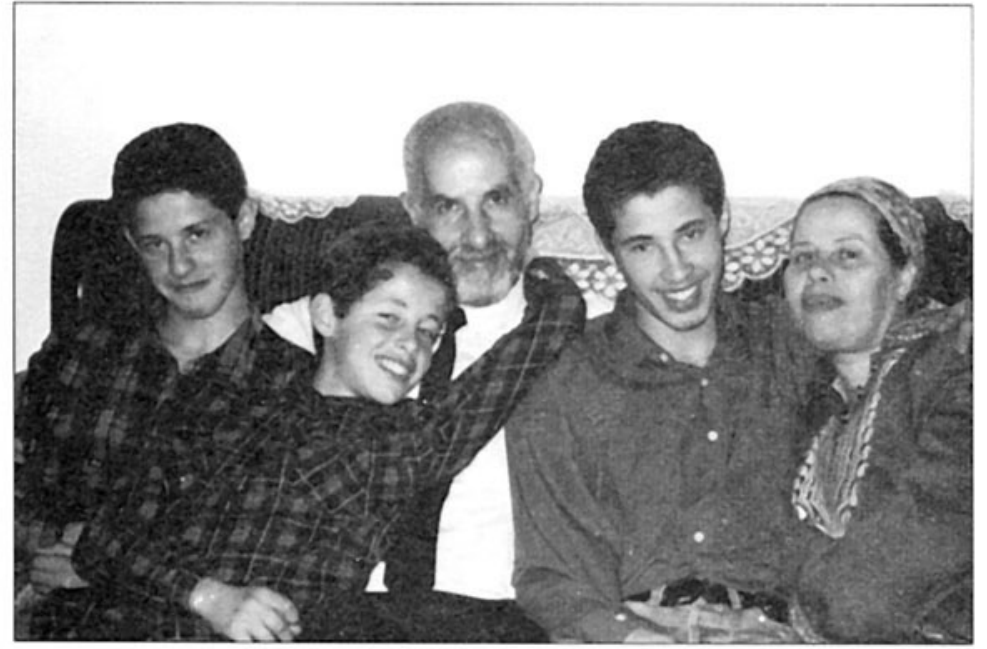

- مرة جزائرية

\section{و. تلاقى الدين والسياسة:}

\section{ا عامـــة}

تم إســــــدام الـديـن بصفـة إنـــــانيـة عبر

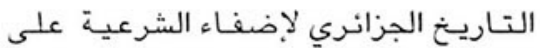

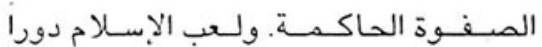

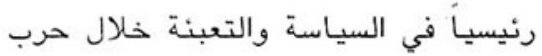
التحرير الجزائرية، وفي الفترة التالية لذلك الكيان

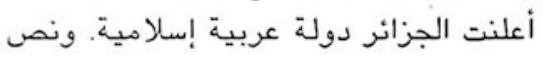

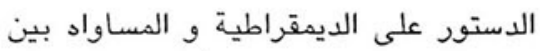

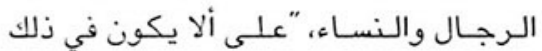

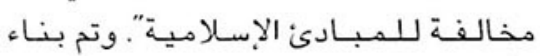
الألوف من المساجد خلال السبعينات والثمانينات كما ظهر التأثير الحكومى القوى على الرسائل الدينية المتمثلة في الخطب

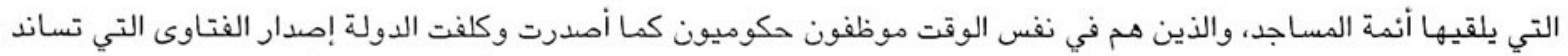

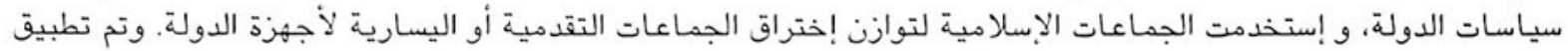

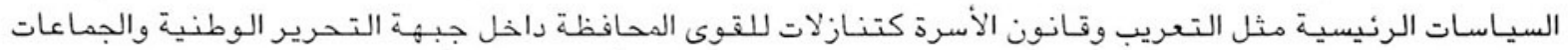
الإسلامية. كما ساندت الدولة إنشاء الجمعيات الخيرية في المساجد التي كثيراً ما كانت تهول من دول الخليتج.

قانون الاسرة الجزانرى.

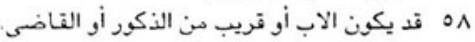
Hessini, 1997, P. 2.3 ०9

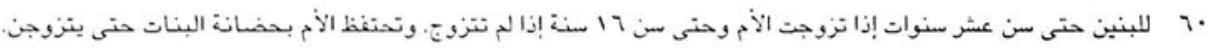




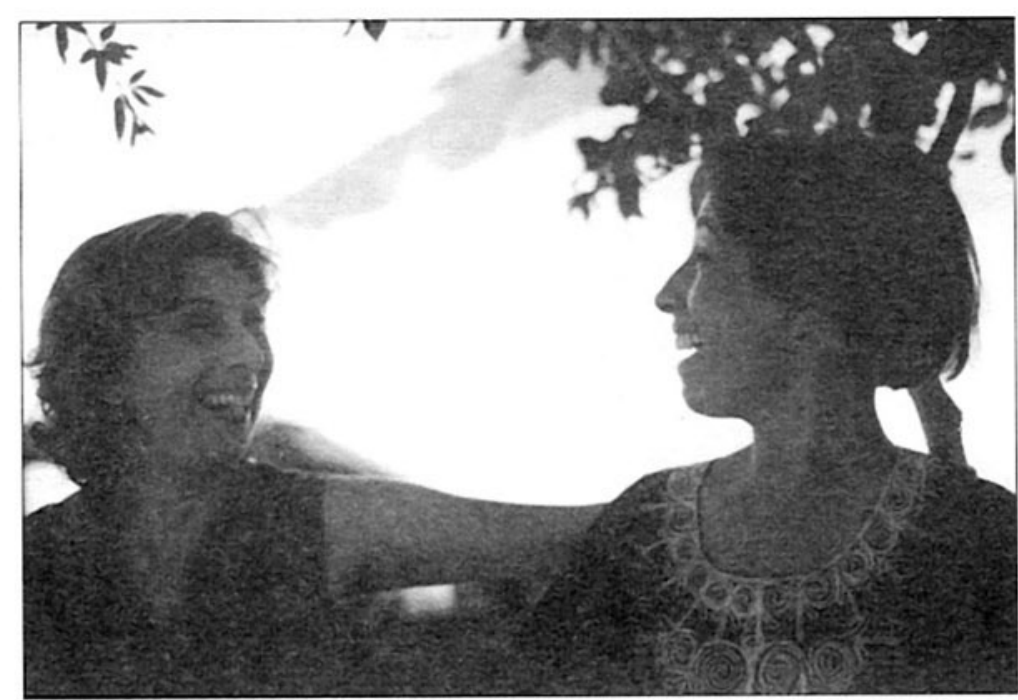

مديقتان

تمتع الرجال في الجزائر تاريخياً بالحق

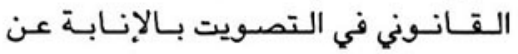
أعضاء الأسرة من الإناث. وقد تم تعديل هذا الحق وليس النائه" قبل الإنتخابات الإت التعديل

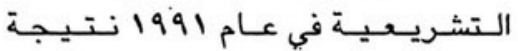

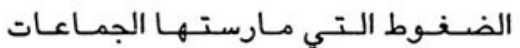

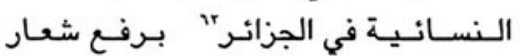

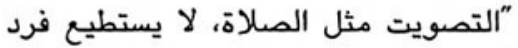

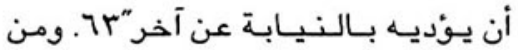

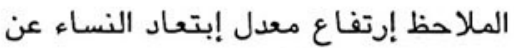

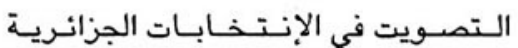
ولايرشح إلا عدد قليل من الإنساء أنفسهن

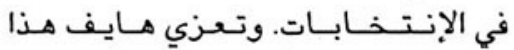

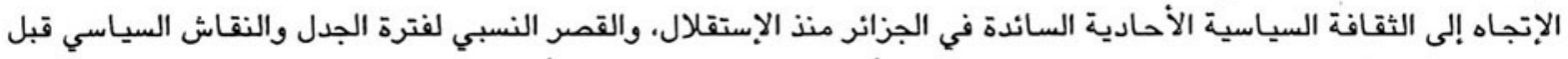

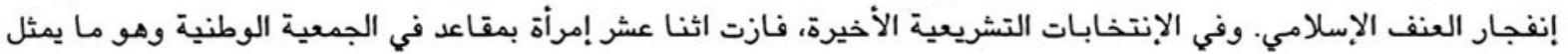

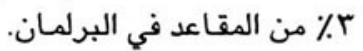




\section{$\frac{1}{203}$}

أ. خلفيــــة

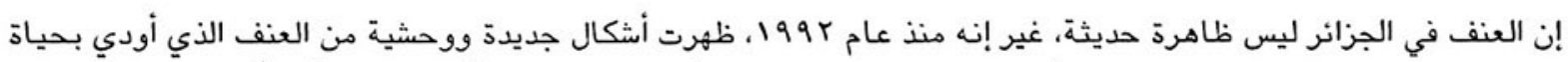

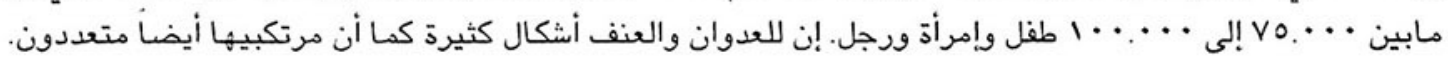

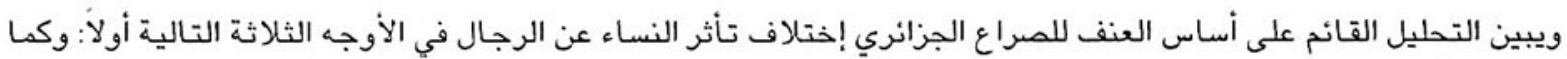

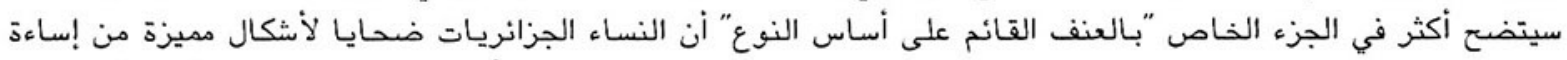

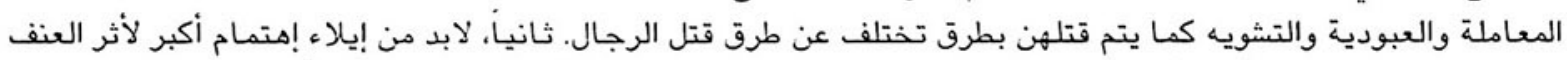

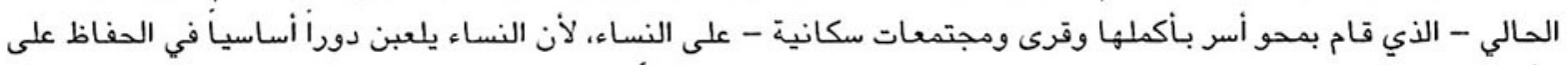

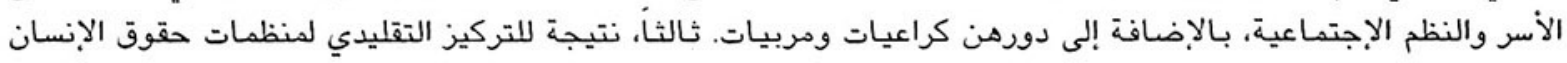

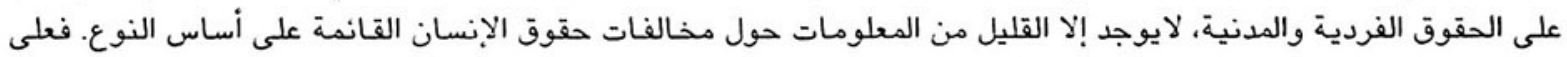

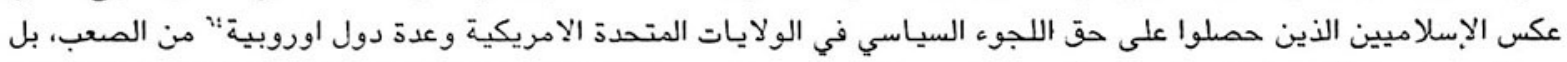

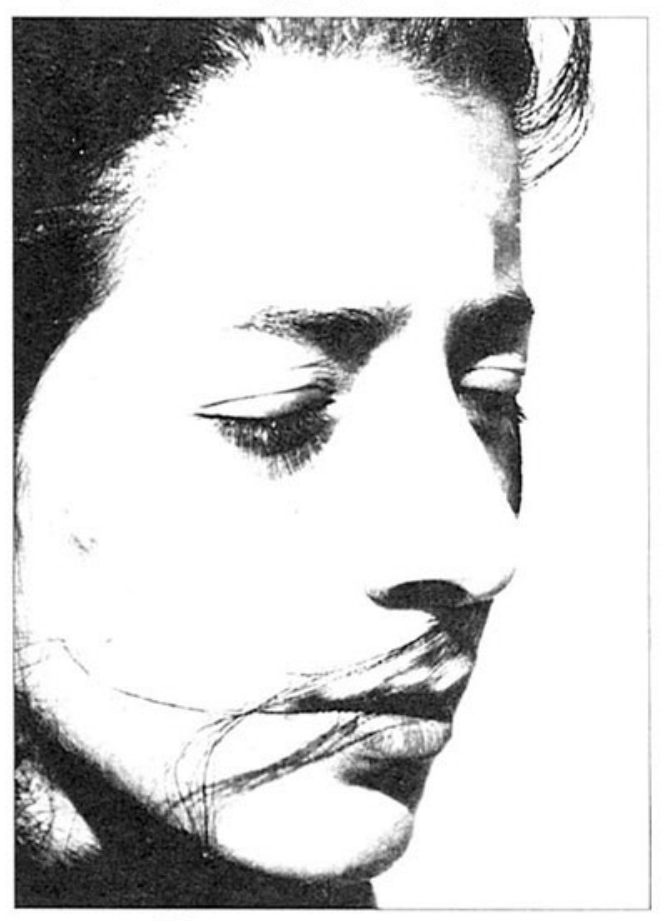

Lal Tribune نسيخ جزانرى. نصوير لويزا

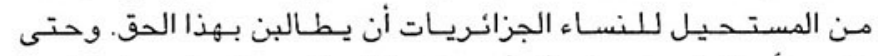

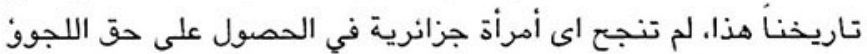

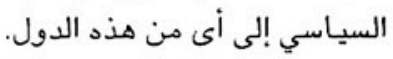

تركز الفصول التالية على دور الجماعات الإسلامية المسلحة والدولة

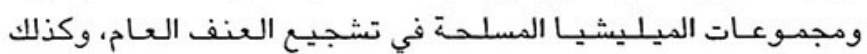

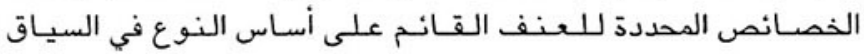
الجزائري.

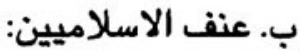

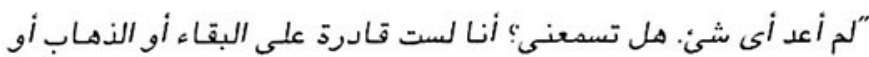

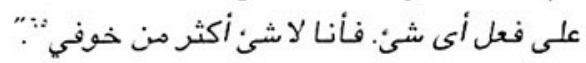

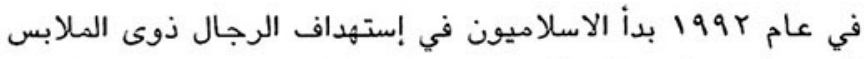

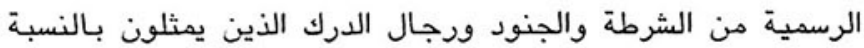

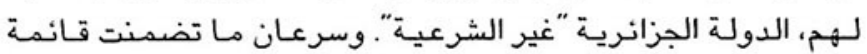

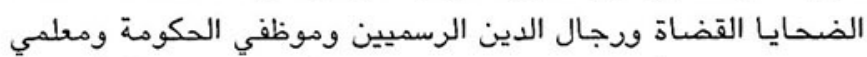

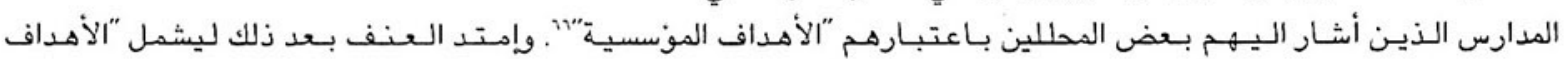




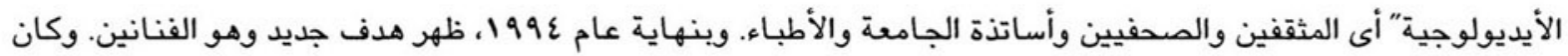

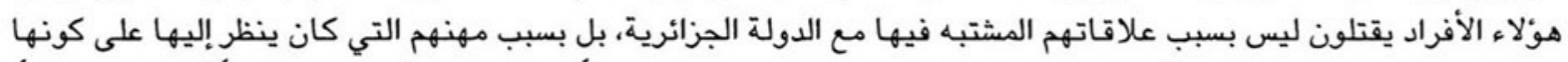

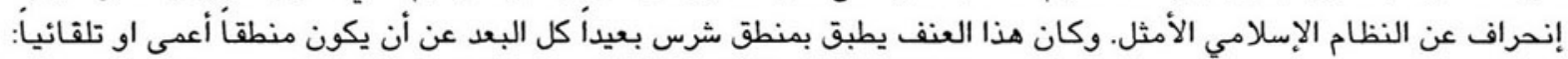

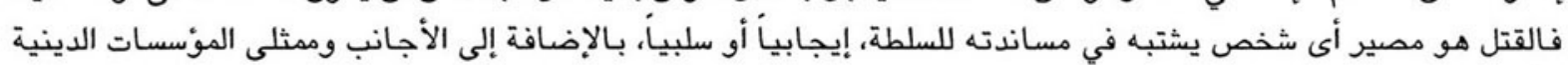
الأخرى.

ومع بداية عام 1991 تطور العنف الجماعى بحيث أصبح فيه النساء والأطفال من المناطق الريفية الضحايا الأساسيين. وقد أعلن

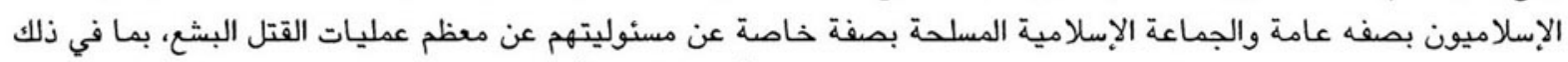

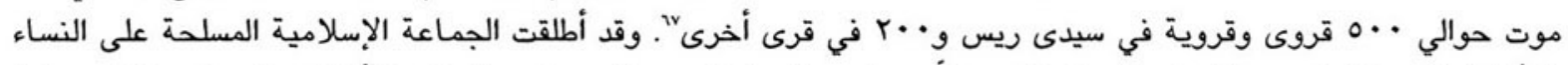

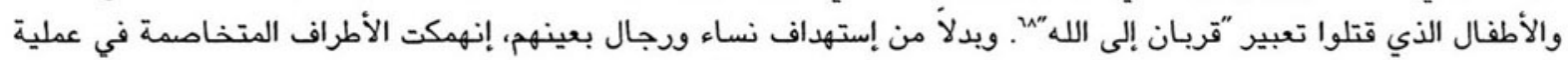

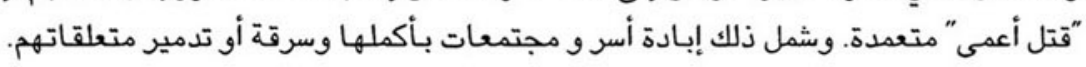

\section{ج. عنف الدولة:}

$$
\text { "إن الناس يشعرون إنهم خُلوا وتم التذلى عنهم. هل سنعيش طويلاً في هذا الوضع المأساوى"" }
$$

ليس من السهل الحصول على إحصائيات حول عنف الدولة في الجزائر. والوثائق التي قامت بجمعانها منظمة العفو الدولية

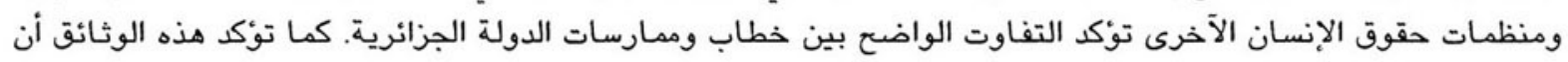

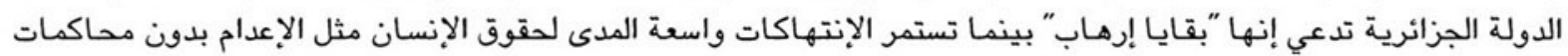

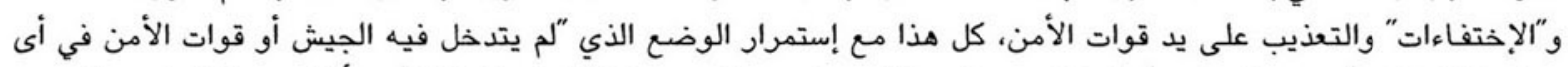

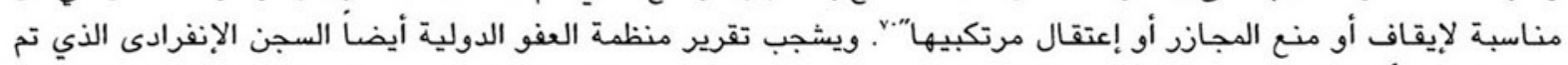

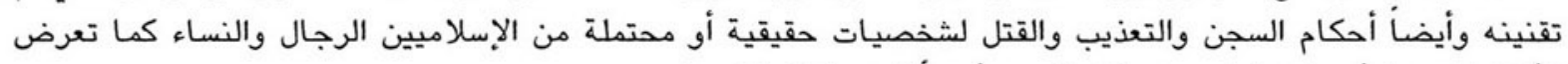

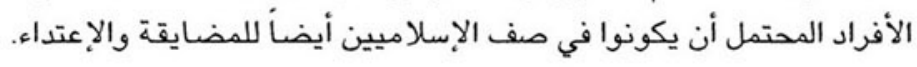

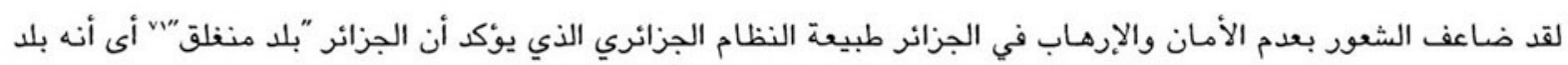

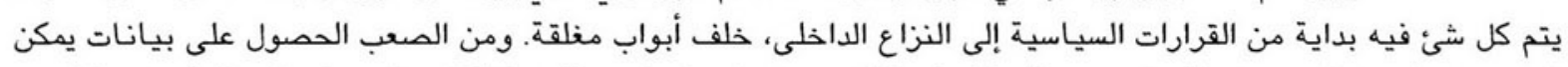

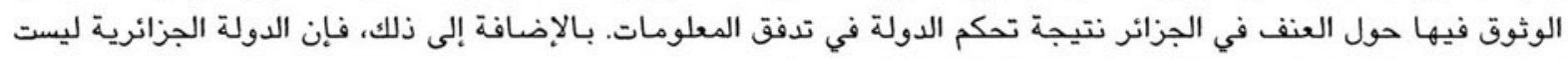

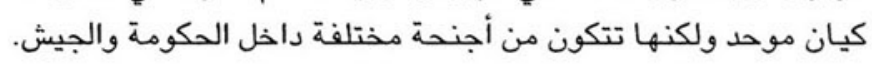

إن واجب أى دولة هو حماية المدنيين بها. لذا فقد يتساءل البعض عما إذا كانت الدولة الجزائرية تستخدم كافة مواردها لحماية

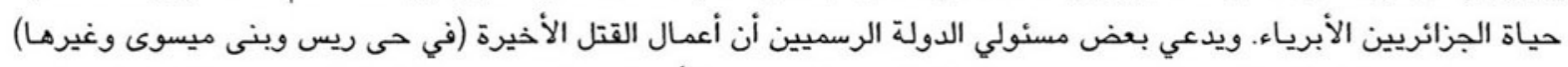

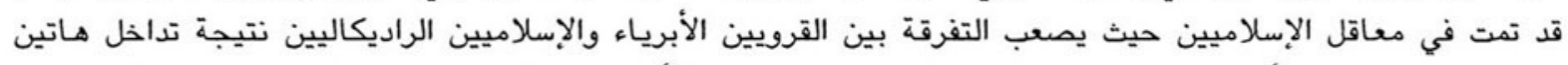
المجموعتين. علينا إذن أن نتساءل بجدية عن حجم الإختيارات المطروحة أمام هؤلاء القرويين في سياق يتسم بغياب الدولئ الإمين.

\section{د. جماعات الميليشيا المسلحة:}

"يستطيع الإرهابيون أن يقتلوننى ولكن إذا قتلوا أحداً من أقاريى سأقتل أسرهم بأكماها: أنها اللغة الوحيدة التي يفهمها

Algérie Informations: Revue de Presse. October - November 1997, No. 250. Paris, P. 8 iv Balil, A. "Resistance" in El Watan, September 27, 1997, P. 1. 认

El Watan, April 24, 199779 Amnesty Intermational 1997, P. 1, 23 vAddi, P. 16-17 Vi

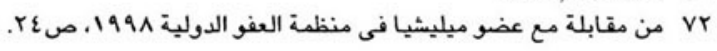




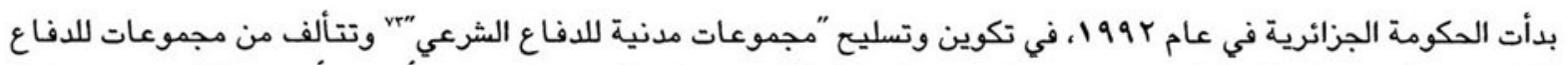

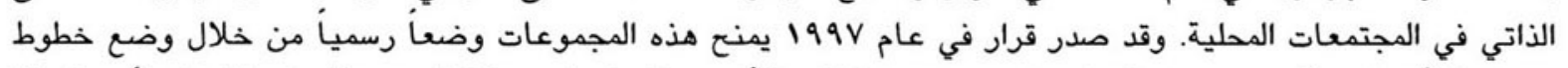

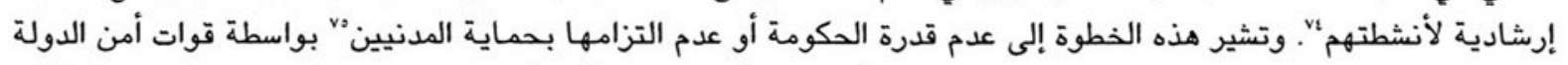

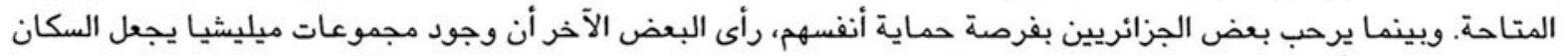

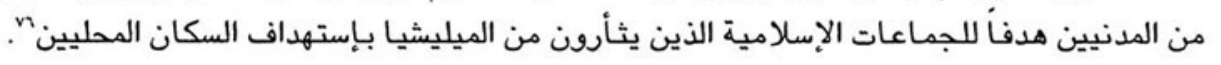

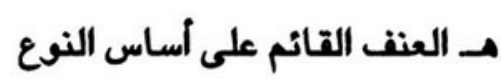

"إن النساء هن العدسة الرمزية للصراع الجزائري"."

إن عنف الإسلاميين له جذور عميقة ترجع إلى السبعينات عندما شنت الجماعات الإسلامية حملة ضد التعليم "المختلط"

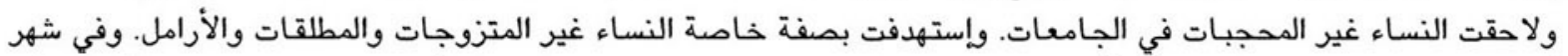

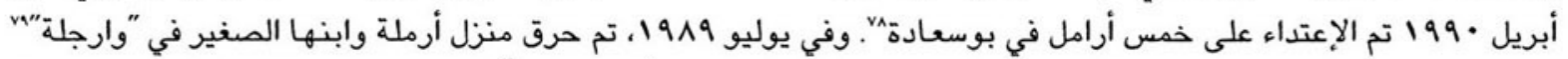

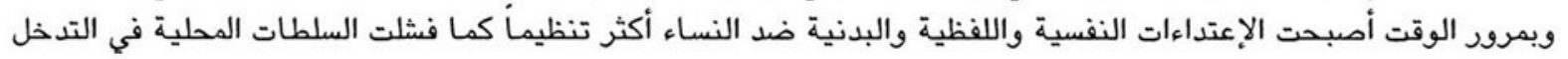

وعلى الرغم من أن الرجال والنساء على حد سواء ضحايا للعنف الوحشى الآن، إلا أن النساء يعتدي عليهن ويشوهن ويقتلن العناء

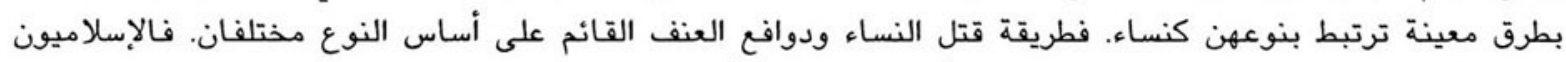

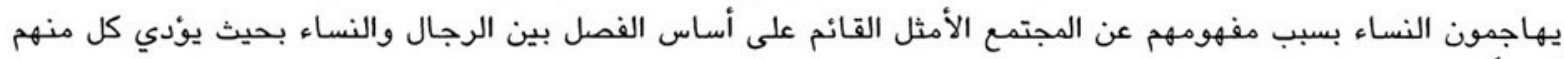
أدواراً مكملة لبعض ولكنهاء ليست متدواخلة.

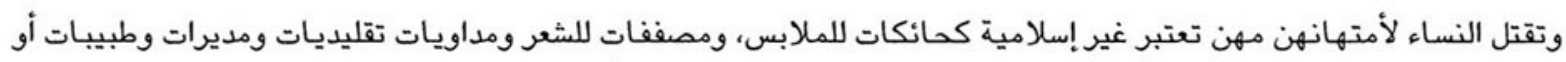

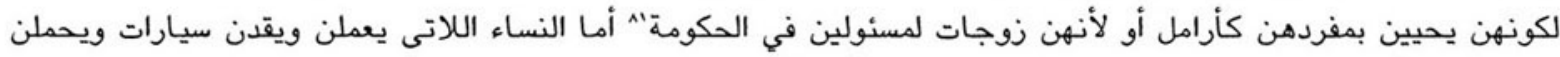

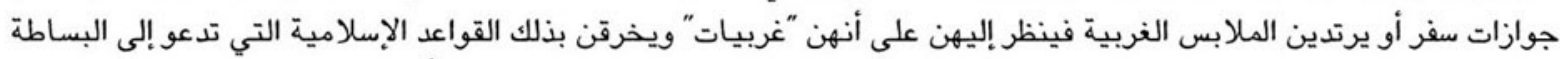

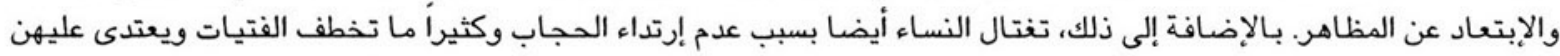

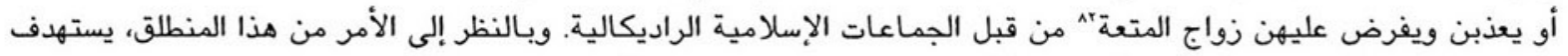

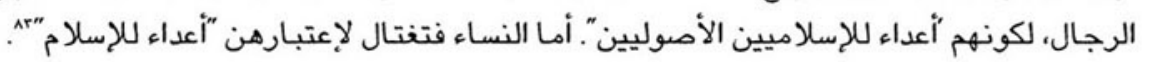

وينجلي عنف الجماعات الإسلامية في الخطاب العام الذي يهدف إلى تقنين أدوار النساء في المجتمع ويحد من حرية حركتهن

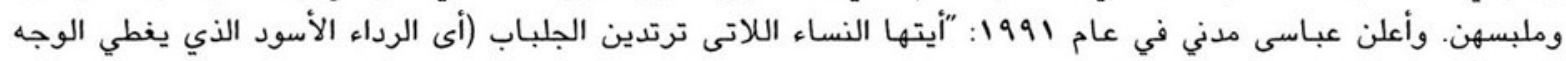

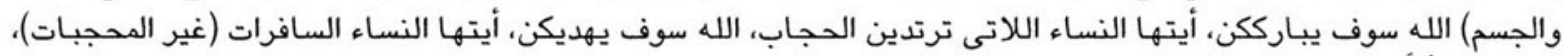

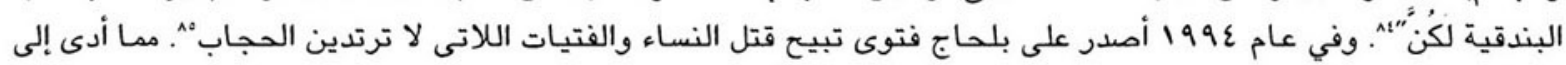

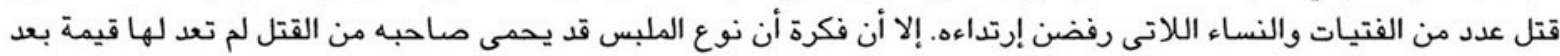

Groupes de légitime défense $v r$

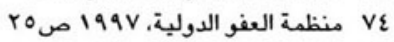

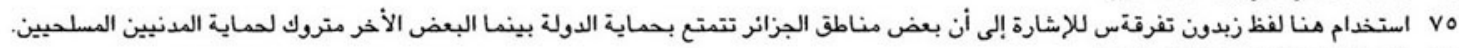

Amnesty International, P. 24 vา

Simone, 1995, P. 16 vV

Bennoune, Karima. Algerian Women Confront Fundamentalism. Monthly Review. September 1994, P. 33. VA

نف نفس المصدر VA

Hessini, 1996, p. 14 كا ذكر في Kader 1994-1996, P. 14 A.

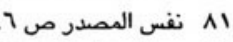

Ar ي يحظر زواج المتعة نظرياً عند المسلمين من السنة ولكنه يمارس بين المسلمين من الشيعة.

Hessini, 1997, P. 5 ^r

Bennoune, 1995 as quoted in Hessini $1997 \wedge \varepsilon$

Benali, Zinab. "Le Viole et la Parole" Unpublished Paper, 1995. ^^ 


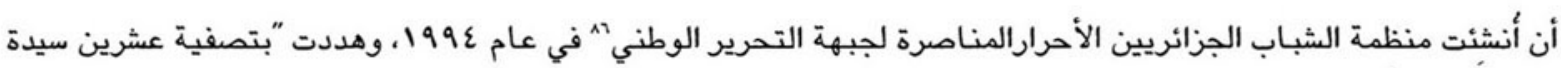

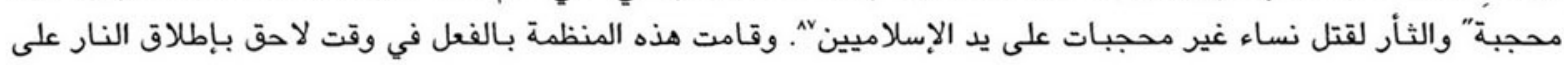

وفي عام 1990 أصدر على بلحاج فتوى أخرى خاصة بغنائم الحرب، وكأن فرض نوع الإق معين من الرداء على النساء لم يكن

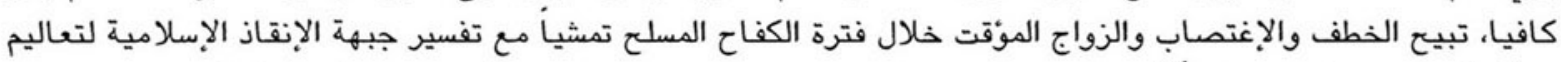

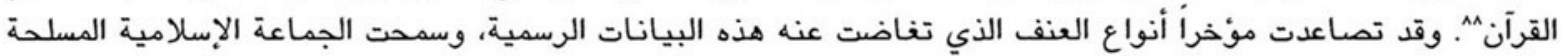

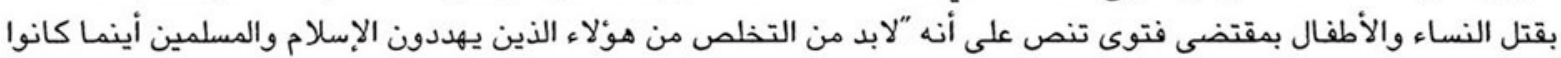

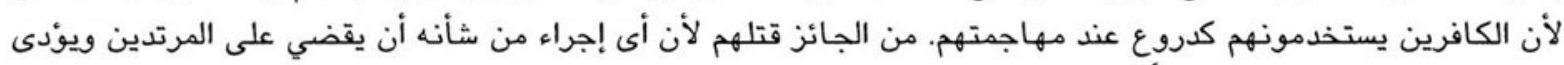
إلى هزيمتهم يعتبر إجراء مشروعاًْي^.

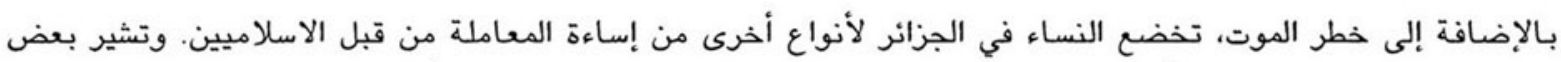

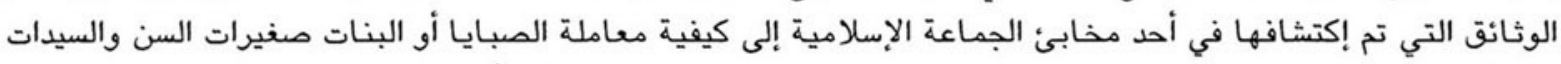

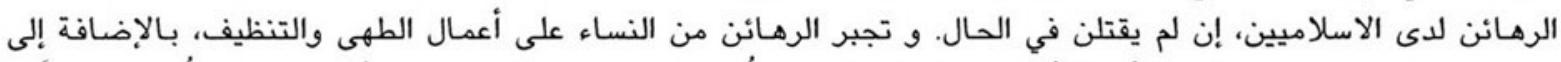

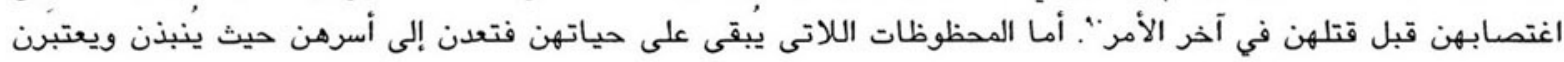
مسنولات عما حل بهن.

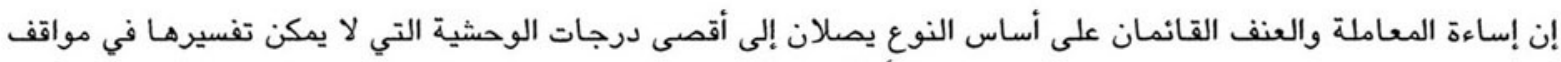

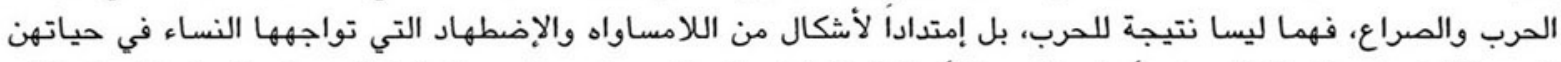

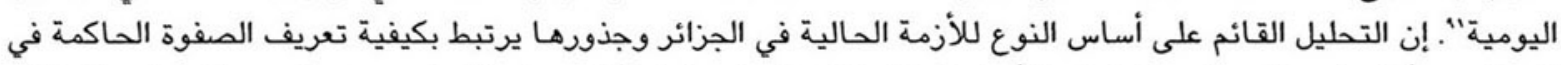

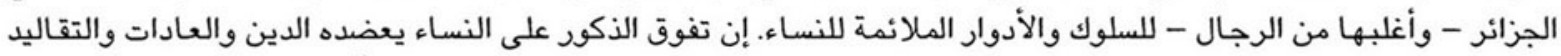

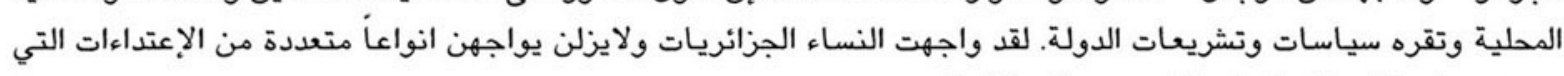
تحرض عليها الدولة والعنف الذي يدعو إليه الإسلاميون.

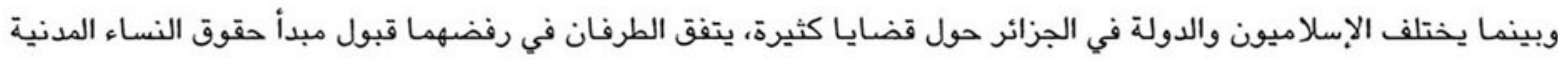

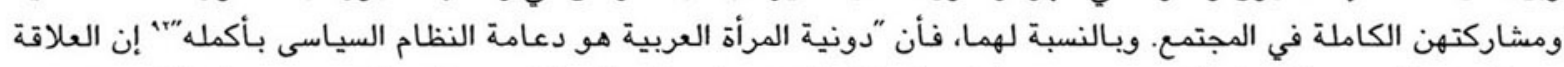

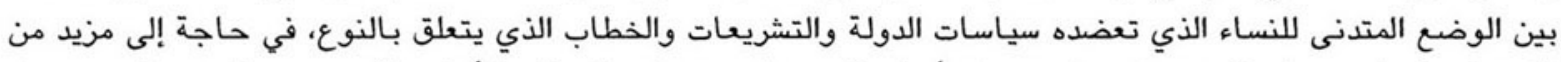

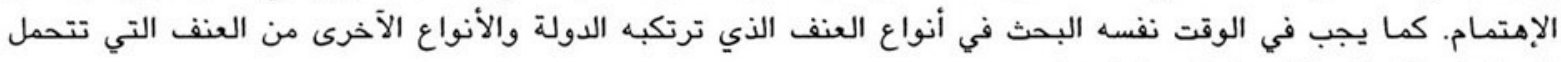

الجماعات الإسلامية المسلحة مسؤوليتها.

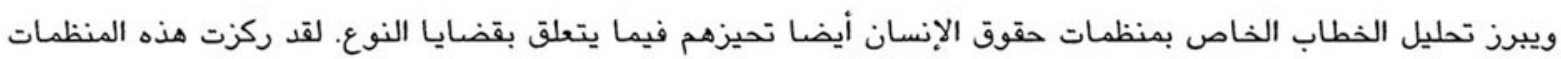

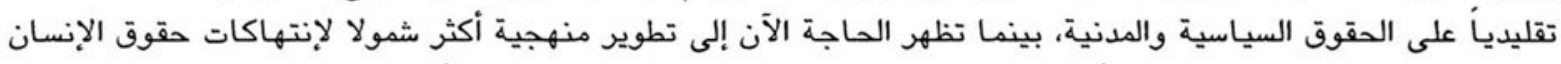

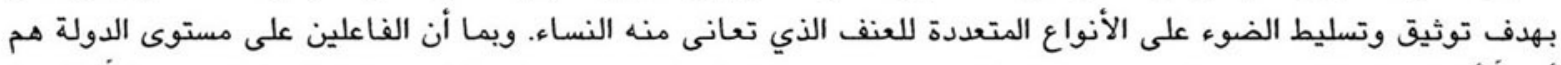

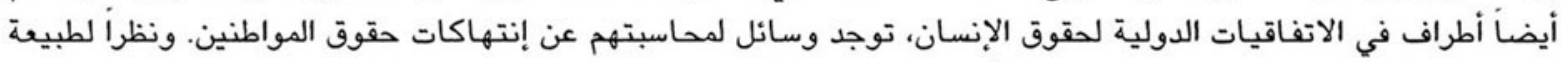

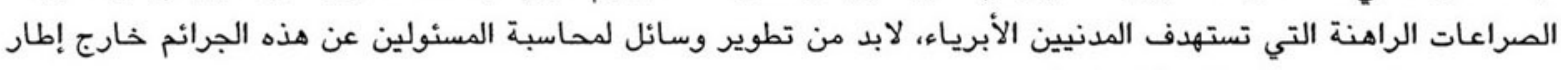
الدولة، مثل الجماعات الإسلامية المسلحة.

L'organization des jeunes Algériens libres $\wedge 1$ Slymovics, Susan ."Hassiba Ben Bouali, If you could see our Algeria". MERIP, 192, 195. Av Benali, 1995, P. $6 \wedge \wedge$ El Watan, October 9, 1997 ^9 9 9 99 نفس المصدر

Network Women in Development Europe, 1998 al Mernissi, Fatima. Islam and Democracy: Fear of the Modern World. Trans. Mary Jo. Lakeland: Addison-Wesley Publishing company, ar 1992, p. 153 


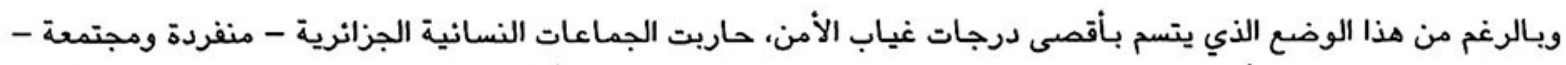

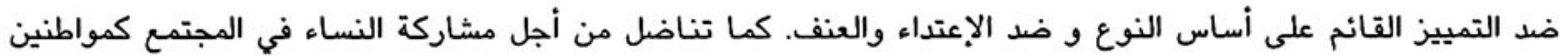
متساويين. ويقدم الجزء التالى لمحه تاريخية عن نشاط التهاء التنظيمات النسانية الجزانرية.

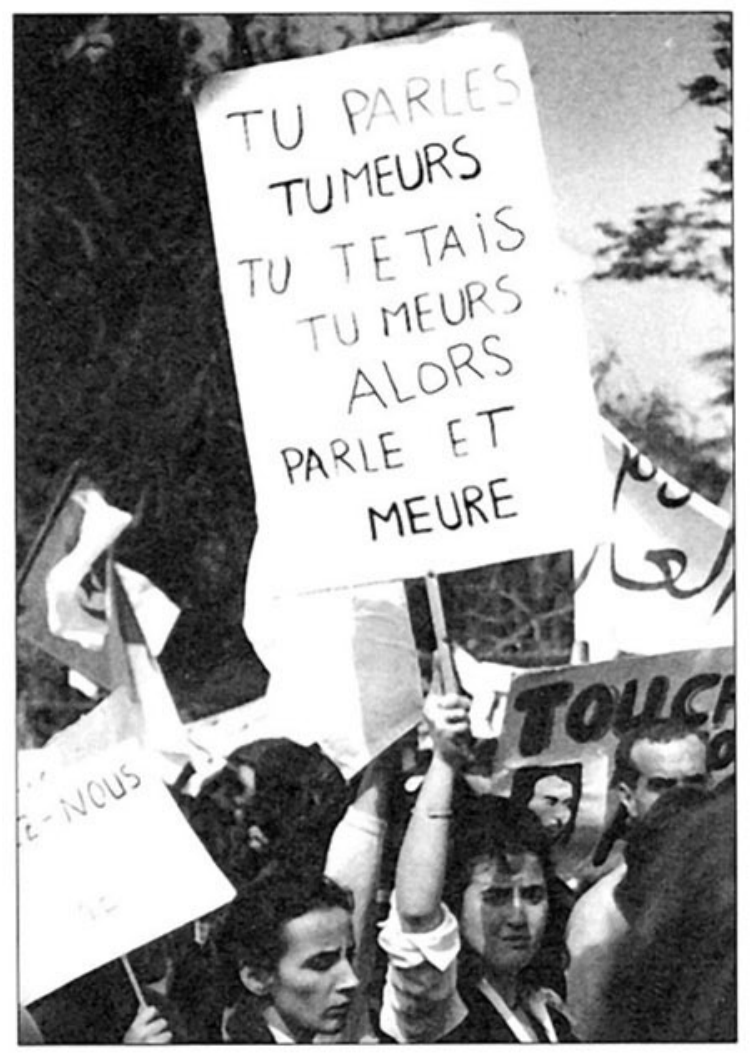

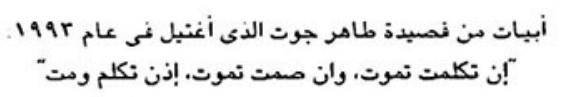




\section{رابعا: النشاط النسائى فى التاريخ الجزائرى}

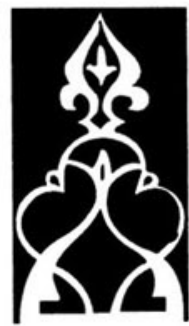

\section{أ. المركات النسانية من الإستقلال حتى الثمانينات}

"تتحدث كلمات الأسى أيضا عن الحياة"r"

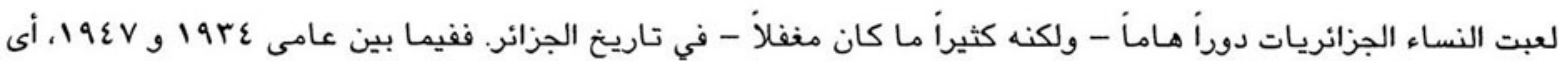

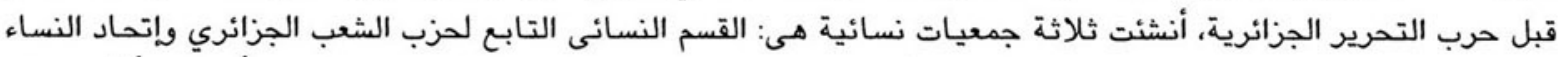

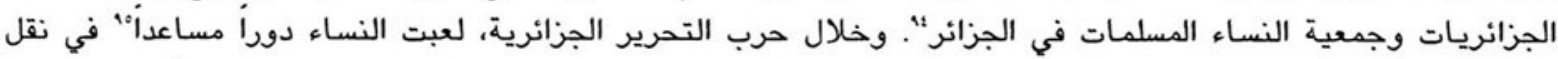

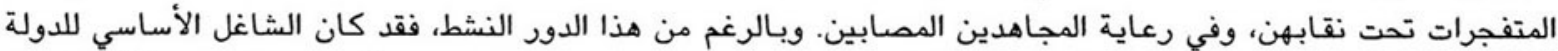

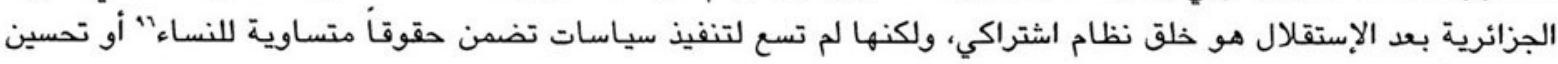
وضعهن أو تمكينهن من لعب دور عام في الإنياة.

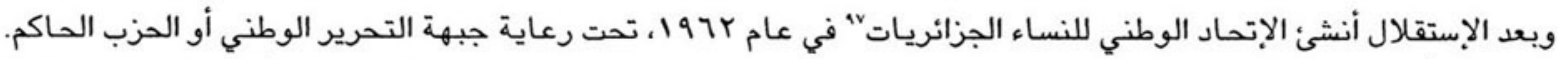

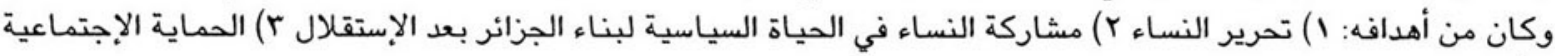

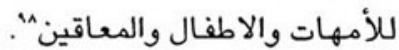

وفي السبعينات والثمانينات، عملت أغلب المجموعات النسائية تحت لواء عدد من الأحزاب السياسية. ثم تغير هذا الوضع في وتئ

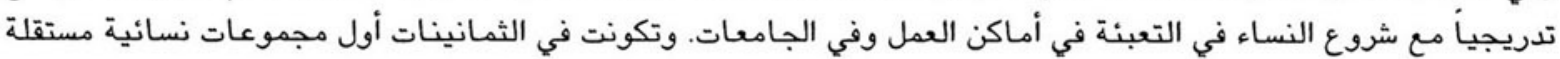

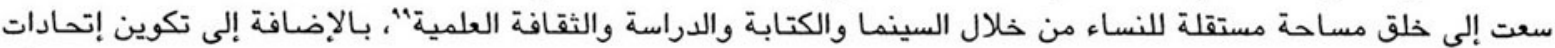

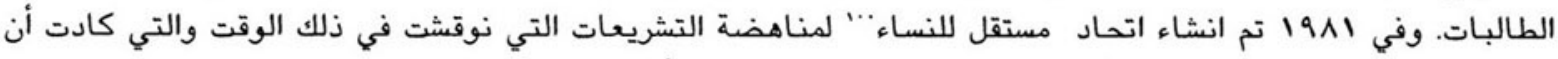

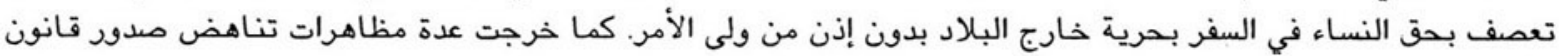

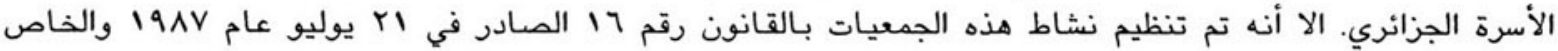

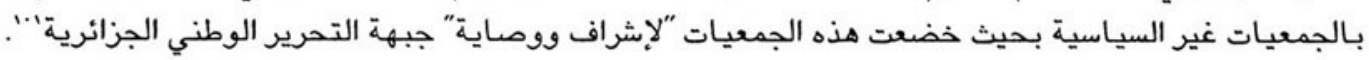

أصبحت السياسات والتشريعات التي أصدرتها جبهة التحرير أكثر رجعية مـ منح الجبهة إمتيازات سياسية للقوى المحافظة

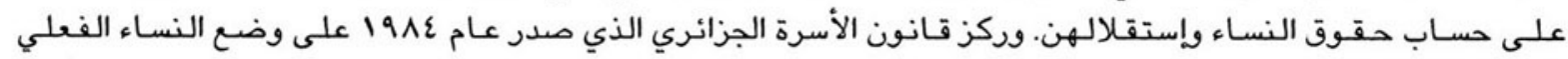
كمواطنات من الدرجة الثانية واعتبارهن قاصرات مدى الحياة. وفي نفس الوقت، كان يشار إلى النساء الجزائريات على النى أنهن

L'Algérie. Textes et dessins inédits. Casablanca: Le Fennec, 1995, P.17. १r

Bouatta, Cherifa. Evolution of the Women' Movement in Contemporary Algeria: Organization, Objectives and Prospects. Helsinki: $9 \varepsilon$ United Nations University and World Institute for Development and Economic Research, 1997, P. I.

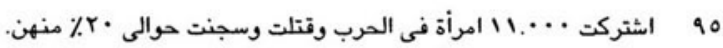

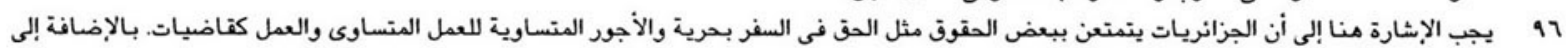

المساواة فى الدستور الجزائرى بين النساء والرجان الرجال.

The National Union of Algerian Women qv

9A

99

Collectif Independent de Femmes 1...

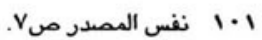


"أركان المجتمع"، كما تبوأ عدد منهن بعض المناصب المهنية الهامة في بعض القطاعات الحيوية.

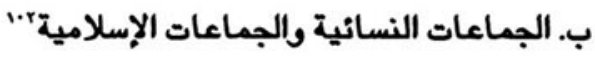

"أفضل سيدة مرتدية النقاب عن الف خطبة جمعة"+.

يمكن القول أن أغلبية النساء العضوات في تنظيمات مقرهـا الجزائر العاصمة ينحدرن من أسر متوسطة اجتماعياً ويشتركن في الإسيا

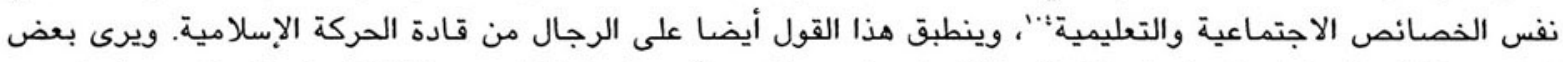

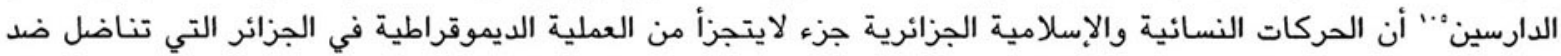

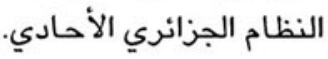

وبالرغم من أن التظظيمات النسائية والإسلامية تستخدم المجتمع المدني للدعوة من أجل التغيير المجتمعى، إلا أن التغييرات

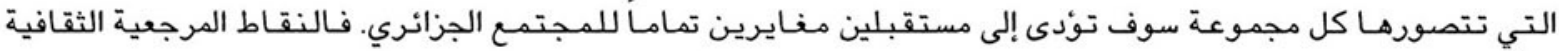

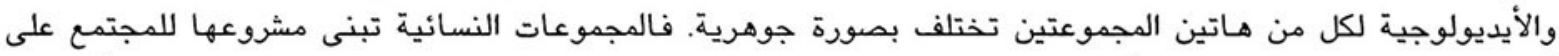

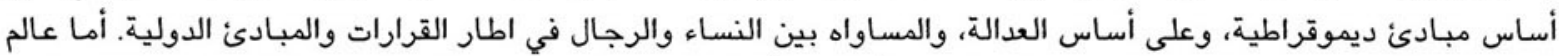

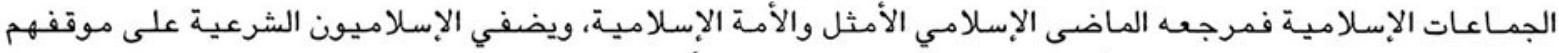

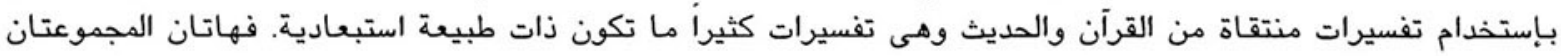
لاتستفيدان من نفس الامكانات لتحقيق التغيير المجتمعى. وتتمتع الجماعات الإسلامية بالتمويل والتيل والقدرة الكبات الكبيرة على التنظيم

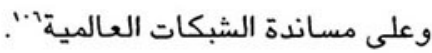

وجرى حشد المجموعات النسائية كرد فعل للتناقض الذي تواجه النهاء النساء في المجتمع الجزائري. فمن ناحية إغتنمت النساء

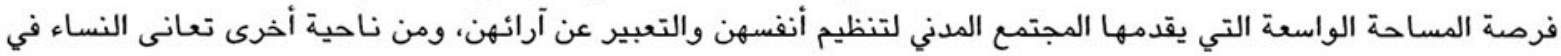

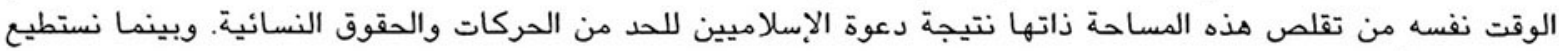

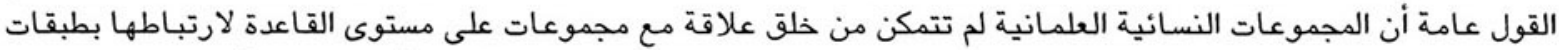

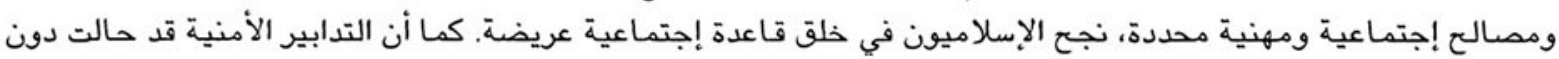

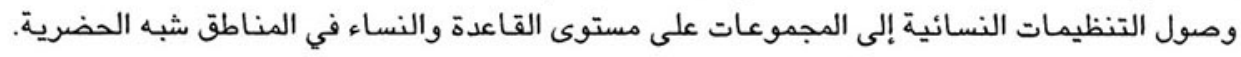

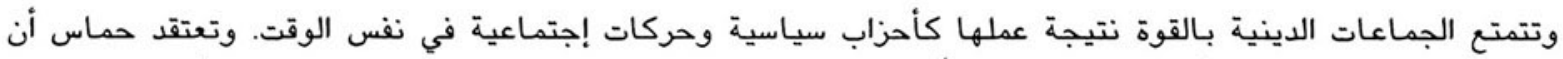

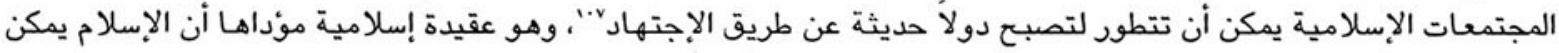

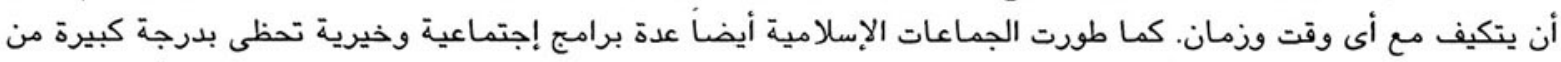

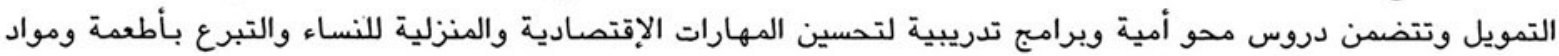

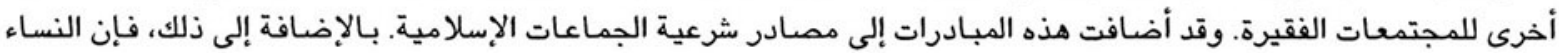

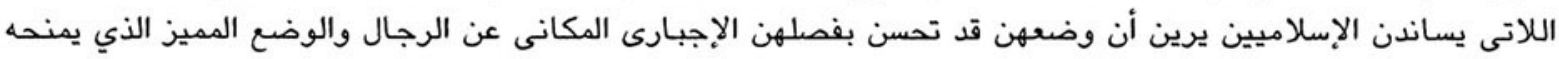

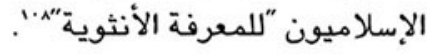

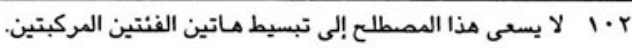

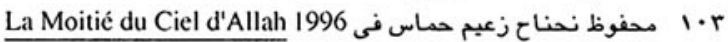

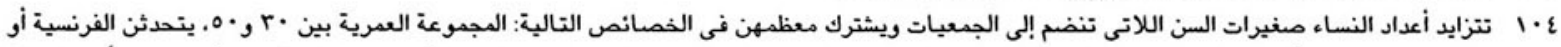

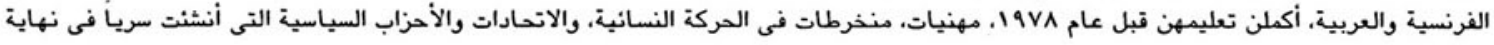
الستينات ويداية السبعينات. Cheriat, Boutheina. "Islamism and Feminism: Algeria"s Rites of Passage to Democracy". In State and Society in Algeria. Ed. Entelis 1.0 and Nayln. Boulder: Westview Press, 1992, 171

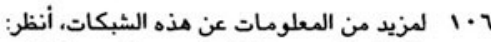

"Les reseaux de soutien au FIS et au GIA en Europe": February 16:1998

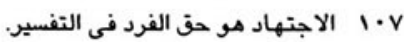

Powers-Steven, Tanya. Briefings on Development and Gender. New York: UNIFEM, 1995, P. 67-88. I.A 


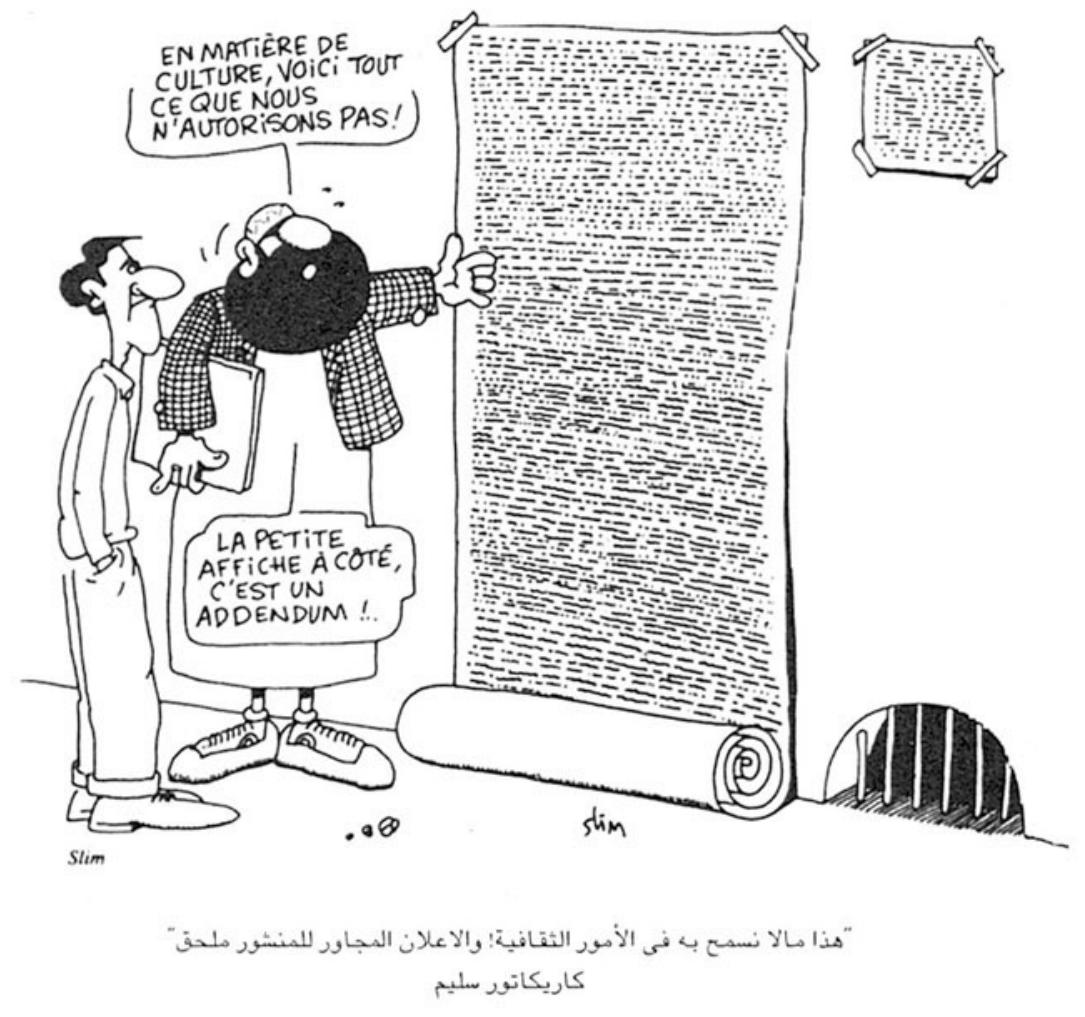

ج. الحق في تكوين الجمعيات التنظيمات النسانية الجزانرية المعاصرة:

تمتع المجتمع المدني بفترة انفتاح شهدت تكوين جمعيات مستقلة في الفترة التي تلت تعديل الدستور الجزائري عام 9 التو 19، فتم

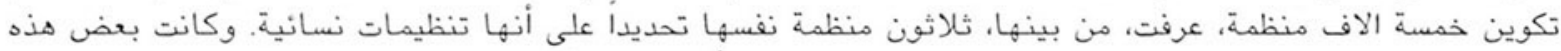

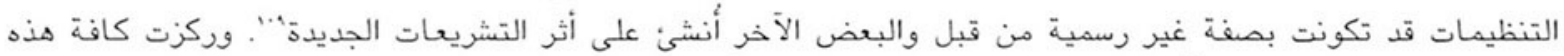

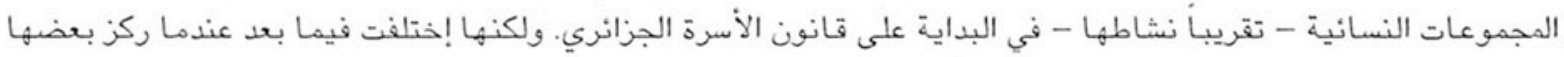

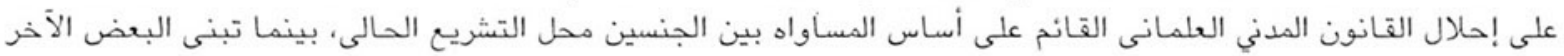
إستراتيجية تسعى إلى تغيير النصوص التي تميز بصفة خاصة ضل الند النساء ضمن التشريع الحالي.

وبصفة عامة، تبنت المجموعات النسائية العلمانية المستقلة مواقف وأساليب تضرب بجذورهـا في نشاط بعض أعضائها

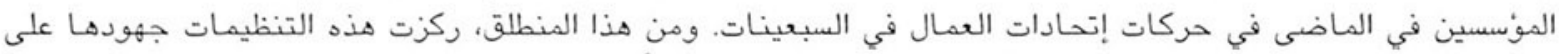

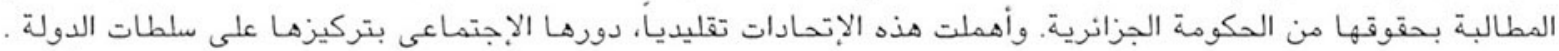

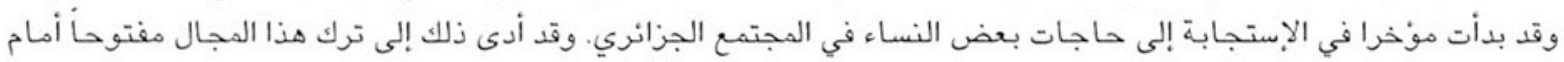
الجماعات الإلامية التي طورت - من خلال التمويل المتوفر لديها وإتصالاتها - عدة براهي إنج إجتماعية وثقافية وتعليمية

لللمجتمعات المختلة.

وفي عام 19 ا تم تكوين جمعية نسائية جديدة وهى جمعية المساواة بين الرجال والنساء أمام القانون بهدف "المشاركة في خلق واقتراح تدابير وخطوات محددة لتحقيق المساواة بين الرجال والنساء أمام القانون". ولم تسجل هذه ودأ الجمعية في وزارة الداخلية رسميا. ولم يحصل الجزائريون على حقوقهم في حرية التعبير وتكوين تنظيمات إلا بعد الإصلاح الدستورى في عام 1919. 
وبين عامى 1919 و 1991 إشتركت عدة جمعيات في شبكة مشتركة لتطوير جدول أعمال لأهدافها المشتركة. وكان هدفها

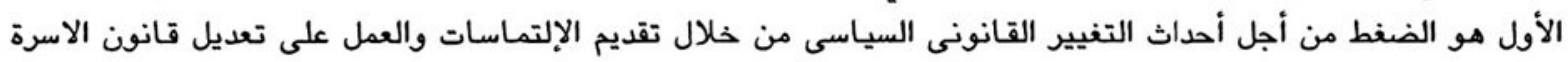

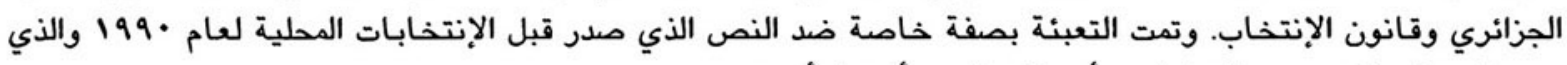
سمح للرجال بالتصويت بالنيابة عن أريعة نساء من أعضاء أسرهم.

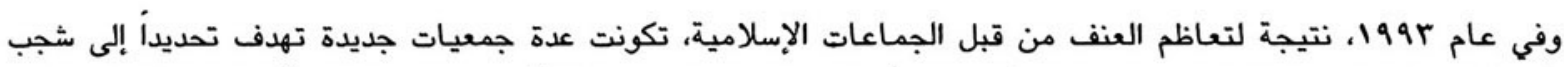

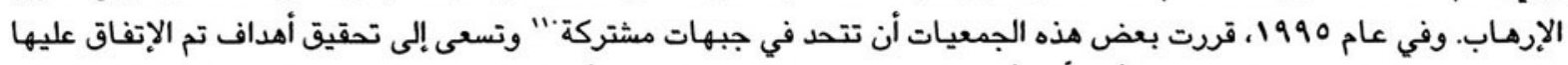

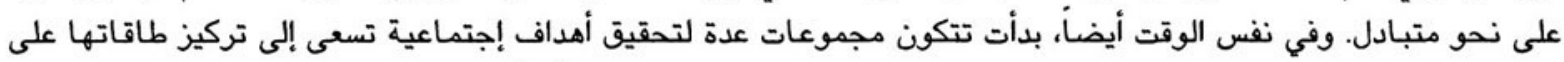

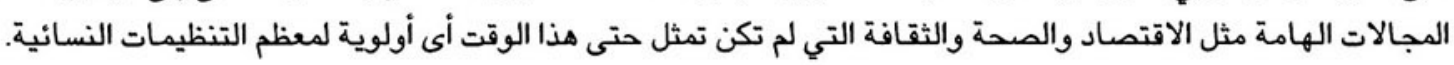

وقد أتاح المؤتمر الدورى الرابع للنساء (بكين 1990) فرصة للتنظيمات النسائية الجزائرية والإقليمية والأفراد للإلتقاء.

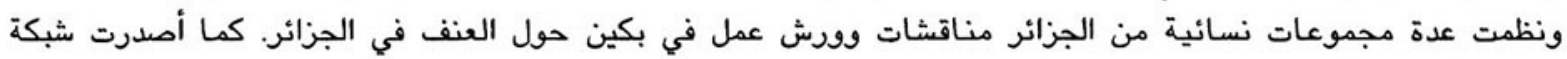

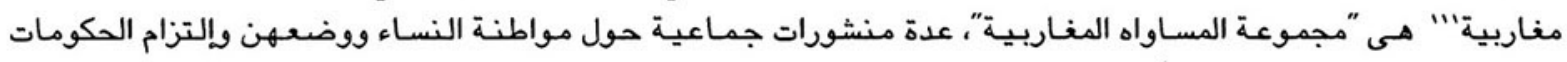
بحماية حقوق النساء في شمال أفريقيا.

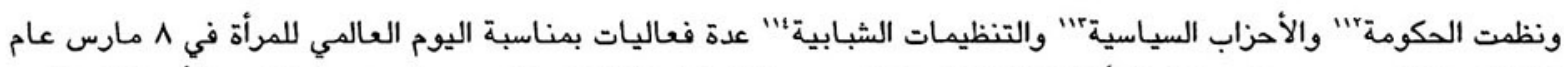

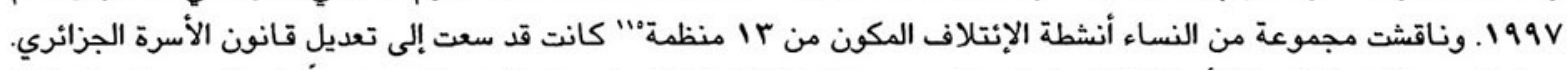

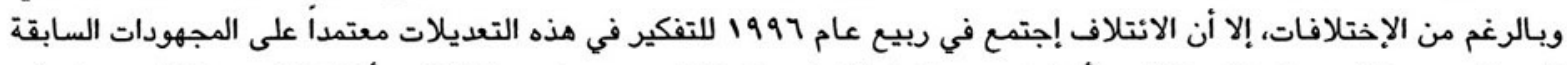

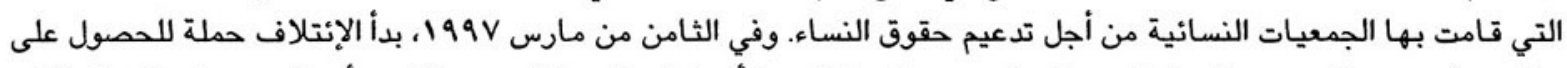

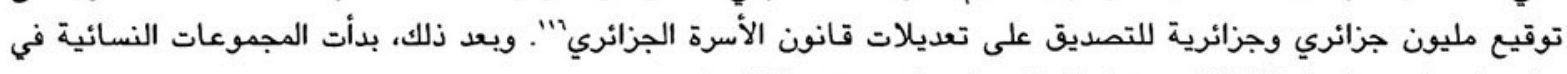
تطوير إستراتيجيات لمناقشة التمييز في التشريعات على لمئمئ مستوى القاعدة.

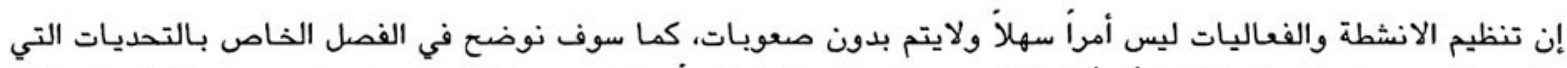

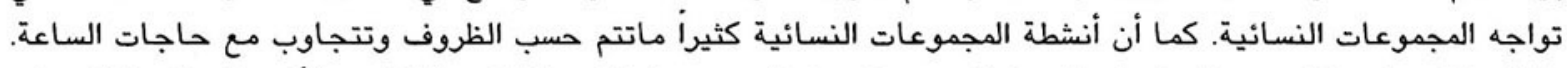

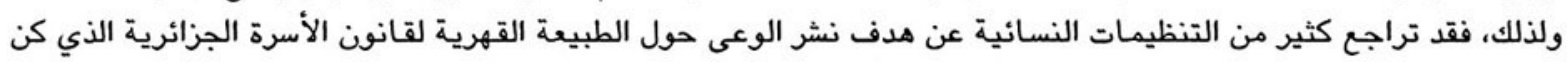

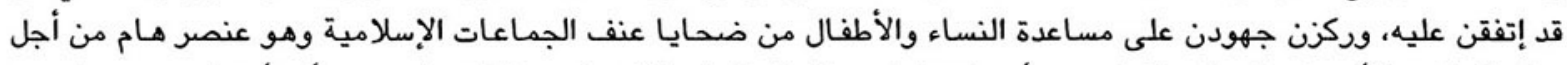

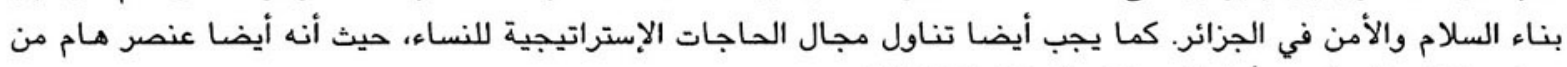
عناصر كفاح النساء من أجل المساواة والمواطنة الكاملة.

Le Rassemblement Algérien des Femmes Démocrates (RAFD); Le Rassemblement Contre le Horga et pour les Droits des $\quad 11$. Algeriennes (RACHIDA).

(II

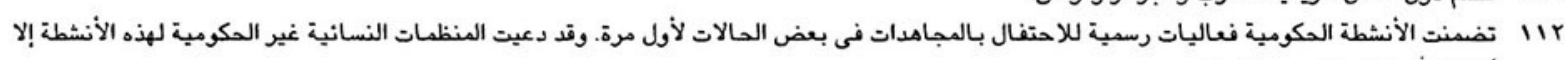
أن كثيرا منها اعتذرت عن الحضور.

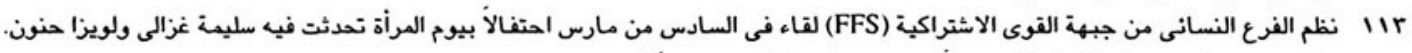

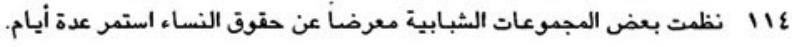
ما 11 تكون الانتلاف من المنظمات الستة المذكورة اعلاه والمجموعة المغاربية للمساواة، المواطنات، الأزهار، نجمة عقبو الثقافية، النساء والاتمالات، مرخات النساء، وأصوات النساء. 7 רا 11 كان رد فعل حزب النهضة هو أن الحزب سيعمل على جمع توقيع ثلاثة ملايين مواطن لمساندة التشريعات القانمة ومعارضة التعديلات المقترحة. 


\section{خامسا: خصائص وأنواع التنيمات النسائية}

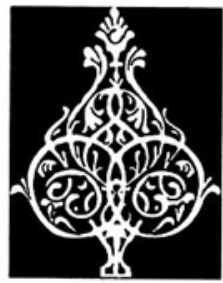

"من خلال عزم نسائنا، ومن حطامك سوف تولدين أيتها الجزائر"v"

\section{أ. من المطالب إلى العمل الإجتماعى: توجه التنظيمات النسائية الجزانرية:}

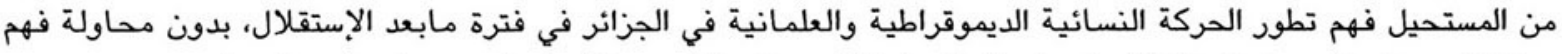

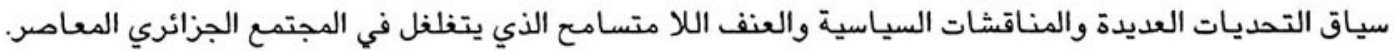

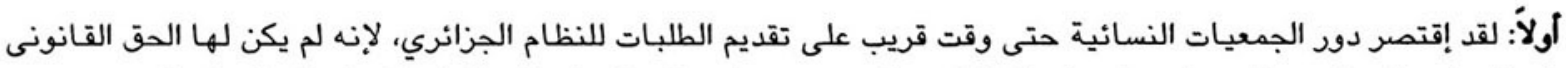

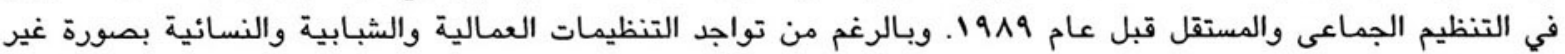

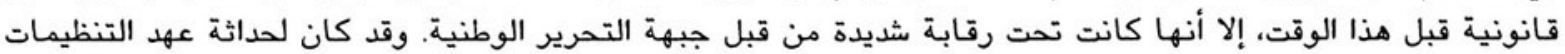

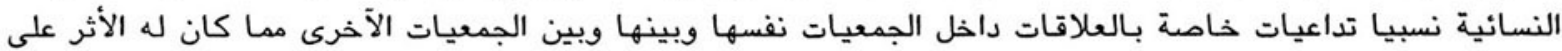

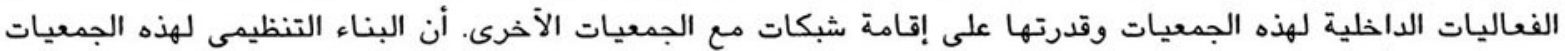

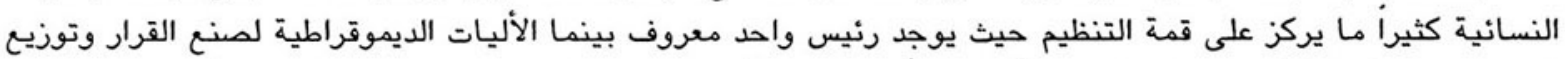

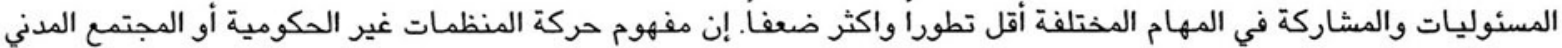

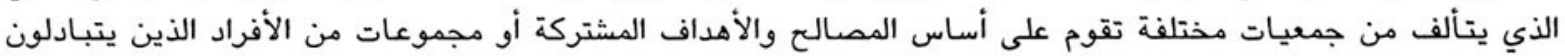

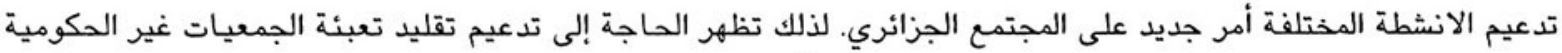

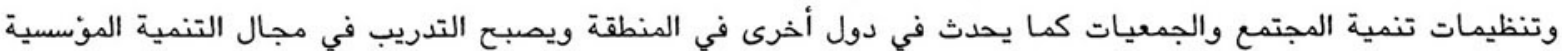

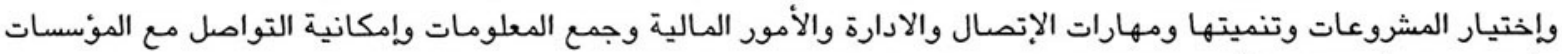
الأخرى من الأمور ذات الأولوية لكافة المنظمات الجزات الجمائرية.

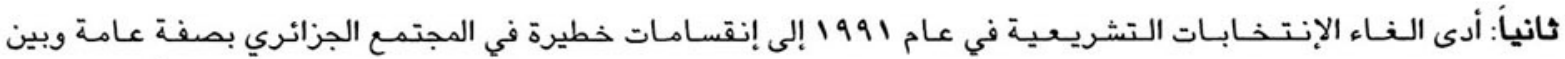

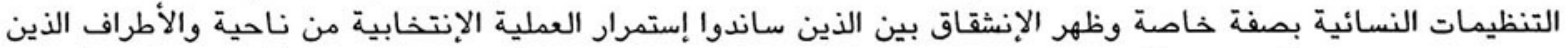

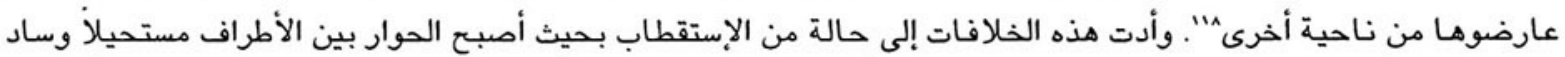

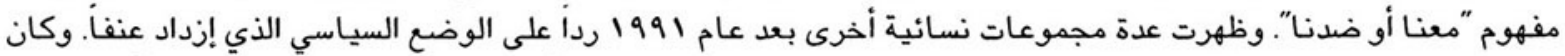

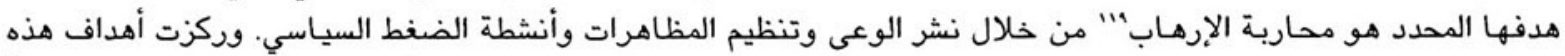

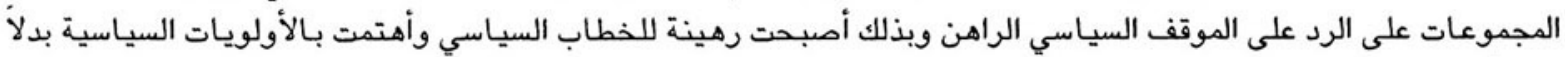
من الأمور الخاصة بالعلاقة بين الجنسين.

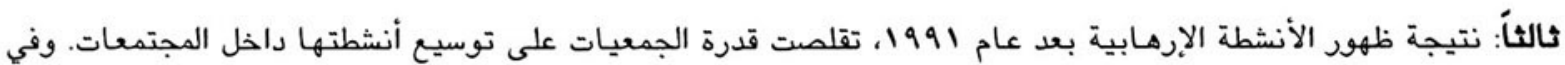
الوقت الذي بدأت فيه المجموعات النسائية في التنظيم والتفكير بطريقة إستراتيجية من أجل العمل العل على ألى مستوى القاعدة

Ben Mansour. Latifa, 1997. IIv

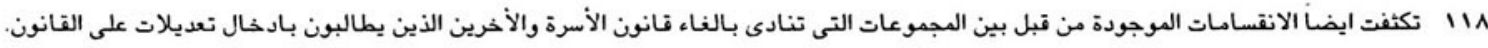
RACHDA وتجمع RAFD, RA 
وتطوير برامج محددة، أصبحت الأمور الخاصة بالأمن من الأمور الخطيرة. وإنطوت زيارة بعض الأحياء في الجزائر العاصمة الخداء

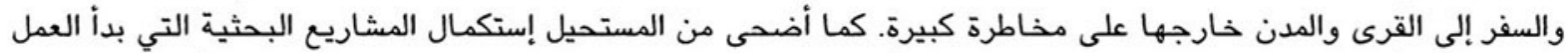

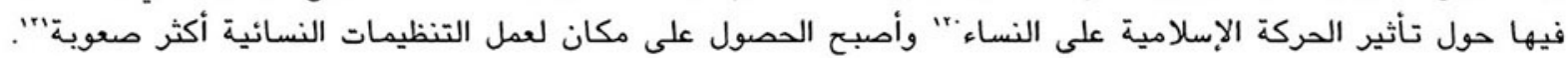

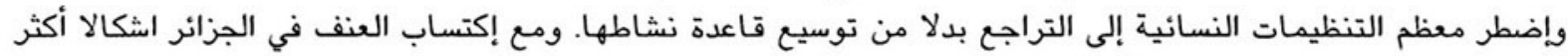

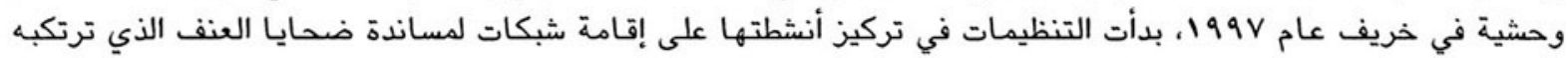
الجماعات الإسلامية.

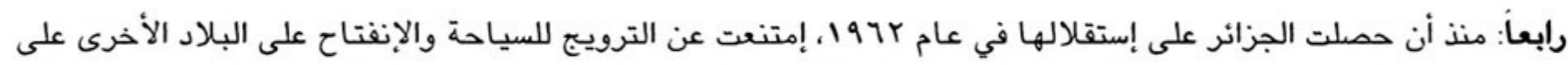

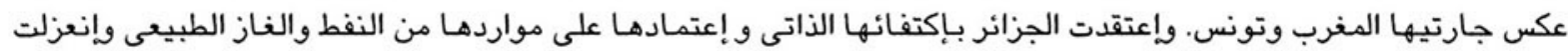

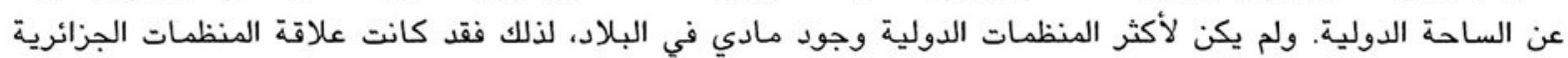

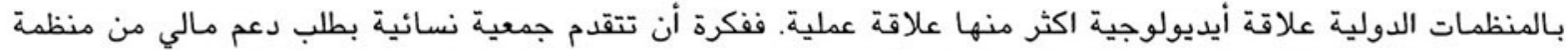

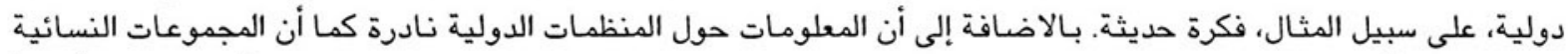

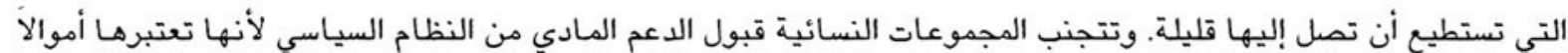

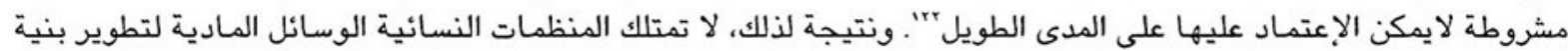

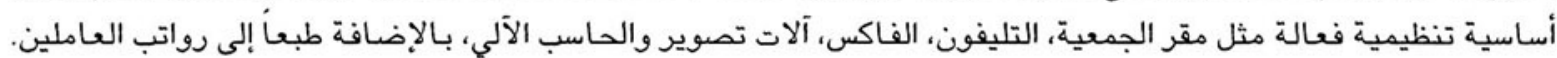

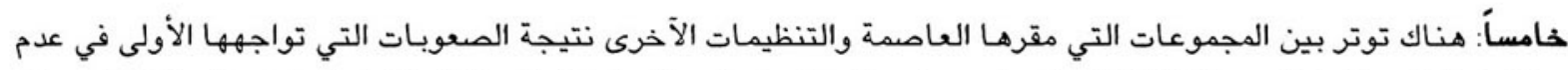

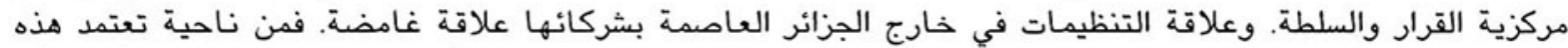

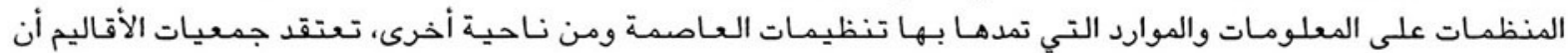

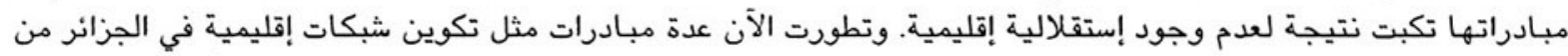

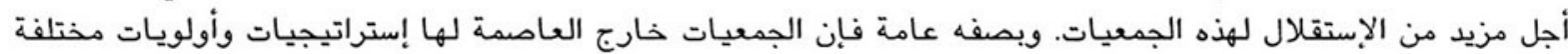

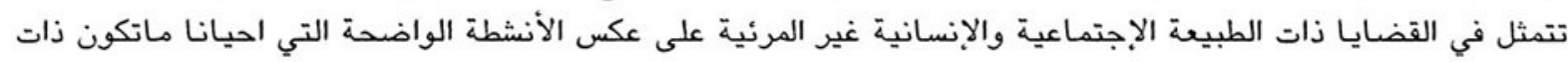

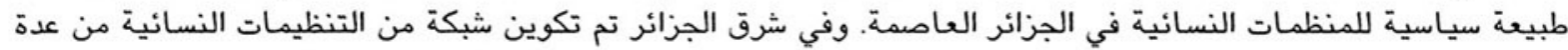

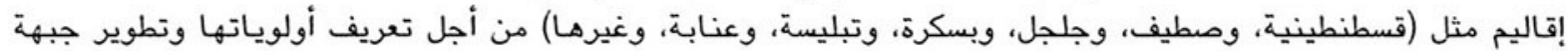

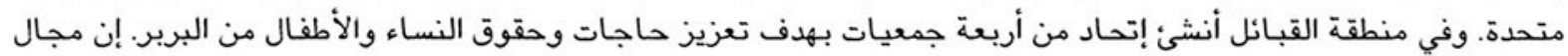

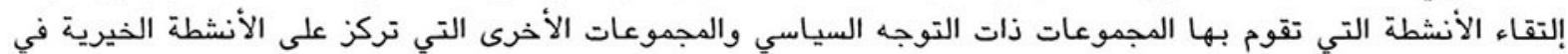

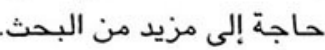

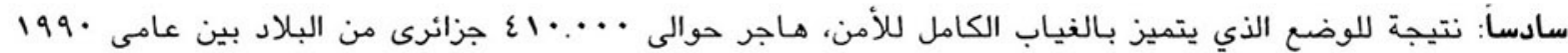

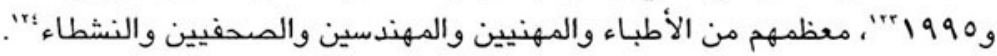

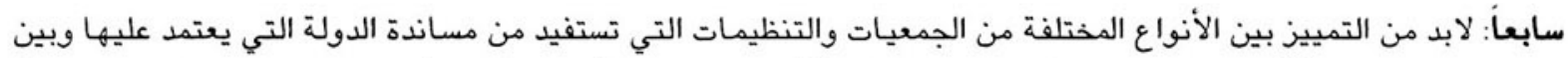

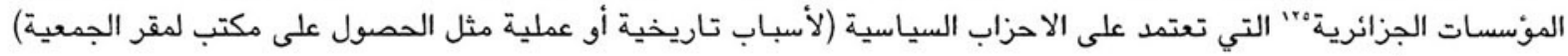
والمنظمات الأهلية المستقلة.

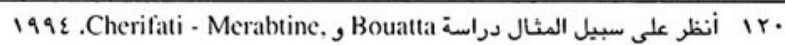

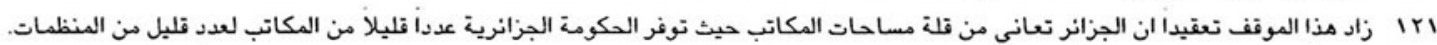

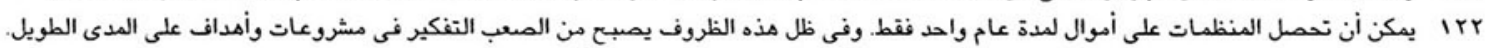

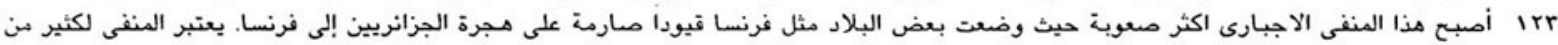

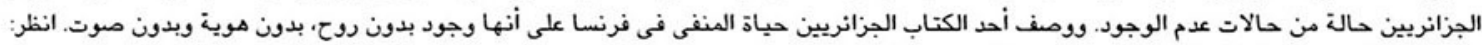
Koudil, Haffsa Zinai. Sans Voix. P’aris: Editions Plon. 1997. Office National des Statistiques, Algiers. Algeria. 1996. ir£

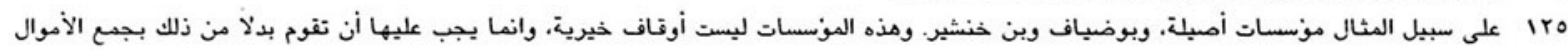
لتغطية مصروفاتها. 
ثامنأ: تختلف القواعد التي تمثلها هذه المجموعات فيما بين التنظيمات النخبوية الأكثر نظرية ورجعية في توجهاتها، وبين تلك الجماعات التي يتمثل هدفها في نشر الوعى والتعبئة على مستوى القاعدة. وسوف نقدم نظرة عامة الى نقاط قوذ ونقاط ضحف التنظيمات النسائية في الجزائر.

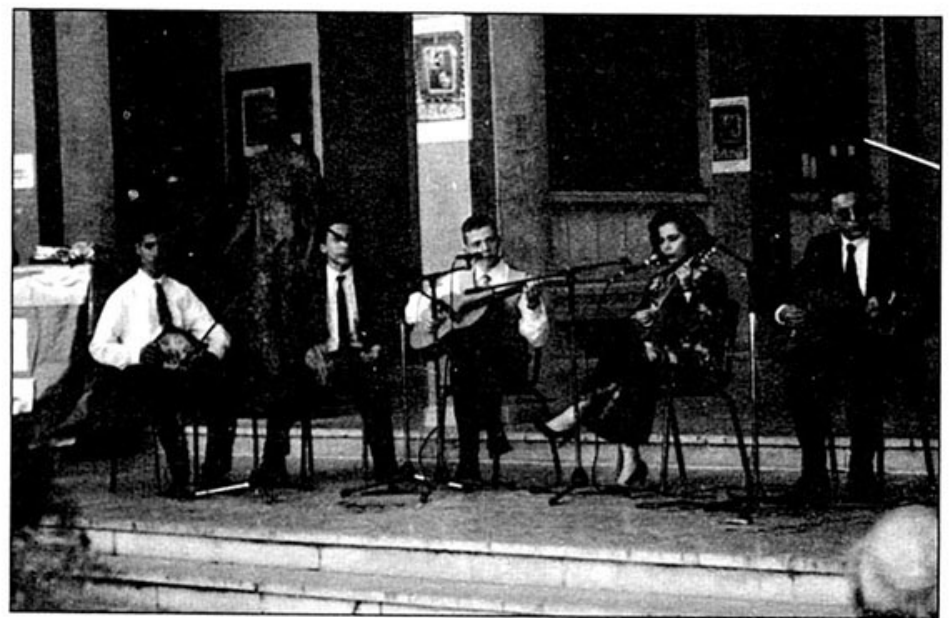

فرقة موسيقية جزانرية تعزف الحانا اندلسية بمناسبة الإحتفال بذكرى وفاذ الدكتور أصيلة الددير السابق النقانق

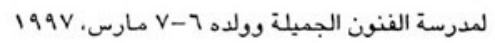

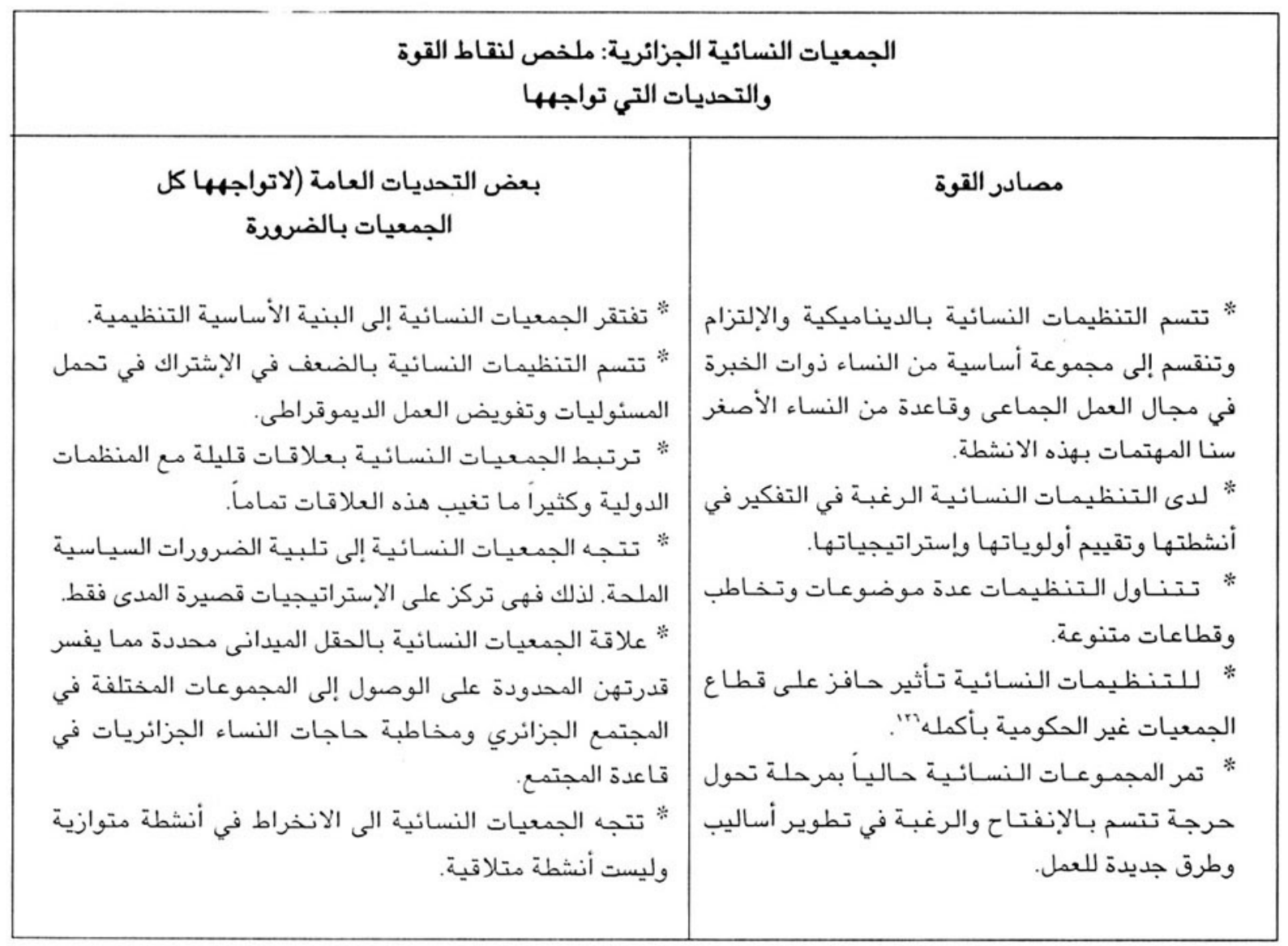

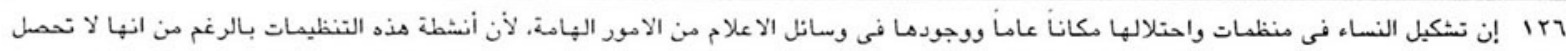
على مساندة كافة النساء تساعد على تحفيز الأخرين. 


\title{
ب. أنواح الجمعيات: إحتلاف الأمداف والأرلويات
}

\author{
"إن السجن الذي يقهرنى واسع. من أين تأتين أيتها الحرية؟" أغنية بريرية.
}

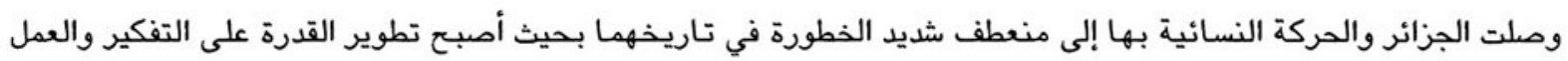

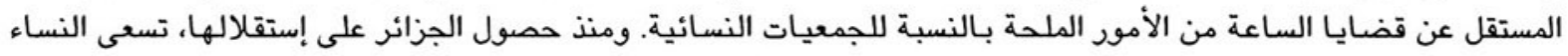

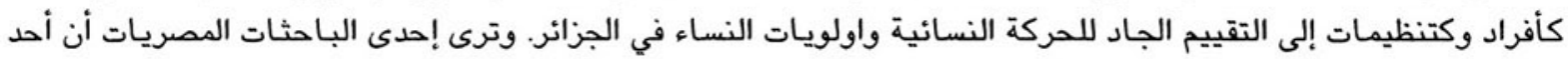

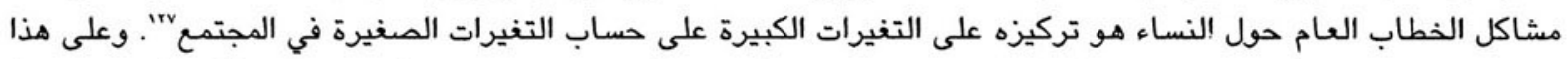

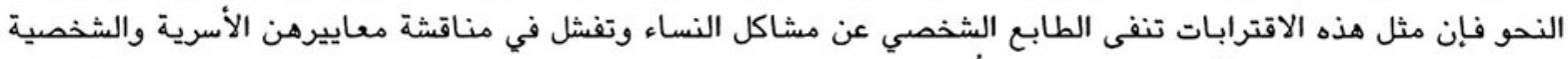

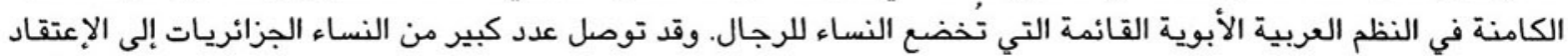

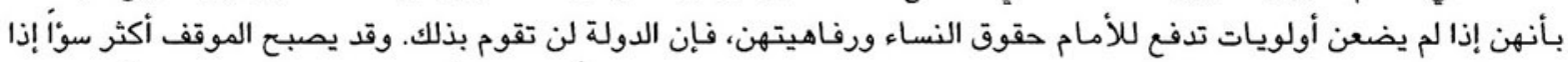

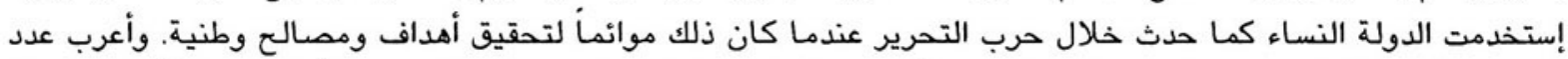

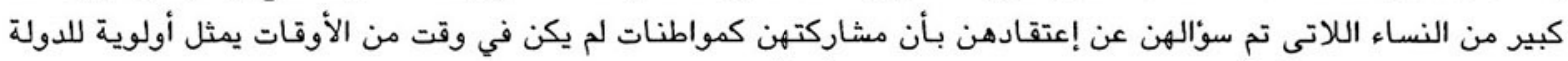

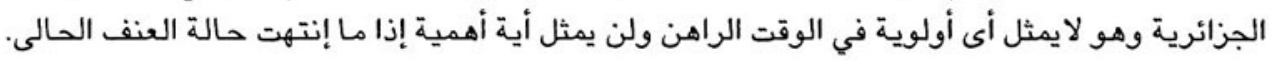

لذا، فإن المجموعات النسائية تفكر بطريقة أكثر إستراتيجية في المزايا النسبية وتركيز طاقاتهن على المهام المحددة في

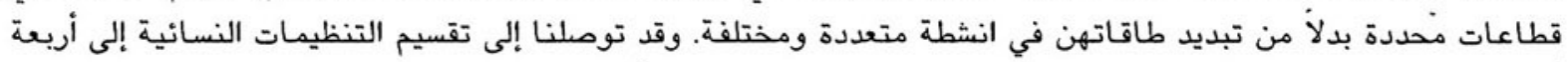

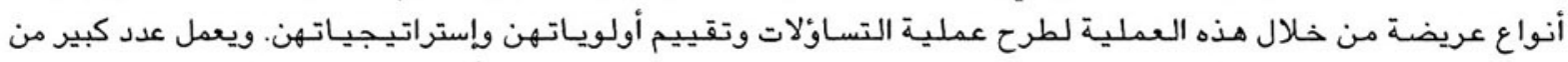

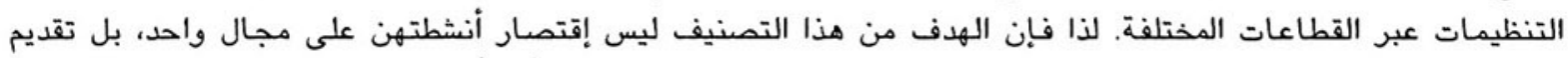

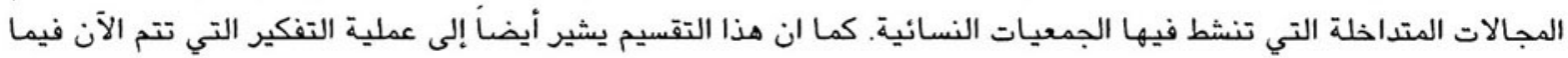
يتعلق بمجالات الإهنمام المختلفة التي تركز عليها التنظيمات النسائية.

تهتم مجموعات الضغط بأنشطة الدعوة ونشر الوعى والأنشطة الترويجية. كما تسعى إلى مطالبة الدولة الجزائرية بمساندة حقوق النساء ورفاهيتهن.

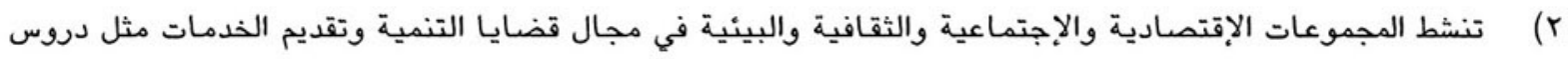

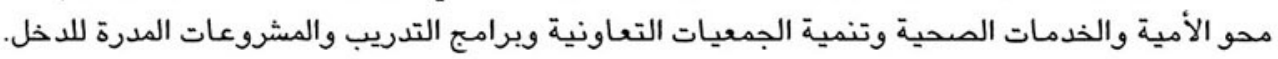

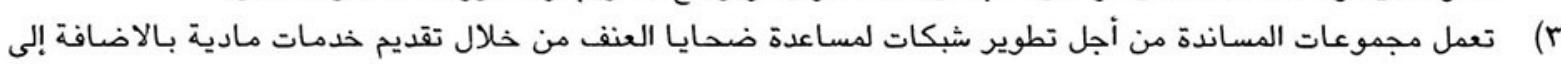

$$
\text { مساعدات قانونية وطبية ونفسية. }
$$

ع) تهتم مجموعات التفكير والدراسة ببحث وتحليل القضايا المختلفة المعنية بشئون النساء المحرم مناقشة بعضها في

$$
\text { السياق الجزائري^^. }
$$

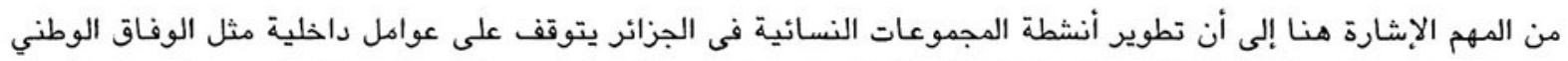

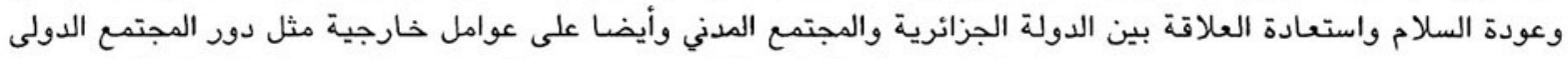

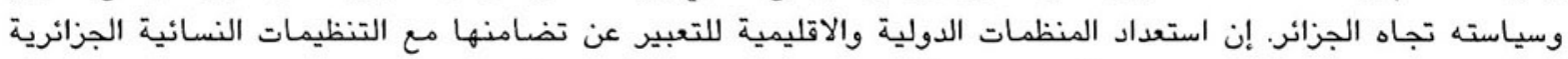

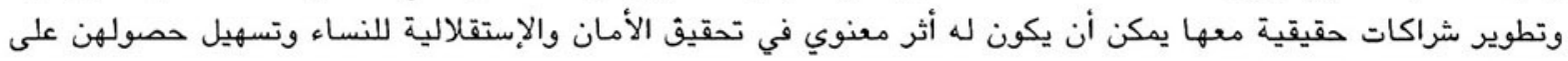
حقوق متساوية في المواطنة.

Hatem. Mervat. “Toward the Development, of Post - Islamist and Post - Nationalist Feminist Discourses in the Middle East." In Arab l.rv

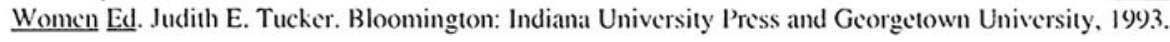




\section{ج. أمثلة من التنظيمات النسائية فى كل مجموعة:}

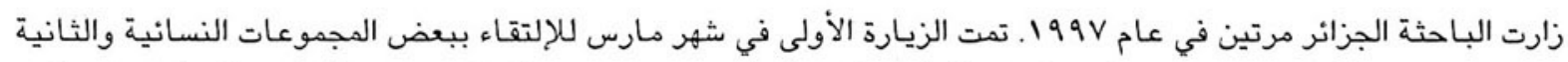

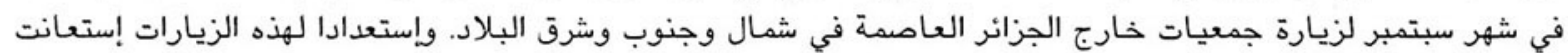

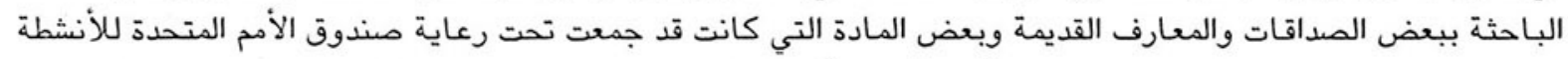

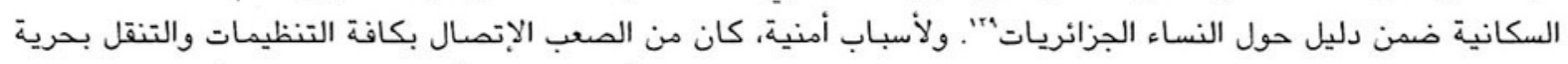

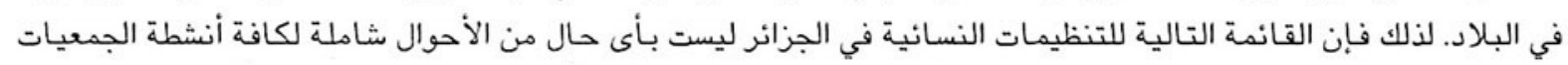

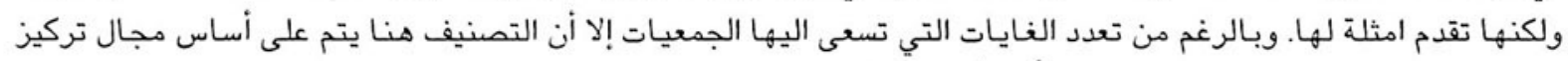

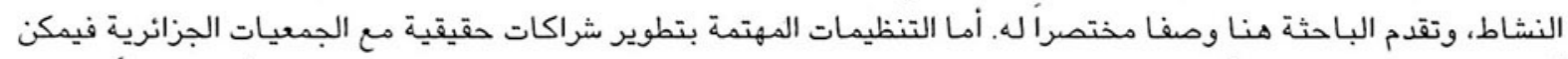

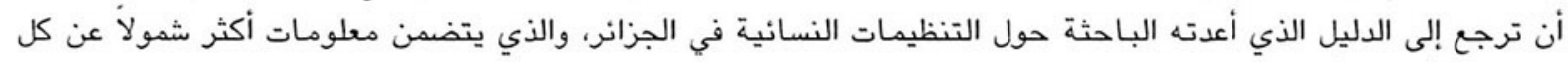

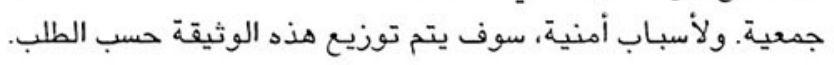

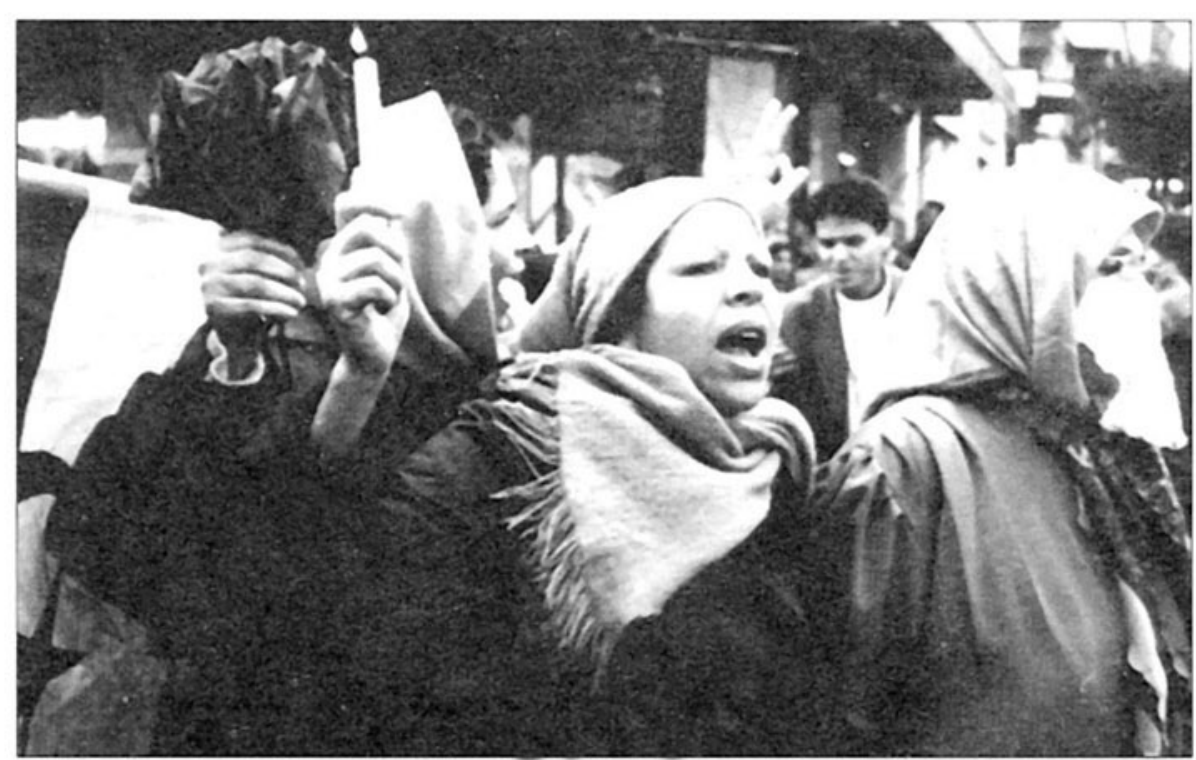

la Tribune مظاهرة نسانية فى الجزائر العاصمة المصورة: لويزا
بصفة عامة، يمكن القول أن للتنظيمـات النسائية

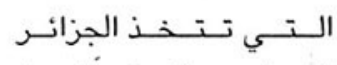

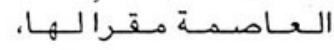
تـوجـهـات سـيـاسية أكثر من الـتــــــــات خـارج العاصمة. وتسعى الأخيره

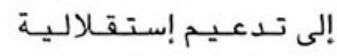
الـنسـاء من خلال تطوير

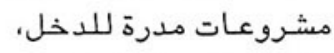

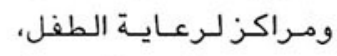

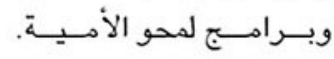
ولمحاولة فهـم التحديات

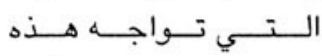
الجمعيـات، يـجب التـأكيد على المصاعب المادية (قليل مديل يل

\section{ا ـ نشر الوعى والدعوة}

تعمل بعض المجموعات النسائية في مجال نشر الوعى والدعوة وتدعيم حقوق النساء ورفاهيتهن “ج". وقد نظمت هذه الجمعيات

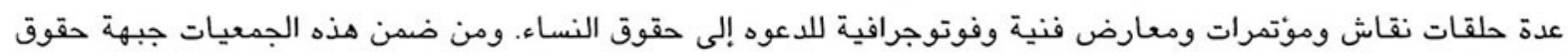

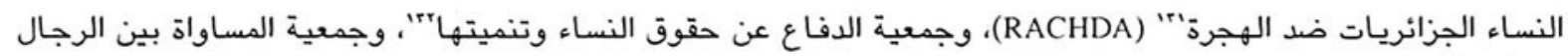

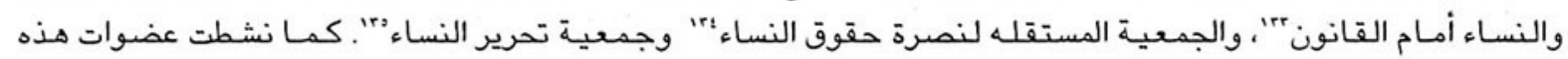

Brac de la Perrière, Caroline. Les Associations Ayant pour But la Promotion des Femmes. Algiers: UNFPA, 1993. Irq

Le Rassemblement Algérien des Femmes Democrates ir. Rassemblement contre la Hogra et pour les droits des Algériennes. ir Association pour la Défense et la Promotion des Droits des Femmes. irr L'Association pour l'Egalité Devant la loi entre les Femmes et les Hommes. Irr Association Independente pour le Triomphe des Droits des Femmes. ir Association pour l'Emancipation de la Femme iro 


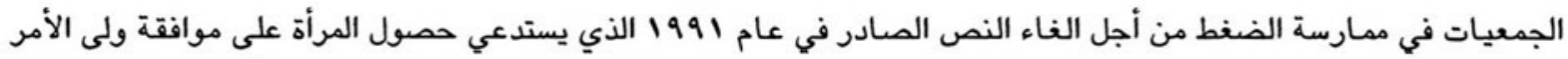

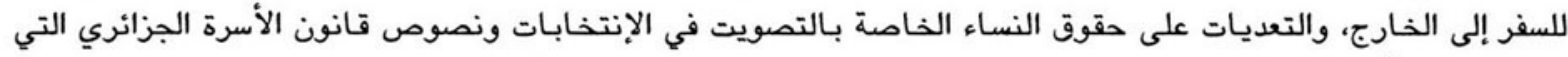

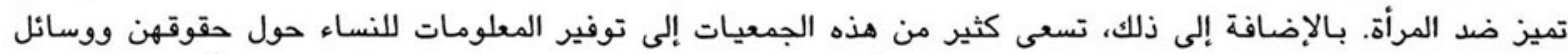

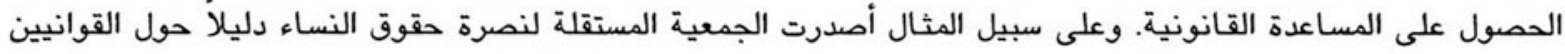
المعنية بالمرأة، كما تعمل جمعية النساء الجزائريات المطالبات بحقوقهن"' (FAUED) في مجال حقوق النساء القانونية ومشاركتهن الكاملة كمواطنات.

\section{RACHDA \\ "نحن النساء اللاتى تهبن الحياة نرفض الموت ونرفض المنفى.

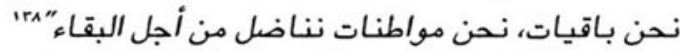

جبهة حقوق النساء الجزائريات وضد الهجرة RACHDA هى مظلة اللتنظيمات النسائية في أنحاء الجزائر،

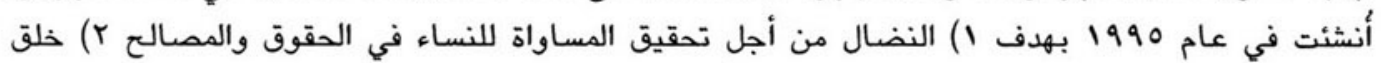

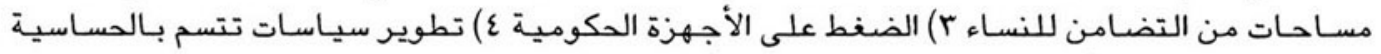

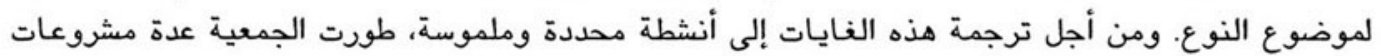

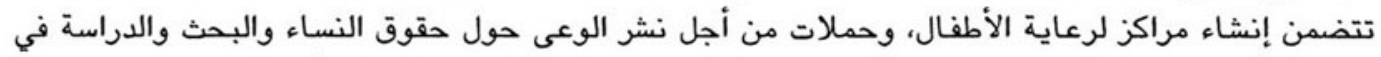

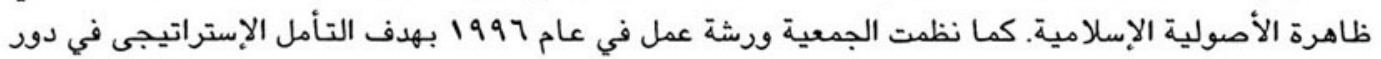

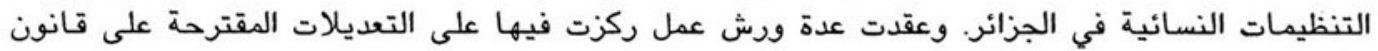

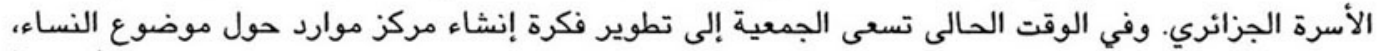

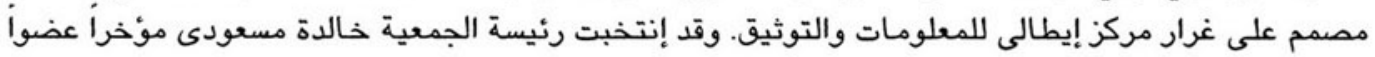
في البرلمان الجزائري.

\section{r. التنظيمات الإقتمادية والإجتماعية والثقافية والبينية:}

\section{(ا) التنظيمات الإقتمادية:}

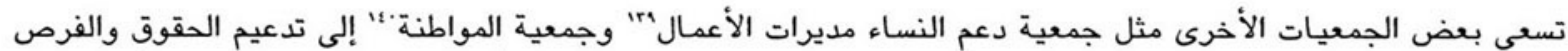

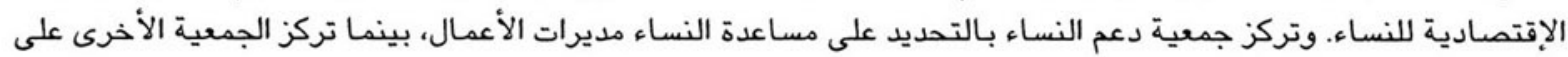

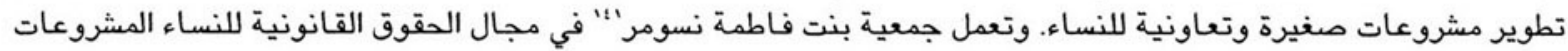
المتعلقة بالمشاركة الإقتصادية للنساء.

أما الجمعية التعاونية للنساء من منطقة المزاب٪' فهى تسعى إلى تنمية المهارات الحرفية للنساء مثل صناعة السجاد

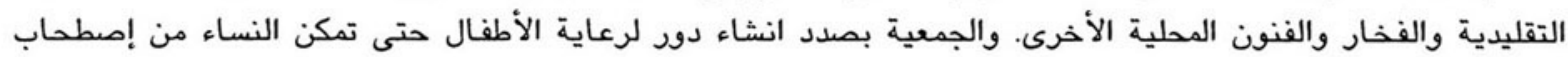

$$
\text { أطفالهن معهن إلى مكان عملهن. }
$$




\section{جمعية دعم النساء مديرات الأعمال (SEVE)}

أنشنت الجمعية في عام r99 ا لتحقيق أربعة أهداف رئيسية. () تدعيم المشاركة الإقتصادية للنساء. r) تدريب

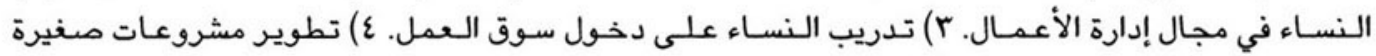

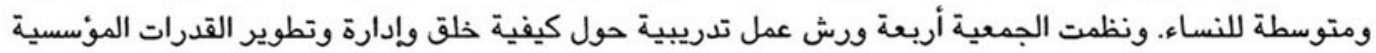

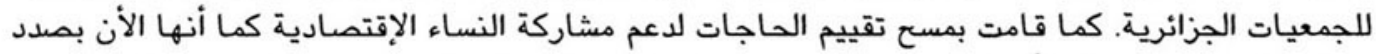

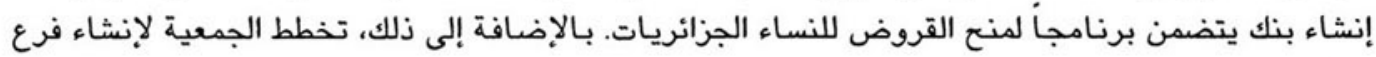
تجارى وطنى للنساء يدافع عن الحقوق الاقتصادية للنساء ومشاركتهن الإقتصادية.

\section{ب) التنظيمات الإجتماعية:}

\section{* | (المحة/ تنظيم الأسرة}

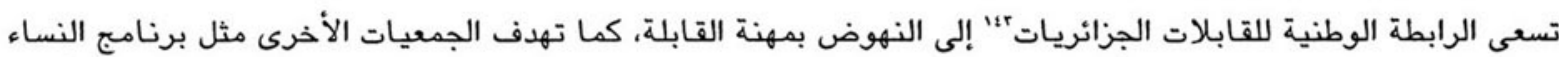

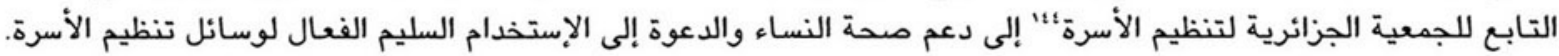

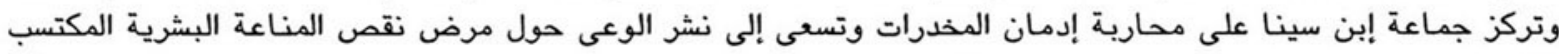

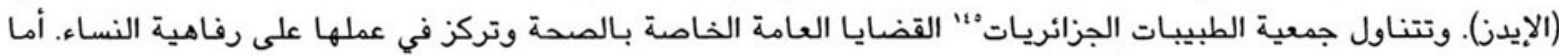

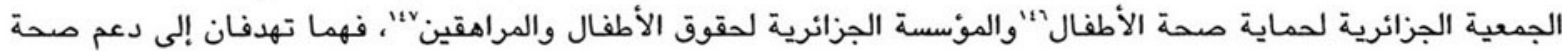

الاطفال والمراهقين وحقوقهم.

\section{جمعية الطبيبات الجزانريات}

بدأت مجموعة من الطبيبات الجزائريات والعاملات في الحقل الطبى في تنظيم لقاءات في وهران منذ فبراير

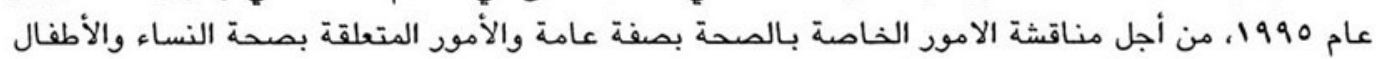

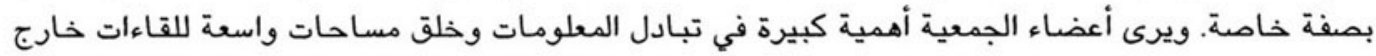

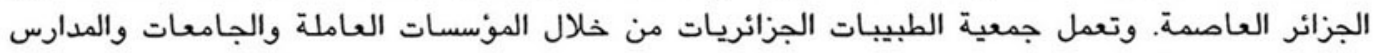

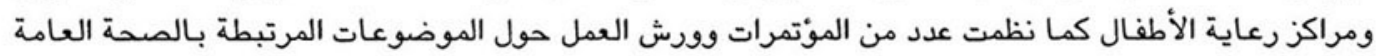

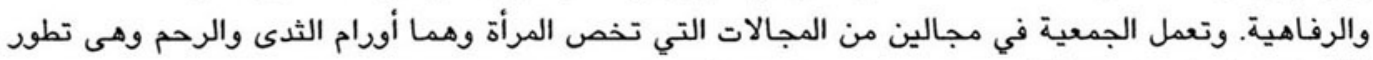
الآن فكرة العيادة المتنقلة للوصول إلى القي القرى المنعزلة في شمال البلاد. 


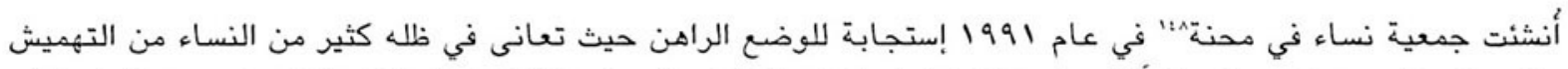

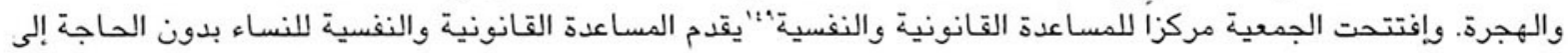

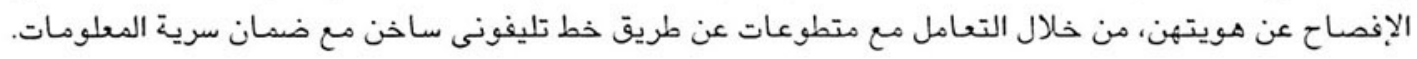

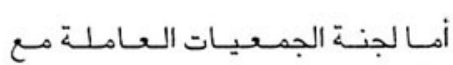

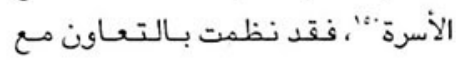

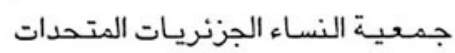
من أجل المساواة ني الحقوق" " دورات تدريبية للمنظمات الجزائرية النشيطة

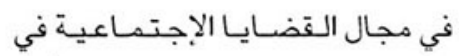
الجزائر العاصمة وخارجها، من أجل

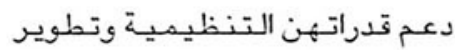
مشروعات مشتركة. وتامت جمعية

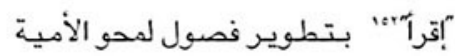

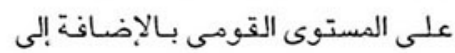

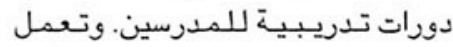

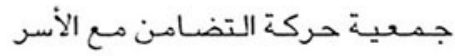

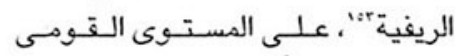
بالتركيز أساساً على المناطق الجنوبية الجنية

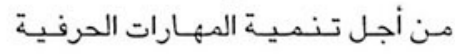

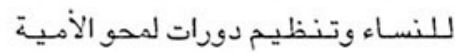

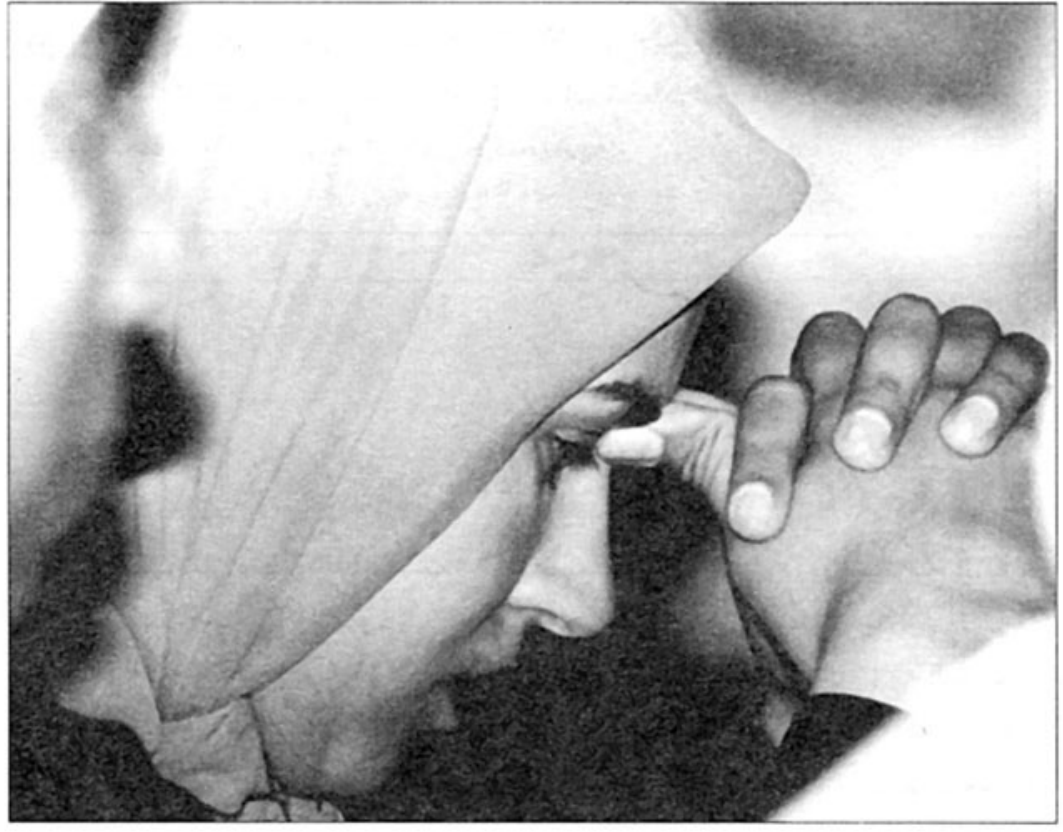

لحظة تأهل المحسورة: لويزا. La Tribune ورعاية الاطفال. أما جمعية الأزهار فهى تقدم السلع الأساسية للمجموعات الههمشة وتسعى إلى الدناع عن تَضاياهـا أمام السلطات الأية

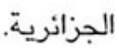

\section{نساء في محنه SOS}

أنشنت جمعية نساء ني محنة SOS في عام $19 V 1$ كمنظمة إنسانية لاتهدف الربت بهدف مساعدة النساء والأطفال ني التغلب على المحن، والدناع عن حتوتهم، وتقديم المساعدة التانونية والنغسية والطبية لهم وإيواء

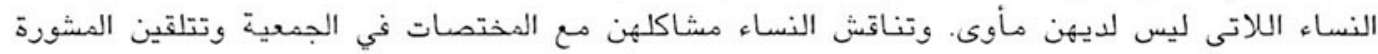

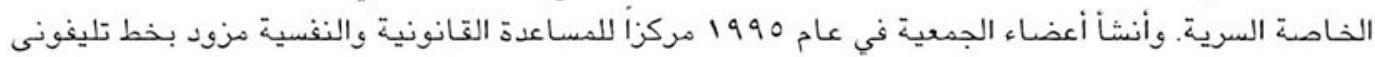

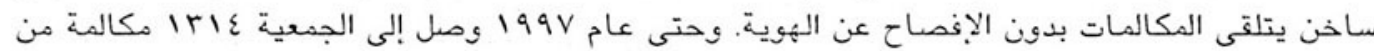

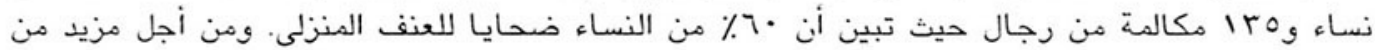

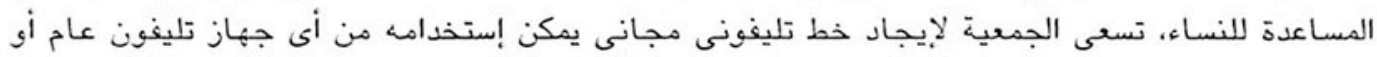

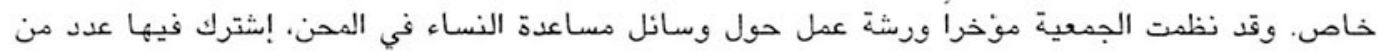

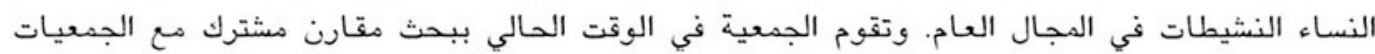
المهاثلة ني المغرب وتونس لبحث الأشكال المختلفة للعنف الذي تواجهـه النساء ني هذه البلاد. 
نظمت عدة منظمـات خارج الجزائر العاصمة برامج تدريبية للفتيات وأنشأت مراكز لرعاية الاطفال لمساعدة الأمهات

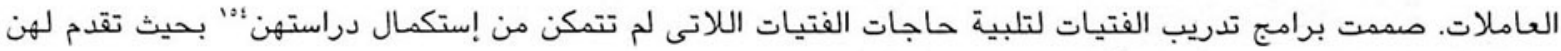
دروس في الحياكة والطهى ومحو الأمية.

ج) المنظمات الثقافتة:

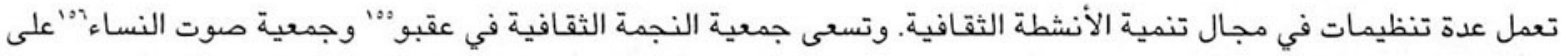

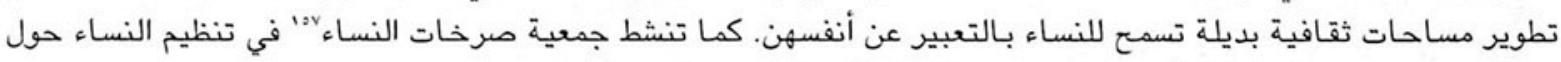
نشاط معين مثل مشاهدة فيلم أو شريط فيديو لمناقشة الأمور التي تشغلهن.

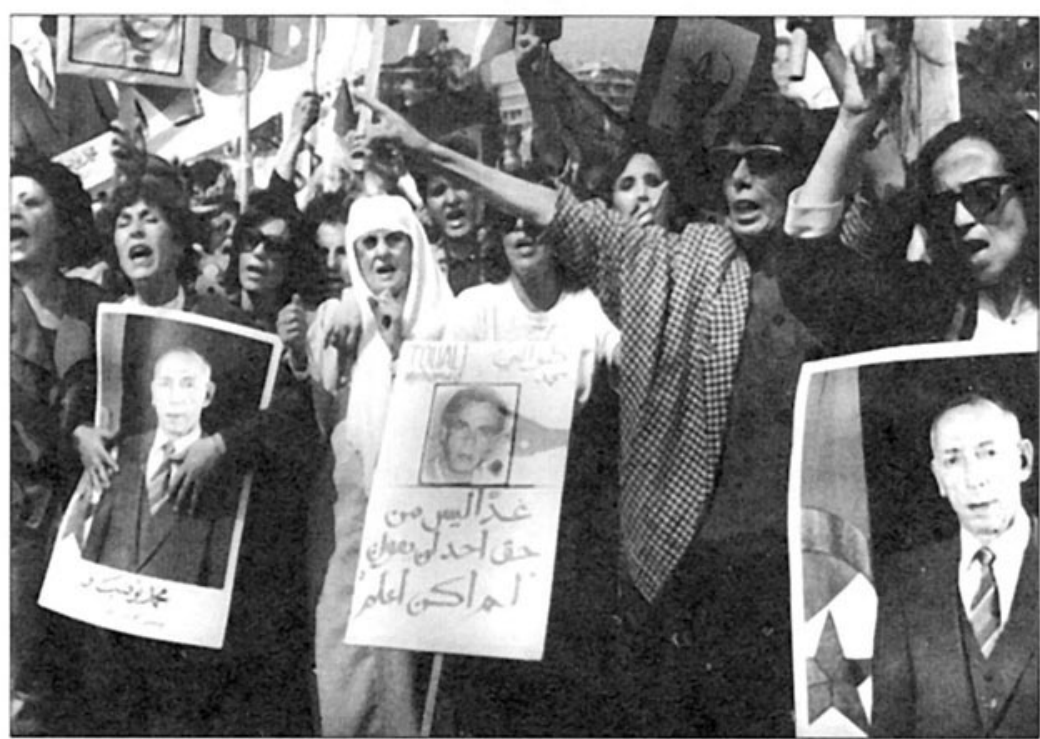

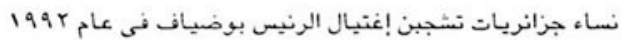

المصورة: لويزا La Tribune
وركزت بعض الجمعيات النسائية^"

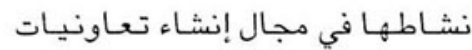
لــنسـاء وتـدعـيـم حـقـوق الـنسـاء الإجتـــاعيـة والقـانـونية. وتسعى جمـيـة النساء والاتصـالات" تنمية الفنون التقليدية كوسيلة لدعم الإتصال بين النساء. وأنشئت مؤسسة الفنة كونة لأنة

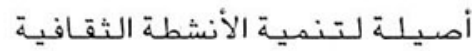
وتشجيع الفنانات الصغيرات، بينما تسعى مؤسسة بوضياف إلى التعاون

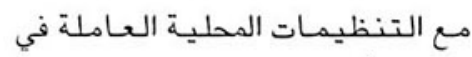
مجال الأنشطة الاجتماعية والثقافية.

د) البينة وحقوق الانسان:

تتناول المجموعات المختلفة حالياً القضايا التي لم تكن تحظي بكثير من الإهتمام من قبل مثل البيئة وحقوق الأطفال.

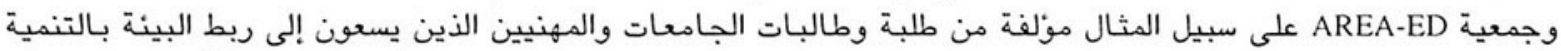

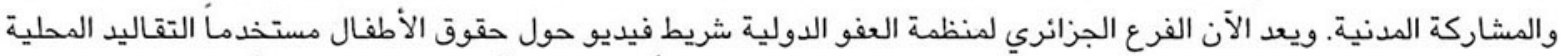

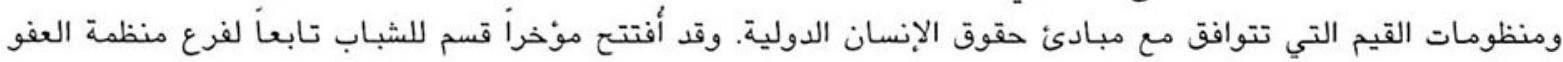
الدولية في الجزائر.

؛ 10 على سبيل المثال، قام المدرسون والمدرسات فى إحدى المدارس التى زارتها الكاتبة فى جوارديا بإنشاء صندوف لمساعدة الأسر على ابقاء بناتها فى المدارس. L'Etoile Culturel d'Akbou 100

Voix des Femmes 107

Cries des Femmes 10V Izerfan N'Temttut / Youyous de Femmes 10^ Femmes et Communication 109 


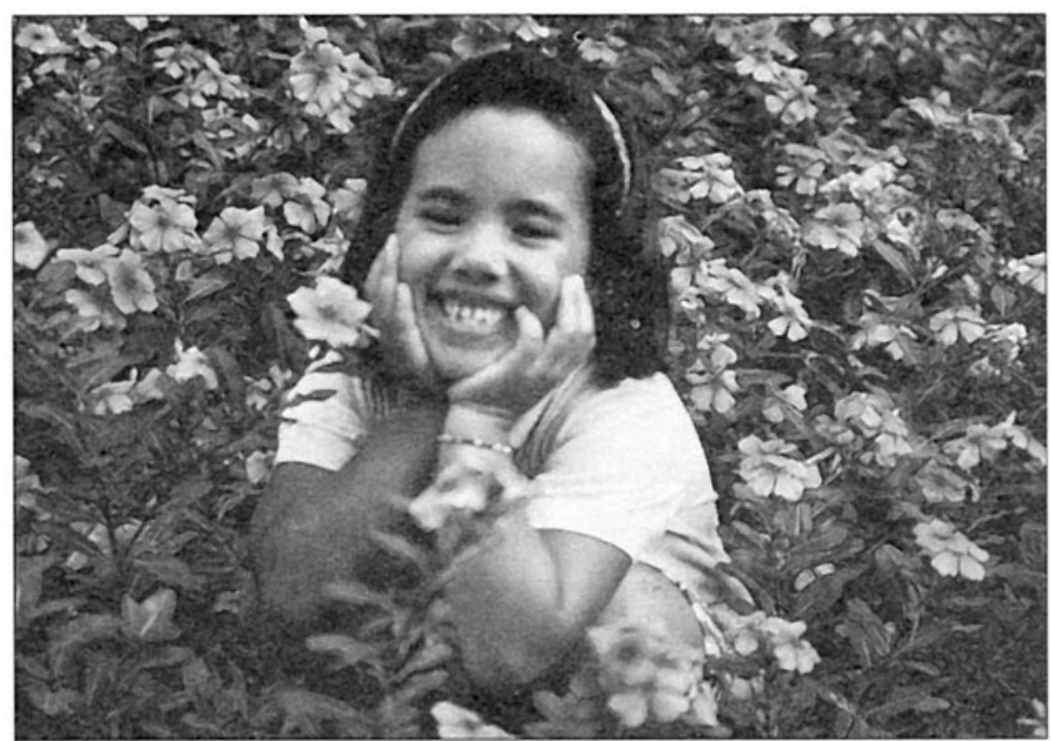

r. شبكات مساندة وإعادة تأميل

ضدايا الإرماب

"بعد العاصفة سوف نواجه الدمار" "'

نظراً لصعود العنف الجماعى ضد أسر

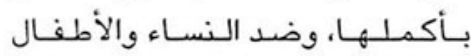
بـالتحديد، تـألفت عدة مجموعـات الأنسات لمساعدة الناجين من أعمال الإرهـاب

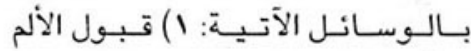
والأسى والتعايش معهما r ) تناول الأل تضايـا العدالة والتكيف الإجتماعى والتي

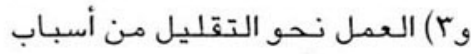

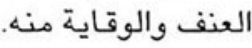

الأطفال هم هستقبل الجزانر

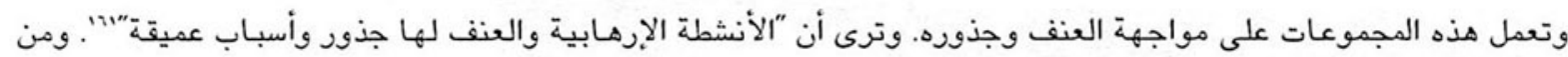

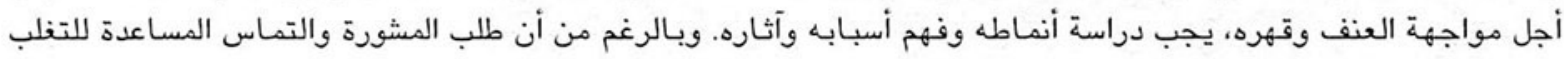

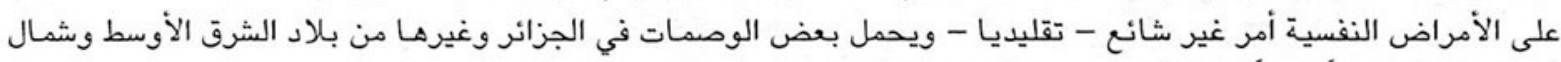
أفريقيا، إلا أن عددأ كبيراً من الأفراد يتجه الأن إلى طلب هذه البع المساعدة.

وقد أنشئ مركز لإعادة التأهيل النفي" وبه" لضحايا العنف من الأطفال والنساء اللاتى تعرضن للإغتصاب بصفة خاصة.

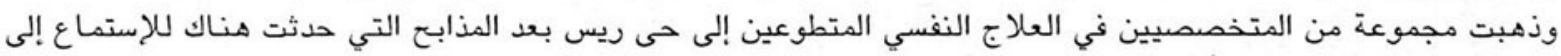

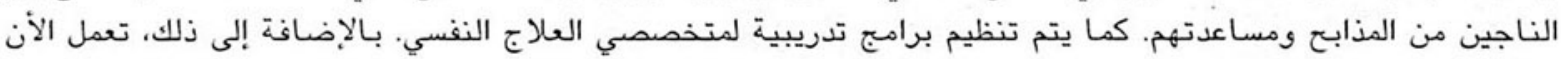

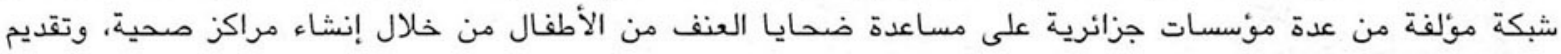

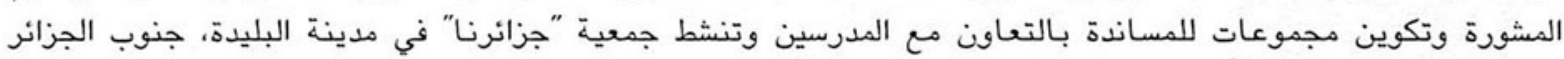

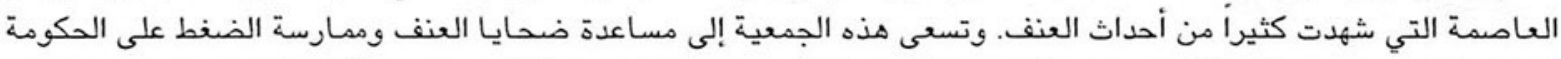

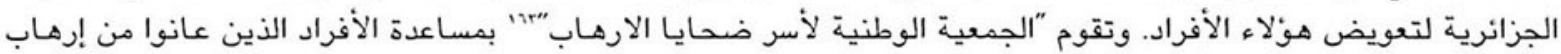

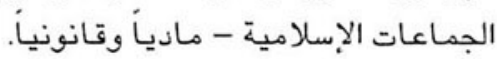

\section{ع. مجموعات التفكير والدراسة ومراكز التوثيق}

تكونت مؤخراً مجموعات للتفكير في بعض القضايا وتوسيع تاعدة المعلومات لدى الرأى العام الجزائري. ويمكن أن تساهم

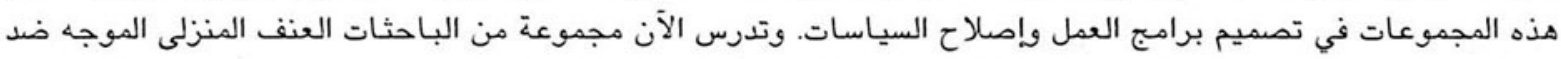

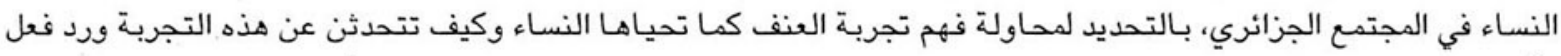

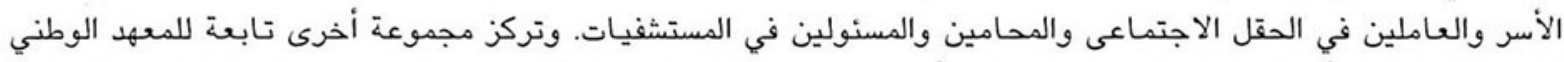

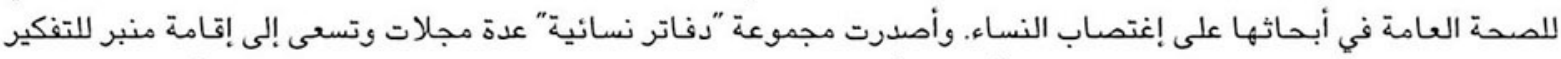

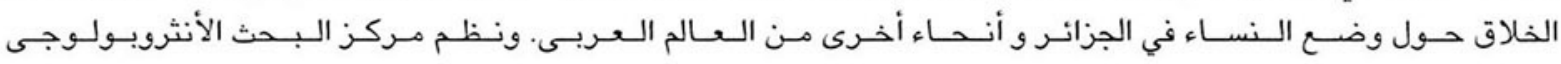




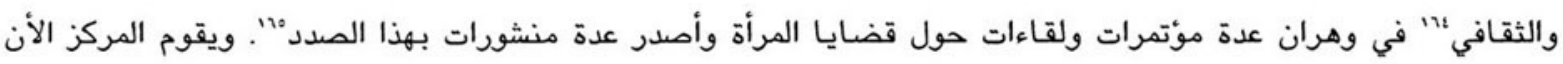

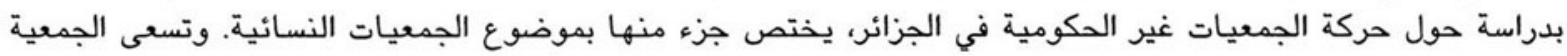

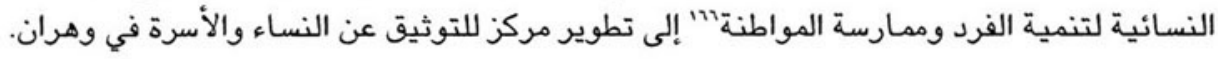

\section{النساء والعنف المنزلى}

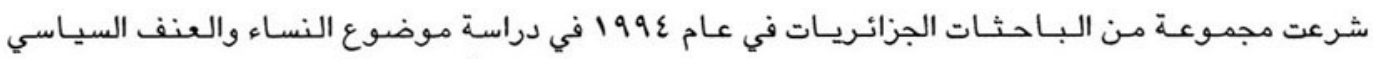

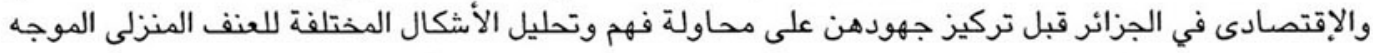

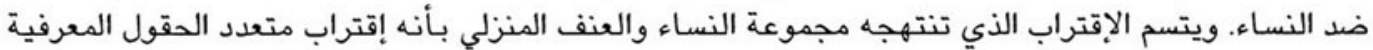

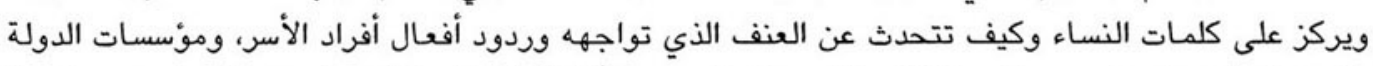

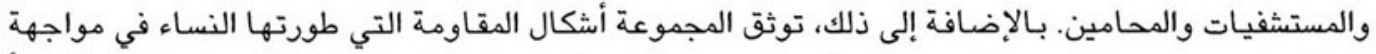

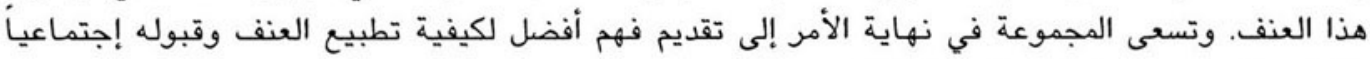

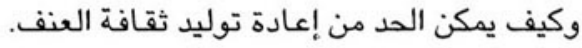

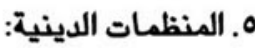

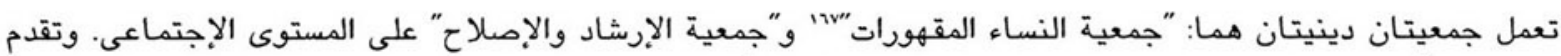

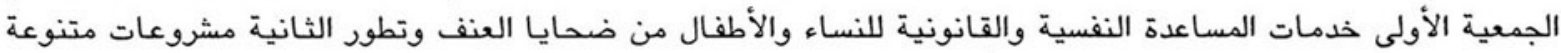

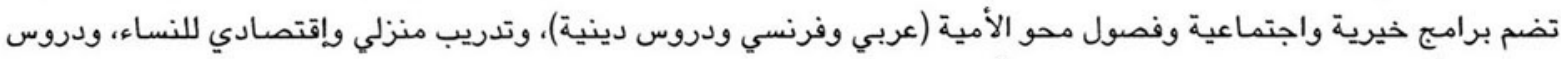
لحفظ القرآن وتوزيع المواد الغذائية والسلع الأخرى على الأهية عربي وفتعات الفقيرة.

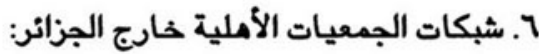

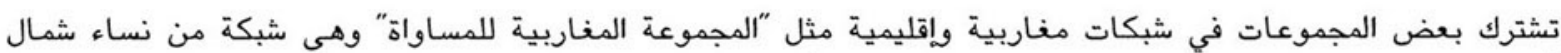

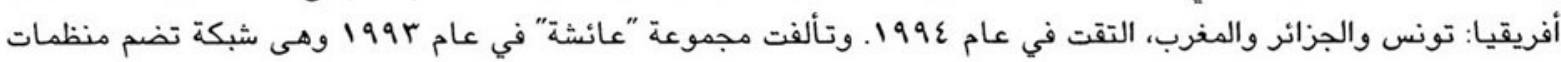

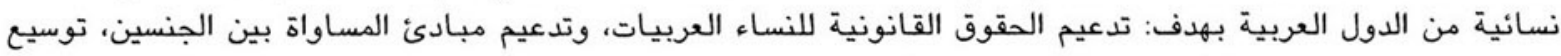

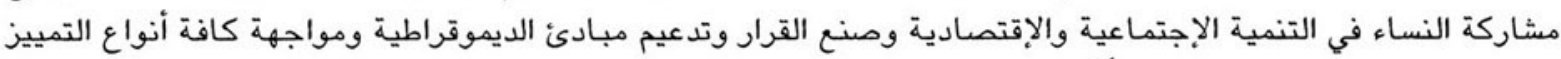

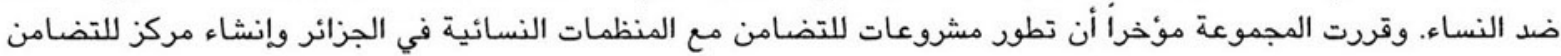
في تونس لتقديم المعلومات للمجموعات الجزائرية. 


\section{Collectif Maghreb Egalité المجموعة المغاريبة للمساواة}

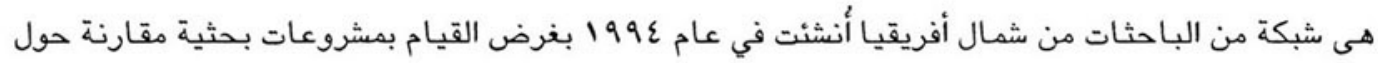

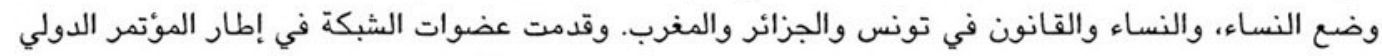

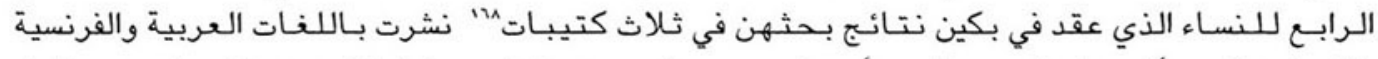

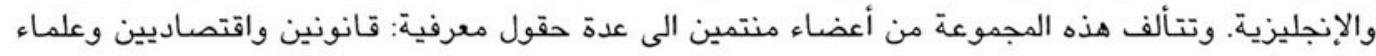

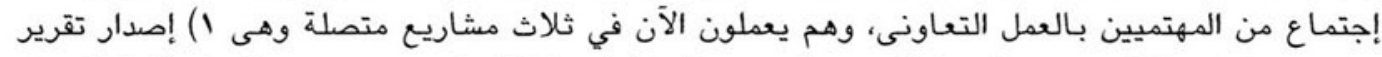

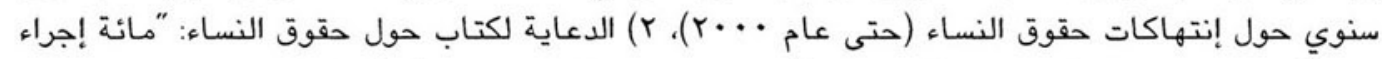

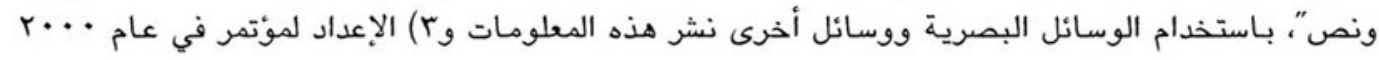
حول حقوق النساء في المغرب.

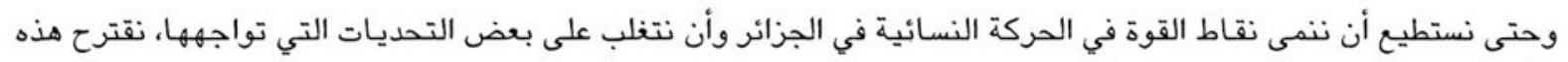

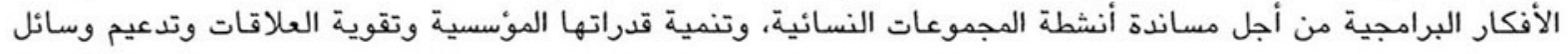
نشر المعلومات بين الجمعيات المختلفة والمساهمة في توسيع دائرة المشروعات أنشية الفعالة. 


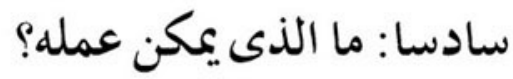

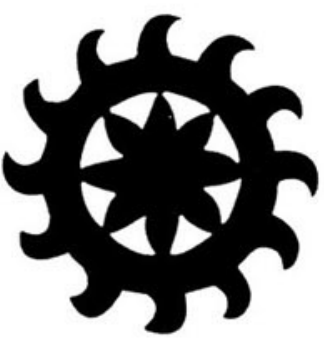

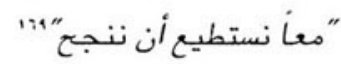

"نحن نتقاسم الخوف وهذا يساعدنا على الحياة" ن."،

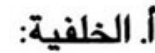

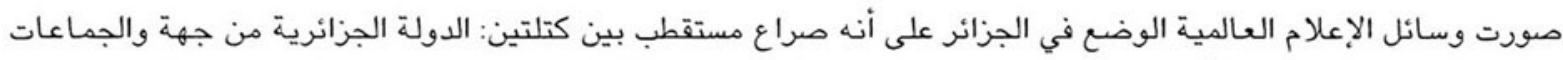

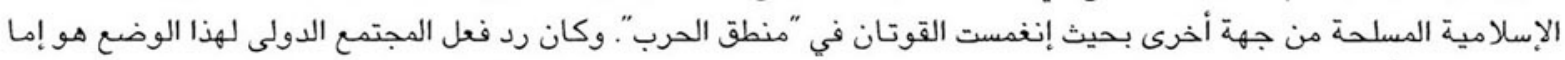

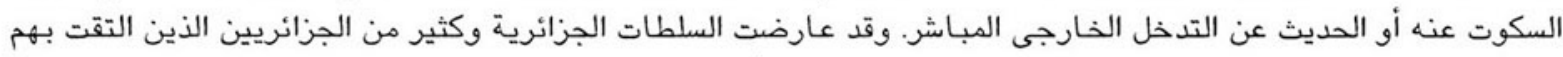

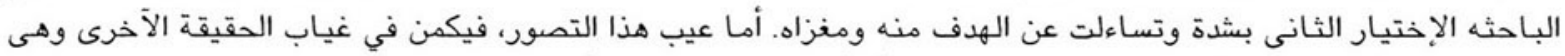

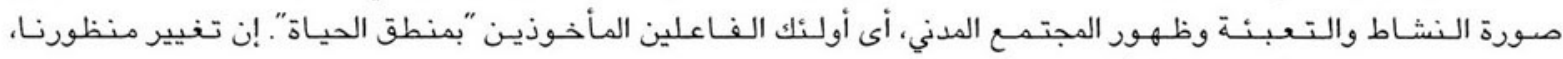
وإستخدام"عدسة النوع"، هو خطوة أولى ههمة في إتجاه تطوير تضامن فعال الهـ وحقيقى مع المنظمات الجزائرية.

ومع تسليمنا بأن إستنصال العنف وتحديد مرتكبيه من الأمور الأساسية، إلا أن التخطيط طويل المدى لتدعيم المجتمع المدني

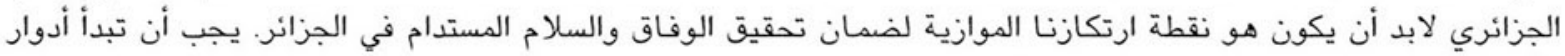

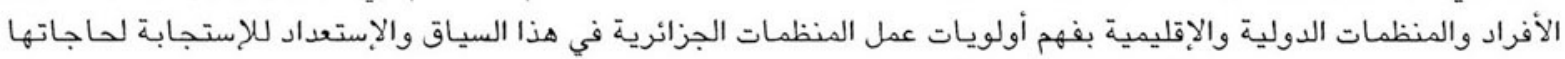
وتدعيم تاعدتها المؤسسية من أجل تنفيذ جدول أعمالها.

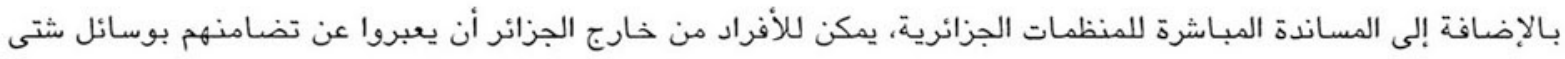

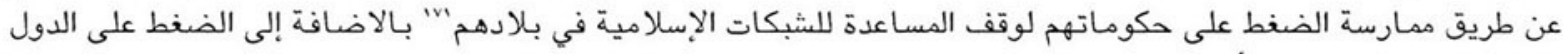

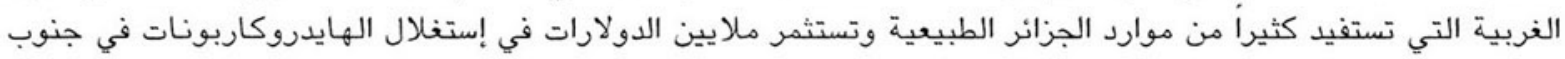

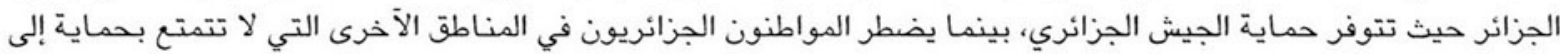
الدفاع عن أنفسهم.

بالرغم من الجو العام الذي يتسم بالهجمات القاسية التي لامعنى لها على المدنيين الأبرياء، تحاول المنظمات والأفراد جدياً

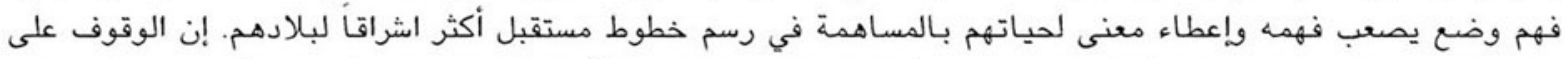

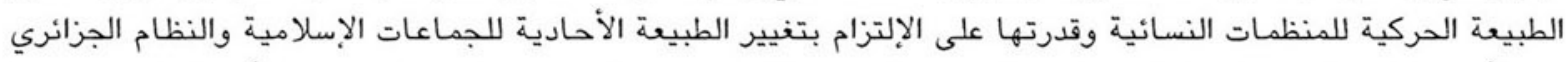

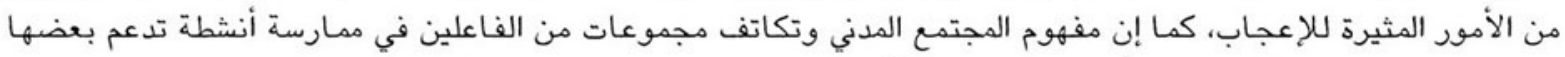

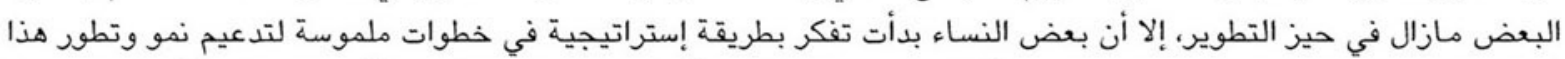

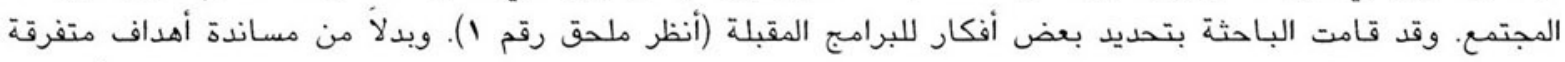
لمجموعات مختلفة، تسعى هذه المحاولات إلى تقوية المجتمع المدني ككل وخلق تعاون بين منظماته بحيث يكون المن الكن الكل أكبر من 
كذأجزاء المكونة له. لذلك فإن أول المجالات المقترح تمويلها هو مجال التدريب لتحسين القدرات التنظيمية وتنمية المشروعات،

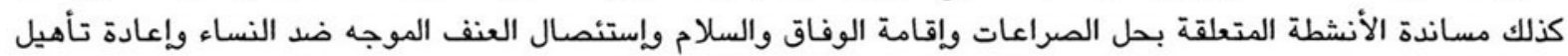

\section{ب. ب. بزانر: نسج السلام}

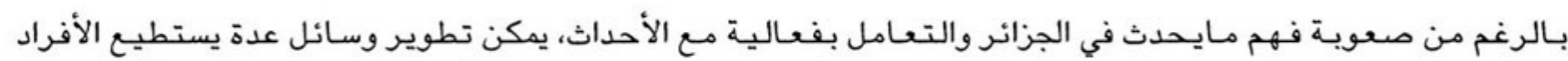

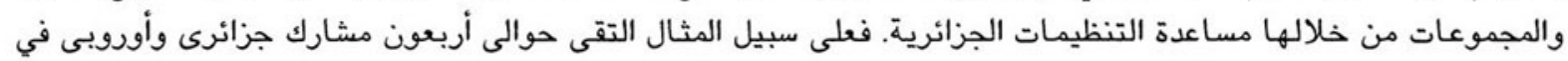

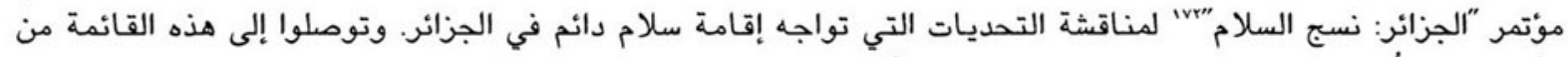

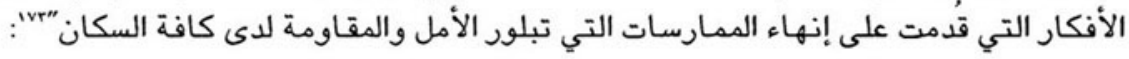

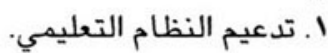

$$
\begin{aligned}
& \text { r. r. إيجاد مستقبل للشباب الجزائري. }
\end{aligned}
$$

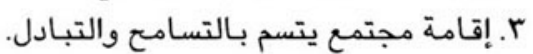

$$
\begin{aligned}
& \text { ع. تقوية الروابط الأسرية. } \\
& \text { ه ـ إعادة بناء الذاكرة الجماعية في الجزائر وتدعيم تغير القية. }
\end{aligned}
$$

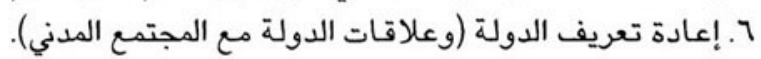

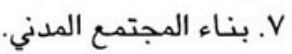

$$
\begin{aligned}
& \text { 1. 1. تثقيف نخب الغد. }
\end{aligned}
$$

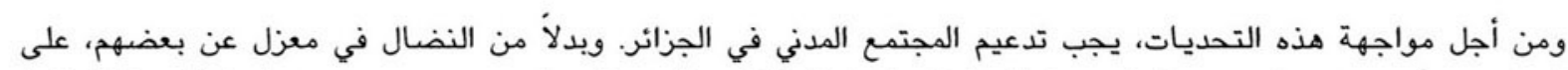

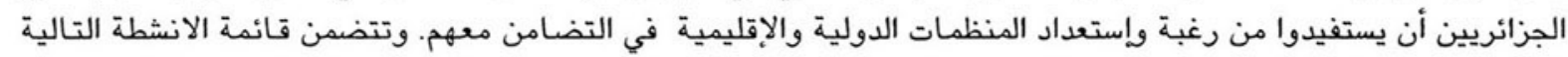

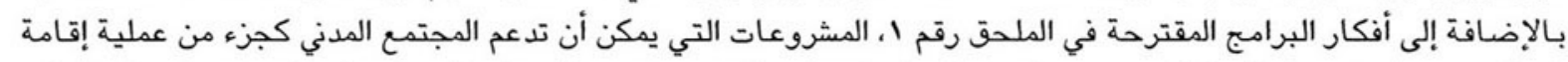

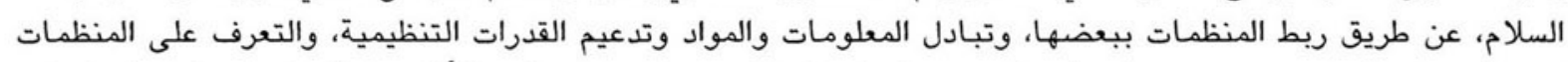

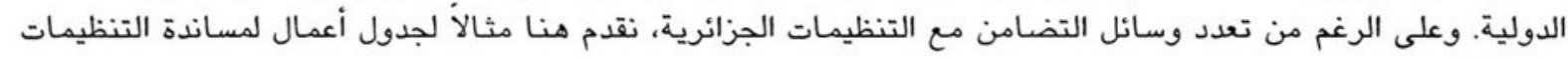
النسائية. - الن

\section{ج. مساممة المنظمات الثناتية والدولية ومينات الأمم المتحدة:}

تستطيع المنظمات الثنائية والدولية وهيئات الأمم المتحدة أن تضغط على الجماعات الإسلامية المسلحة والحكومة الجزائرية

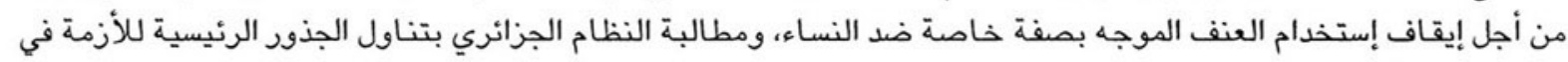

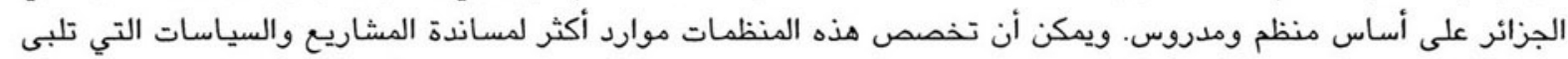

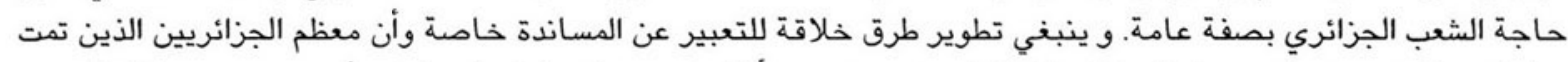

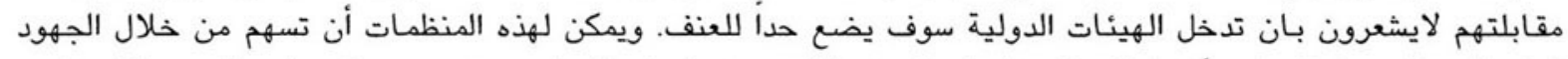

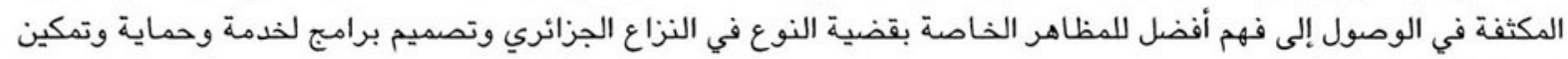
النساء الجزائريات.

\section{د. مساممة المنظمات التنموية:}

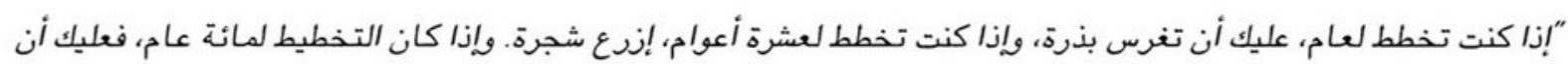

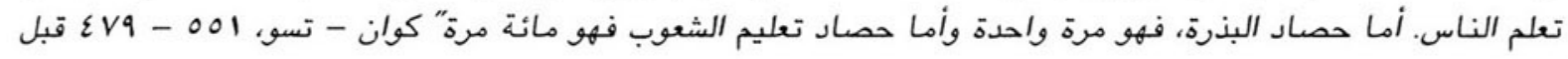
الميلاد. 
تعرف التنمية الإقتصادية، تقليدياً، على أنها "الزيادة المستدامة في مستويات المعيشة التي تتضمن الإستهلاك المادي،

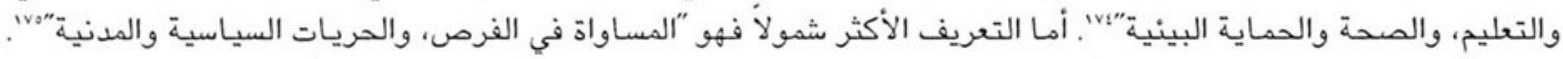

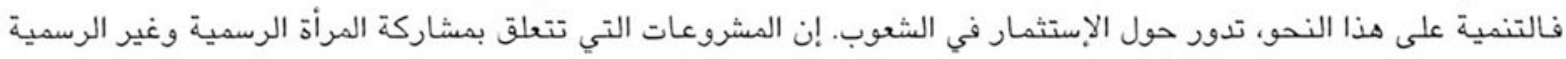

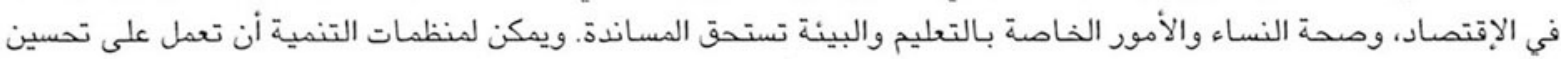

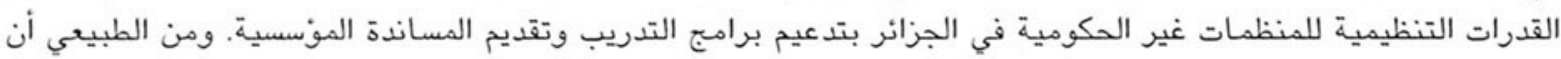
تساهم النساء في تحديد معالم هذه المشروعات التنموية والتخطيط لها وتنفيذهـا.

وقد قامت هيئات دولية عديدة بتسليط الضوء على العلاقة بين الصراع والتنمية، هما يؤكد أهمية تناول الأمور الخاصة بالتنمية في الجزائر كنصر مهم على ولى الطريق نحو تحقيق السلام.

\section{هـ مساهمة منظمات حقوق الانسان}

إن صوت الهنظمات الخاصة بحقوق الإنسان يمكن أن يكون أعلى من غيرها من الهنظمات فيما يتعلق بأنواع العنف القائمة

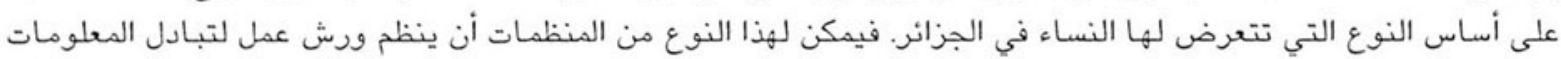

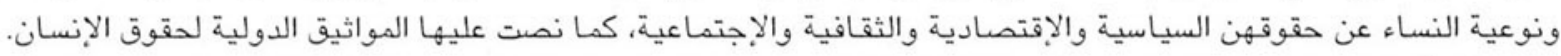

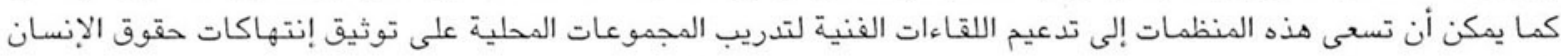

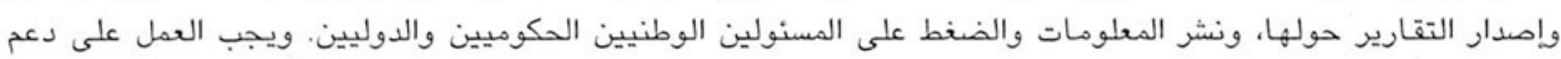

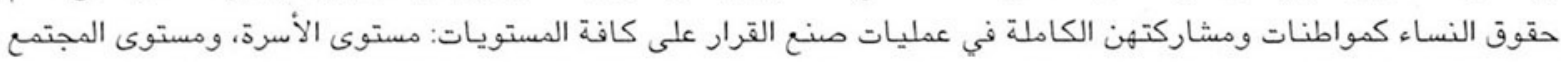

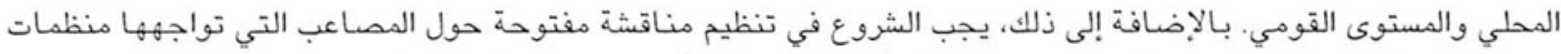

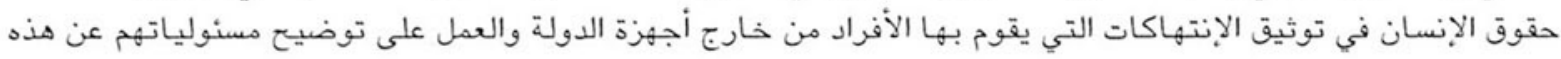

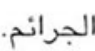

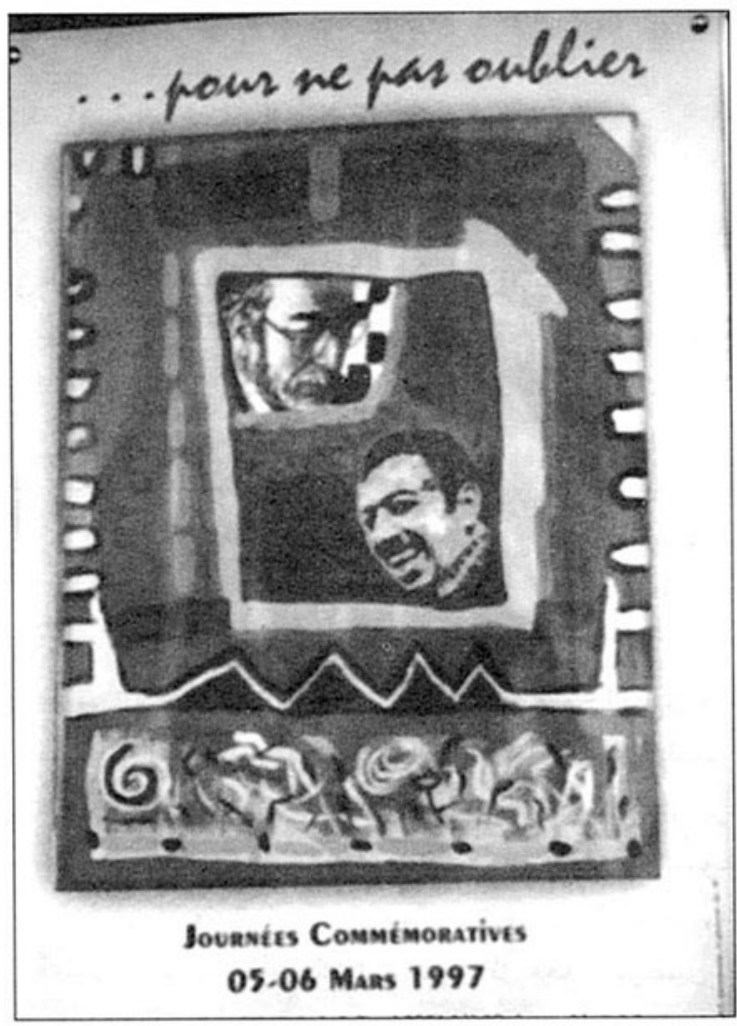

و. مساهمة الصحفيين:

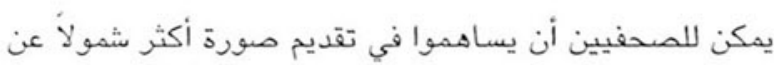

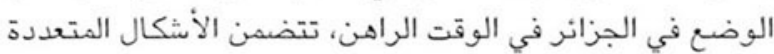

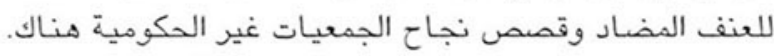

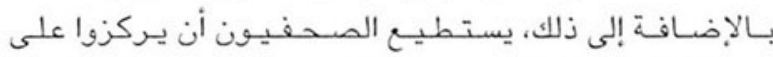

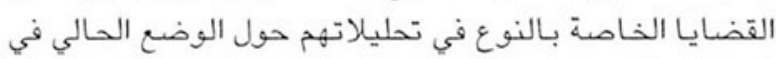

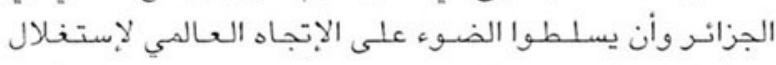

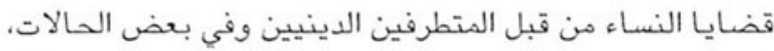

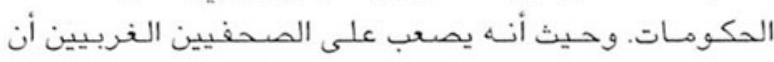

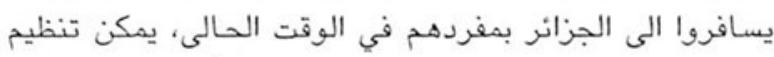

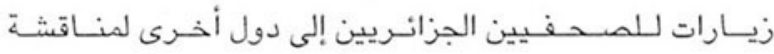

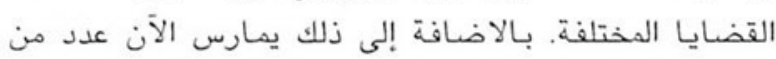

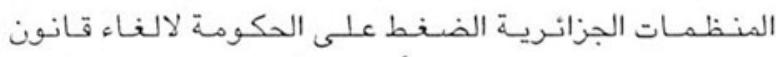

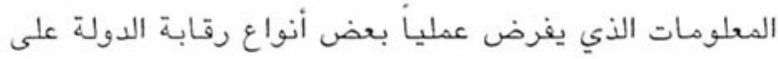

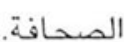

World Development Report. Oxford University Press for the World Bank, 1991, P. 31. IVs IVo 


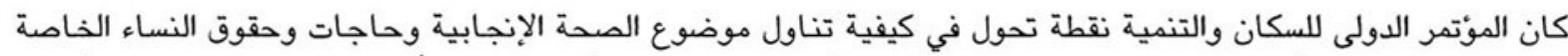

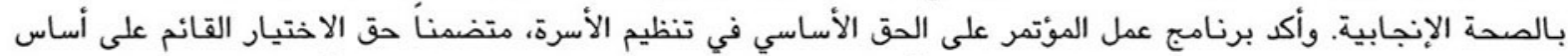

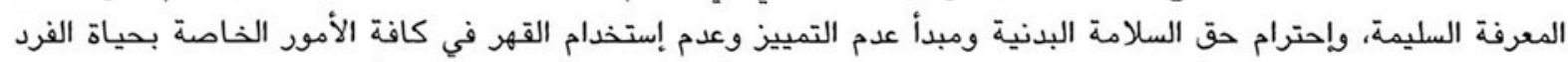

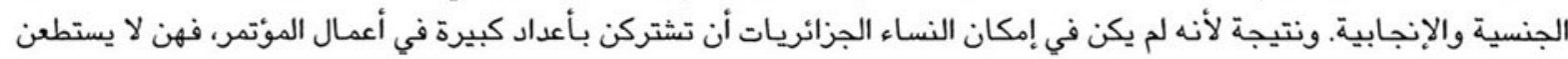

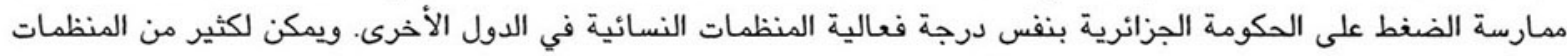

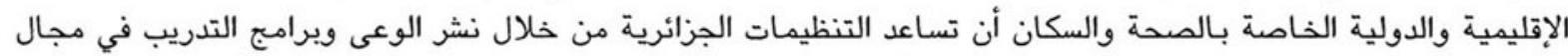

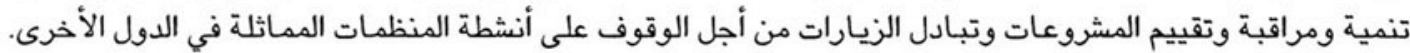

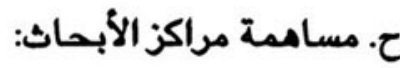

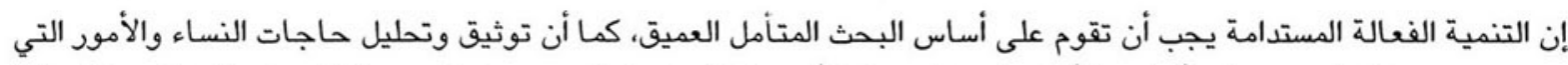

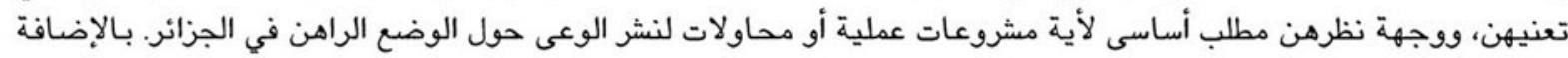
إلى ذلك فقد ركز الجزائريون على الحاجة إلى تطوير منهج علمي لدراسة العنف الذي يتخلل المجتمع الجزائري في الوقت الحات الحالي.

ونتيجة للزيادة المثيرة في معدلات التضخم منذ بداية أحداث العنف في الجزائر، أصبح من الصعب على الجزائريين أن يحصلوا

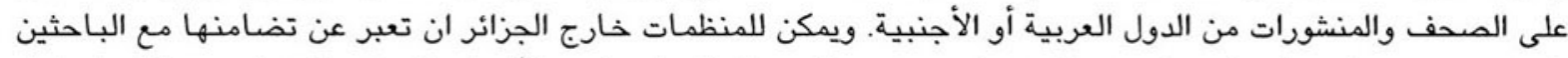

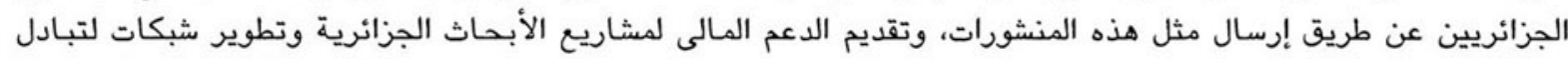

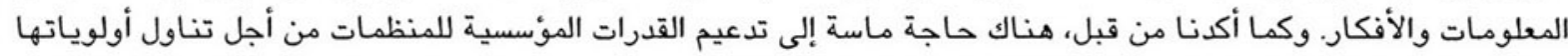

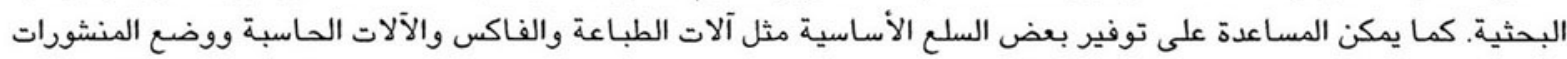

والمعلومات في متناول يد الباحثين.

\section{ط. مساهمة المنظمات النسانية:}

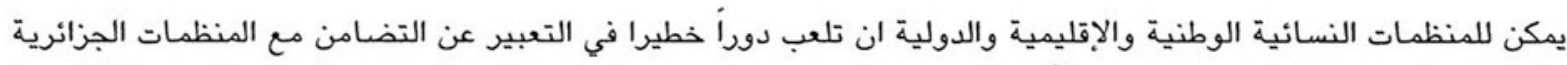

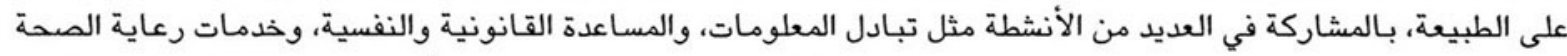

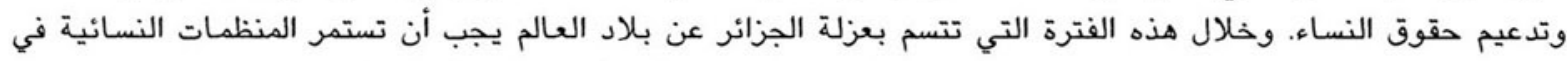

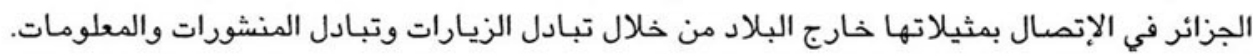

\section{التدابير المونسسية \\ "إن الكل أكثر من أجزائه المكونة له"' الهية}

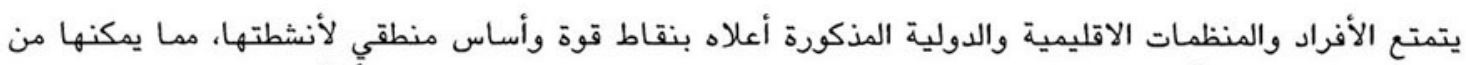

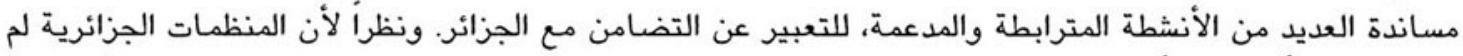

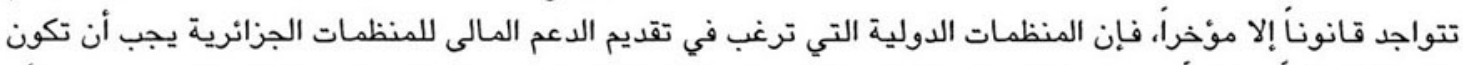

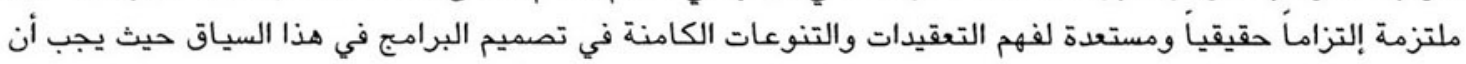

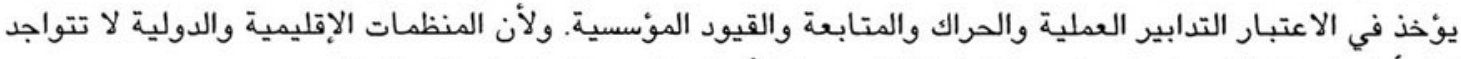

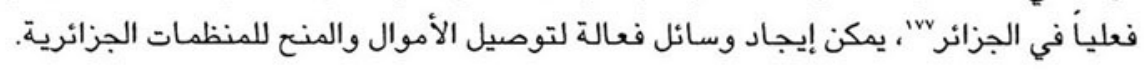




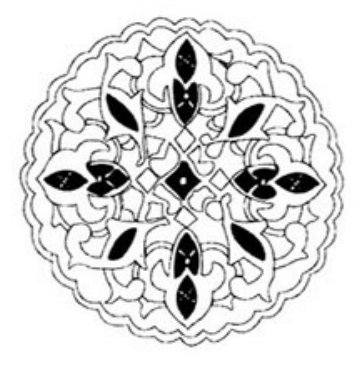

"الحجر من يد صديق تفاحة" (مثل جزائرى).

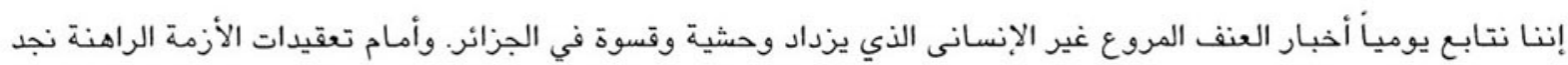

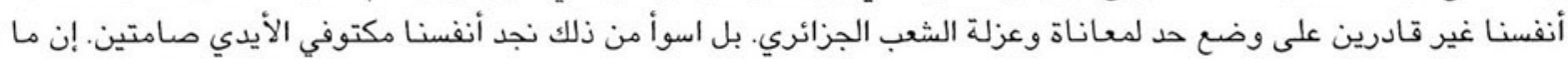

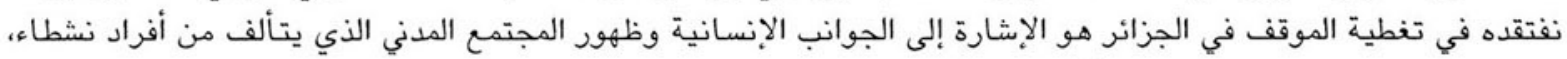

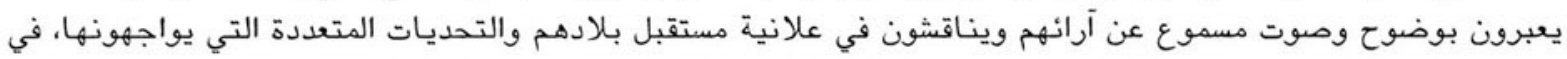

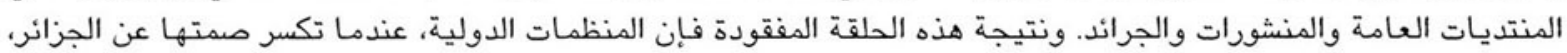

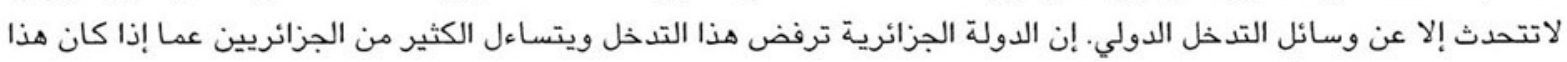

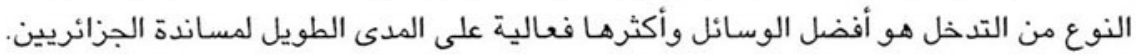

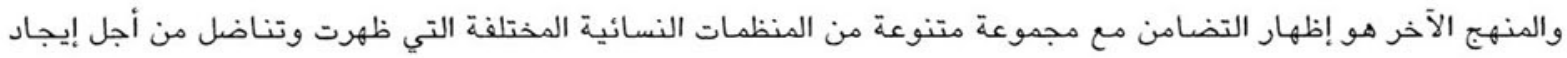

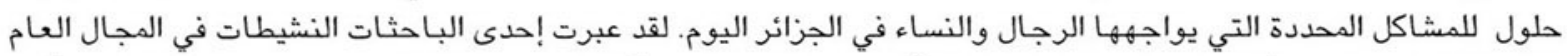

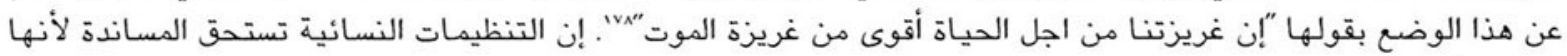

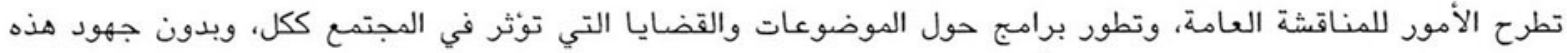
الجمعيات، قد يكون مصير هذه القضايا الأهمال.

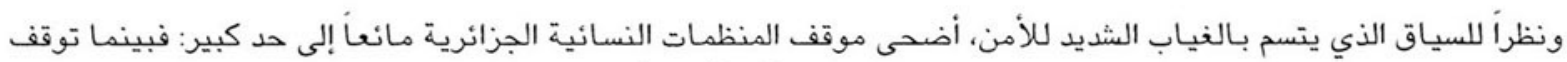

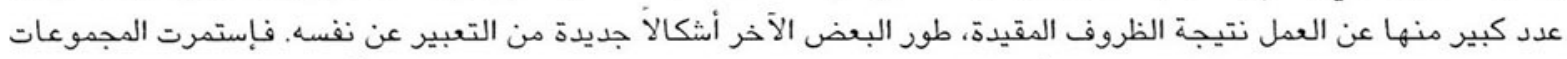

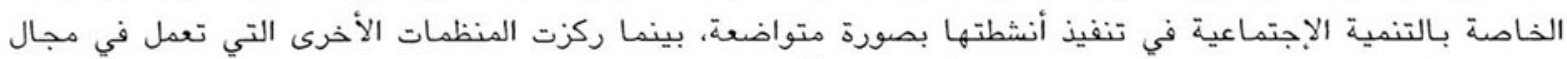

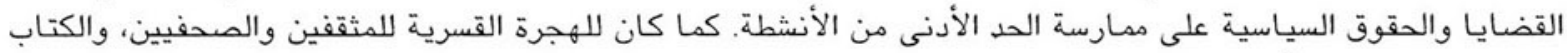
والنشطاء الجزائرين تأثير على عمل هذه المنظمات.

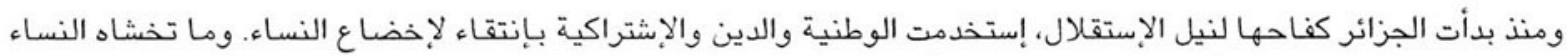

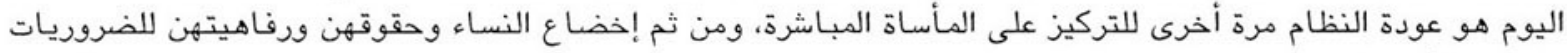

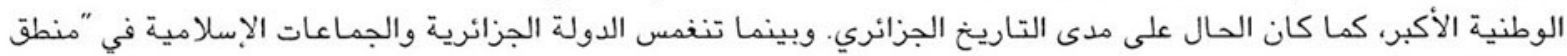

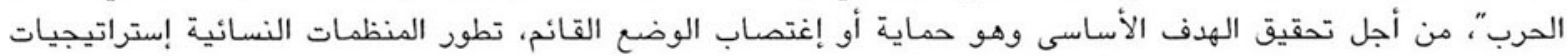

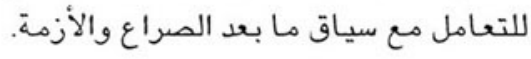

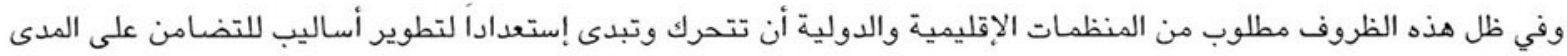

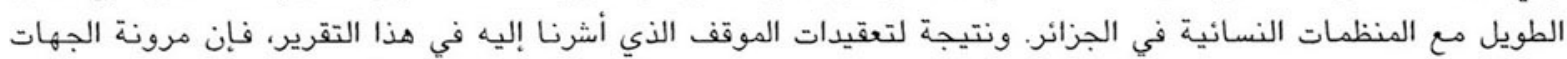

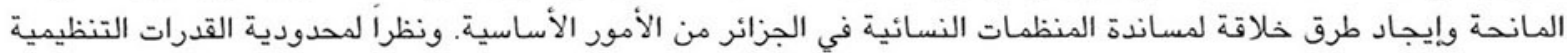

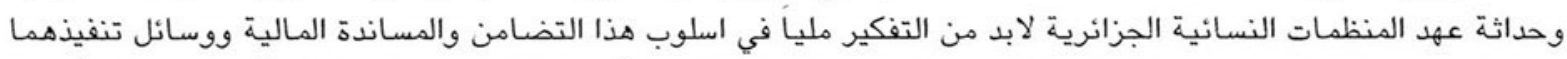

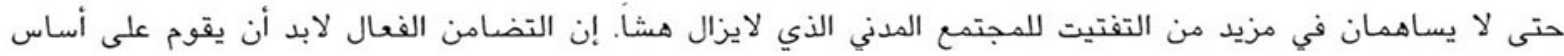
المشاركة الحقيقية في التعلم والمساندة. 


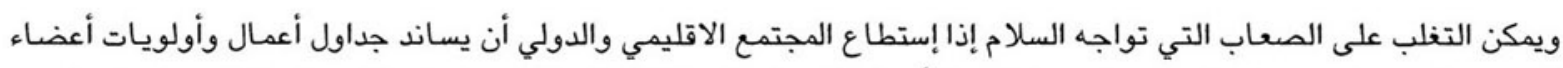

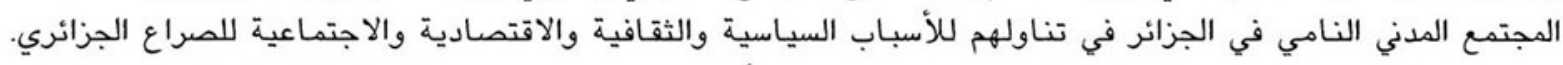

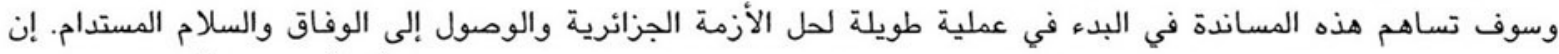

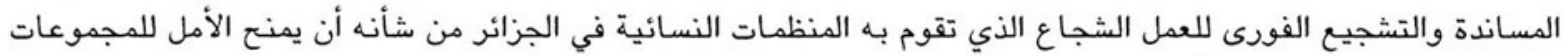

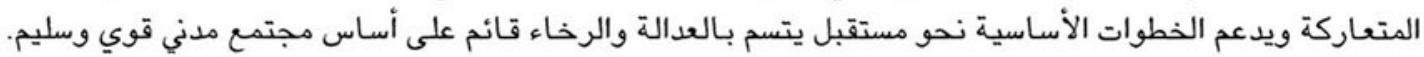




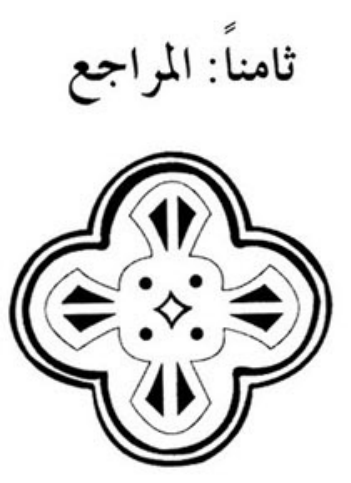

Addi, Lahouari. "L'armée algérienne confisque le pouvoir." Le Monde Diplomatique. Février 1998. pp 16-17.

Ait-Zai, Nadia. "Les droits des femmes dans la famille." Femmes, Famille et Société. Algiers: Organisation Nationale des Droits de L'Homme. 1997.

African Women in Crisis Umbrella Programme. Nairobi: UNIFEM/AFWIC. 1994.

"Algeria: Armed Groups are Tolerated." USIA Daily Digest. Janvier 15, 1998.

Algeria's Civilian Population Caught in a Spiral of Violence. Amnesty International, London, United Kingdom. Novembre, 1997.

Algérie Informations: Revue de Presse. Février 1997; No. 244. Paris

Algérie Informations: Revue de Presse. Mai-Juin 1997; No. 247. Paris.

Algérie Informations: Revue de Presse. Août-Septembre 1997; No. 249. Paris.

Algérie Informations: Revue de Presse. Octobre-Novembre 1997; No. 250. Paris.

Algérie. Textes et dessins inédits. Casablanca: Le Fennec. 1995.

Algérie Tisser la Paix : Huit Defis pour Demain. Foundation Charles Leopold Mayer pour le Progrès de L'Homme. Paris 1996.

Balil, A. "Resistance," in El-Watan Septembre 27,1997. Alger.

Benali, Zinab. "Le Viole et la Parole !" Inédit. 1995.

Bennoune, Karima. "Algerian Women Confront Fundamentalism," Monthly Review. Septembre 1994.

"S.O.S Algeria : Women's Human Rights Under Siege," In Women's Human Rights in the Muslim World. Ed. Mahnaz Afkhami. London: I.B. Taurus. 1995.

Bouatta, Cherifa. Evolution of the Women's Movement in Contemporary Algeria: Organization. Objectives and Prospects. Helsinki: United Nations University and World Institute for Development Economics Research. 1997. 
Bouatta, Cherifa, and Cherifati-Merabtine, Doria. "The Social Representation of Women in Algeria's Islamist Movement." In Identity Politics and Women : Cultural Reassertions and Feminisms in International Perspective. Ed. Valentine M. Moghadam. Boulder: Westview Press. 1994.

Brac de la Perrière, Caroline. Les Associations Ayant Pour But La Promotion Des Femmes. Algiers: UNFPA. 1993.

Cheriat, Boutheina. "Islamism and Feminism: Algeria's 'Rites of Passage' to Democracy." In $\underline{\text { State }}$ and Society in Algeria. Ed. Entelis and Nayln. Boulder: Westview Press. 1992.

Cherifati, Doria. "Femmes-Travailleuses: Une Identité dans la Tourmente." Femmes et Développement Actes de L'Atelier: Oran: Centre de Recherche en Anthropologie Sociale et Culturelle. 1995.

Civil Society in the Middle East. Ed. Norton, Augustus Richard. The Netherlands: E.J. Brill. 1995.

Daniel, Jean. "Une lettre ouverte au President de la Republique," In Le Nouvel Observateur. Janvier 8-14, 1998.

Habib, Ali. "Deux Langues pour Une Identité Controversée." Le Monde Diplomatique. Novembre 1995.

Hatem, Mervat. "Toward the Development of Post-Islamist and Post-Nationalist Feminist Discourses in the Middle East." In Arab Women. Ed. Judith E. Tucker. Bloomington: Indiana University Press and Georgetown University. 1993.

Hayef, Imane. "Algerian Women and Political Choice." Gender and Development 3, no.1(1995):2328.

Hessini, Leila. Living on a Fault Line: Political Violence Against Women in Algeria. Cairo: Population Council and UNIFEM. 1996.

Heyzer, Noeleen. "The Worst Victims of War: The Highest Stakeholders of Peace." In Looking at Peace Through Women's Eyes. Ed. Joy Mutero. Nairobi: Regal Press Kenya Limited, 1996.

Horizon. Février 29, 1989.

Khelladi, Aissa. Peurs et Mensonges. Paris: Editions du Seuil. 1997

Koudil, Hafsa Zinai. Sans Voix. Paris: Editions Plon. 1997

Ladjel, Khadidja. "Statut Social et Femmes en Difficulté." In Femmes et Développement. Actes de L'Atelier. Oran: Centre de Recherche en Anthropologie Sociale et Culturelle. 1995.

L'Algérie Actualité. Décembre 24, 1989

"Les réseaux de soutien au FIS et au GIA en Europe." L’Humanité. Février 16, 1998.

Mernissi, Fatima. Islam and Democracy: Fear of the Modern World. Trans. Mary Jo Lakeland: Addison-Wesley Publishing Company. 1992. 
Morteda, Zabouri. "Algérie On Assassine L'Education." Comité Quebec Algérie. 1995.

Nouredine, Saadi. La Femme et La Loi en Algérie. Casablanca: Le Fennec. 1991

Office National des Statistiques. Alger, Algérie 1996.

Powers-Steven, Tanya. Briefings on Development and Gender. New York: UNIFEM. 1995.

Qanun el-Usrah (Algerian Family Code). Centre National de Documentation de Presse et d'Information. Alger. 1990.

Report of Organisation Nationale des Droits de L'Homme. Alger. 1997.

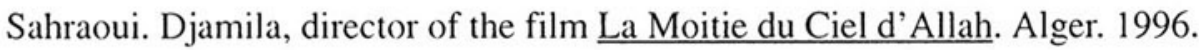

Selmane, Fatiha. "Education et Paix." In Femmes et Développement. Actes de L'Atelier. Oran: Centre de Recherche en Anthropologie Sociale et Culturelle, 1995.

Simone, Catherine. "L'implacable logique d'une violence qui n'epargne personne." Le Monde Diplomatique. Novembre 1995.

Slymovics, Susan. "Hassiba Ben Bouali, if you could see our Algeria." MERIP. 192. 1995.

Tlemcani, Rachid. "Chadli's Petestroika." MERIP. 1990:14.

Tuquoi, Jean-Pierre. "Un Pays en Mal de Croissance Economique." Le Monde Diplomatique Novembre 1995.

Women and Armed Conflict. Position paper presented at the Commission on the Status of Women Meeting, March 2-13, 1998. Network Women in Development Europe.

World Development Report. Oxford University Press for the World Bank. 1991.

The World Fact book. United Nations Programme for Development. New York, New York, 


\section{ملحق رقم 1 : أفكار برامجيه 1va}

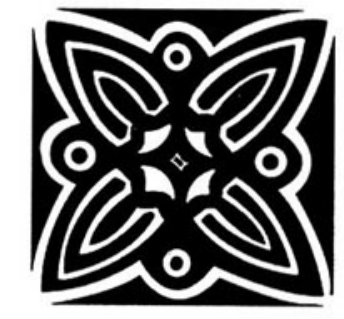

\section{أ. مساندة أنشطة تدعيم القدرات المؤسسيه للمنظمات النساتيه في الجزانر والأنشطه الأخرى.}

$$
\begin{aligned}
& \text { 1- التدريب في المجالات التالية : } \\
& \text { أ - التنميه المؤسسيه والتنظيميه } \\
& \text { ب - إختيار المشروعات وتطويرهـا } \\
& \text { ج - الإتصالات } \\
& \text { د - الإداره } \\
& \text { هـ - الشئون الماليه }
\end{aligned}
$$

الأساس المنطقي:

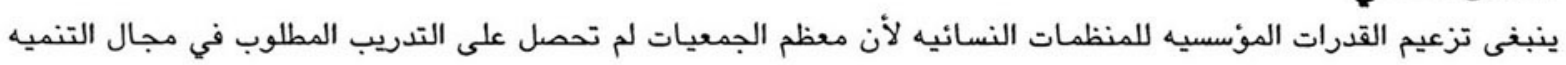
التنظيميه والمؤسسيه ، وإختيار المشروعات وتطويرها والإتصالات والإداره .

تدعيم القدرات المؤسسيه وكفاءة وفعاليه هذه المنظمات من خلال أنواع مختلفه من برامج التدريب التي من شأنها أن تعمل

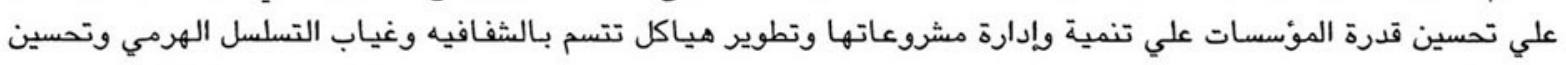

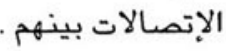

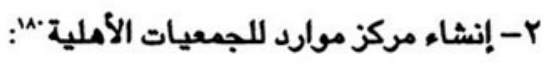

الأساس المنطقي:

يجب تدعيم القدرات المؤسسية للمنظمات الجزائرية حيث انه لا يتوفر لدى معظم هذه الهيئات البنيه الأساسيه والمكاتب لإدارة

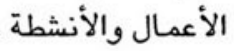

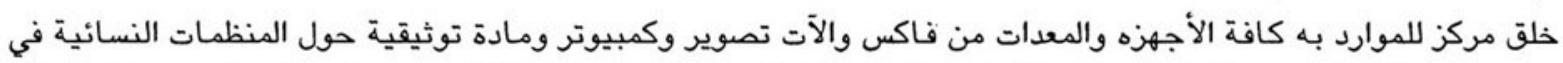

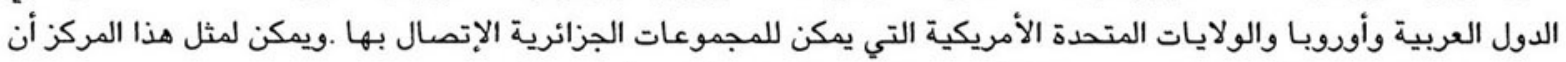
يساعد علي خلق شراكات ومشروعات مشتركة مع المنظمات الجزائرية غير الحكومية.

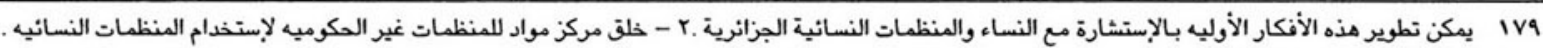

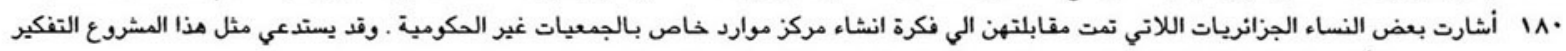

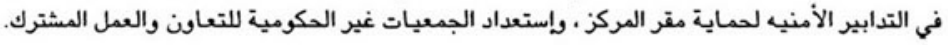


حسب معلوماتنا، لم يتم القيام بأي بحث حول عينة من المنظمات النسائية والهيئات التي تركز علي قضائايا النساء في التياء

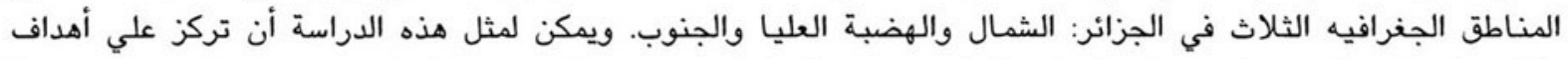

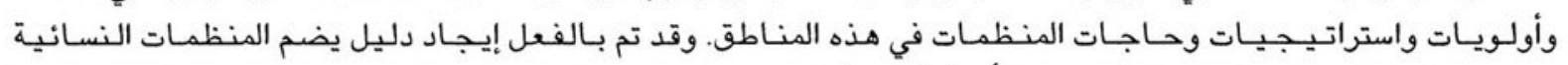

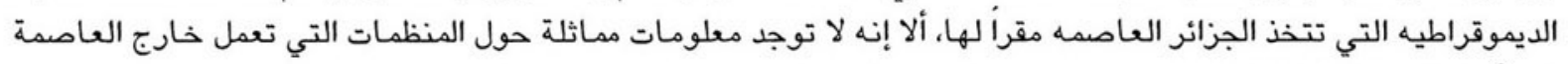

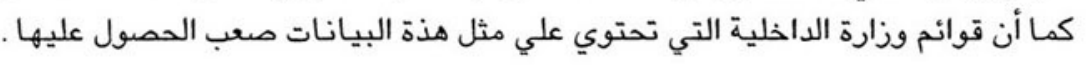

الهدف:

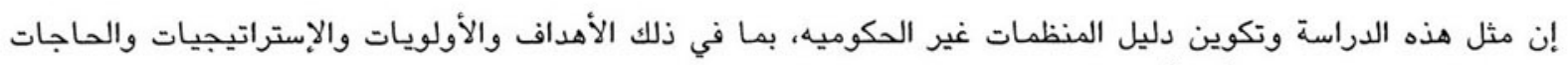

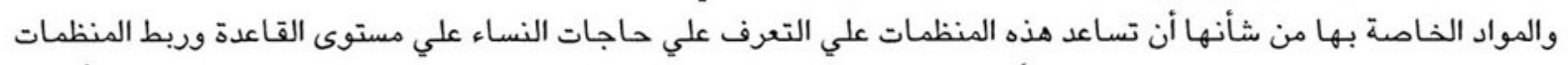

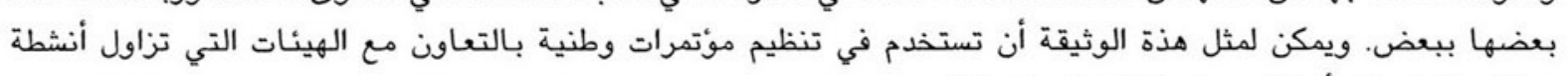
مهاثله، كما يمكن أن تكون مفيدة للهيئات الدولية .

ب - مساندة الأبحاث والتفكير والتحليل في التحديات المختلفة التي تواجه الجزائر بصفه عامه والنساء بمفه خاصه .

الأساس المنطقى: تركز أغلب المجموعات النسائية على العمل. وعلى الرغم من أهمية هذا النوع من النشاط الا أنه يجب أن يقوم - في أفضل

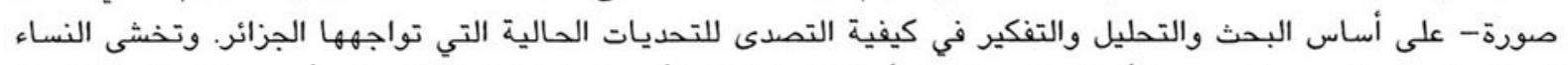

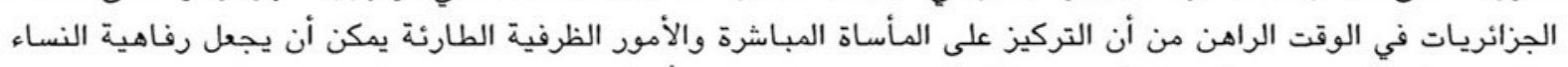

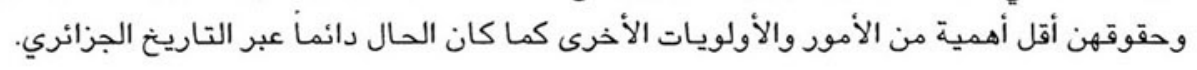

الهدف: الإهتمام بالمعلومات الخاصة بالتحديات التي تواجه الجزائر والربط بينها وبين المشروعات المحددة والتغييرات الخاصة بالسياسات.

\section{ج- مساندة الأنشطة فى مجال حل النزاعات والتوفيق بين الأطراف، ويناء السلام.}

الأساس المنطقى:

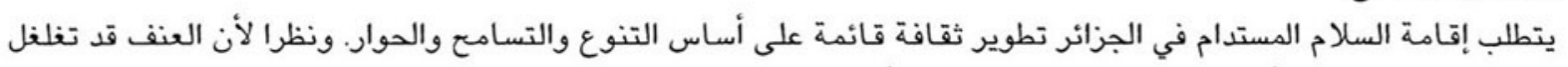

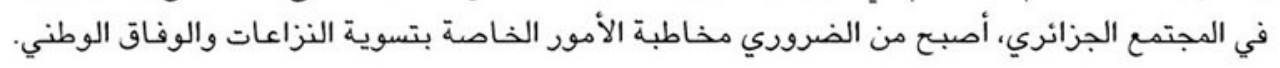

الهدف: المساهمة في خلق وتدعيم سياق ثقافي قائم على أساس التسامح وتسوية النزاعات والتوفيق كمكون أساسى للسلام المستدام.

د- مساندة الشبكات ومراكز إعادة تأميل خحايا العنف

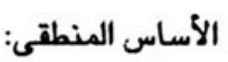

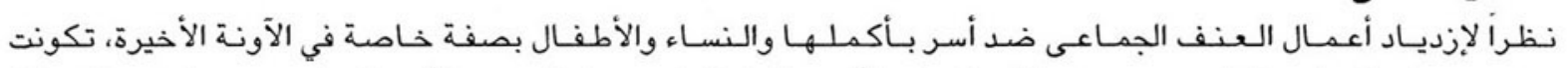

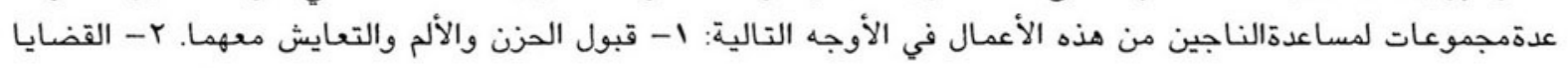


المتعلقة بالعدالة r - التكيف الإجتماعى ع- الوقاية من أسباب العنف أو تعليلها. إن شفاء الجزائريين من الحالة الراهنة

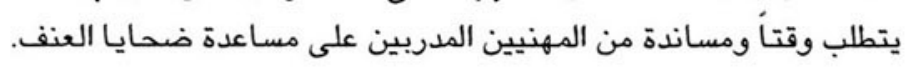

الهدف: تدعيم عملية "الإصلاح النفسى" والتكيف الإجتماعى لضحايا العنف من الجزائريين.

\section{هـ- مساندة المشرعات فى المجالات التالية:}

$$
\begin{aligned}
& \text { 1- النساء والحقوق } \\
& \text { r- النساء والمشاركة الإقتصادية }
\end{aligned}
$$

الأساس المنطقى:

إن حقوق النساء ومشاركتهن الإقتصادية وصحتهن ورفاهيتهن تتعرض لمشكلات محددة تواجه النساء الجزائريات في الوقت

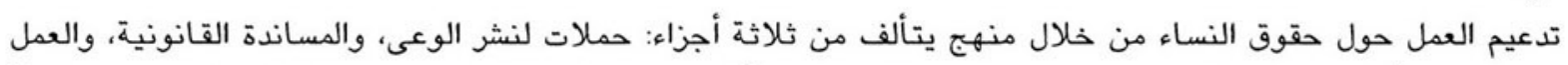

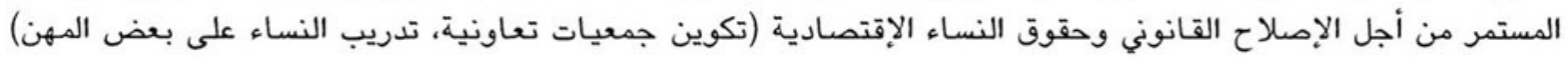
وصحة النساء.

\section{و - مجموعات المساندة فى مجال العنف المنزلي ضد النساء.}

الأساس المنطقى:

أن النساء الجزائريات لا يعانين من أعمال العنف والعنف المضاد فحسب، ولكنهن أيضاً ضحايا لأنواع أخرى من العنف المنزلي والمجتمعي والتمييز.

الهدف: مساندة المجموعات التي تتعرض لهذه الأنواع المتعددة من العنف والتمييز التي تواجهها النساء الجزائريات.

\section{ز- تبادل المعلومات بين الهينات الدولية والإقليمية العاملة في نفس المجال}

الأساس المنطقى:

تعانى الجمعيات النسائية في الجزائر من الإنعزال عن مثيلاتها في شمال أفريقيا والشرق الأوسط والدول الأجنبية الأخرى.

الهدف:

مساندة تبادل المعلومات بين التنظيمات النسائية في شمال أفريقيا والشرق الأوسط والدول الأخرى التي تعمل في نفس 


\section{ملحق رقم (Y)

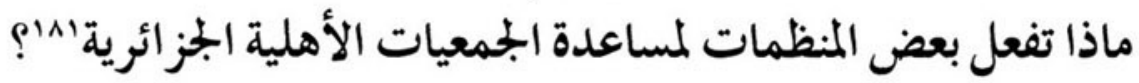

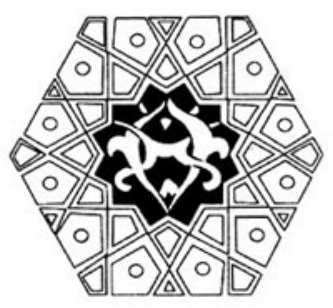

النساء في ظل القوانين الإسلامية - مكتب التنسيق في فرنسا:

هي شبكة دولية من الباحثين والنشطاء أصدرت ملفات باللغتين الإنجليزية والفرنسية تضم مقصوصات من الفواء الصحف عن الجزائر تحت عنوان "مقاومة وتضامن النساء في دول العالم (1990 و و 1997)".

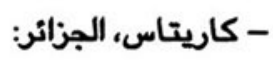

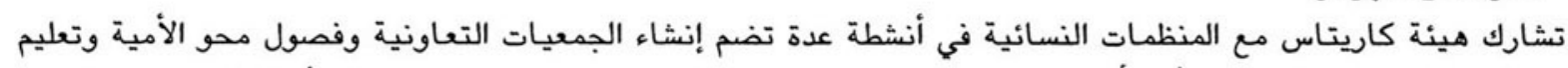

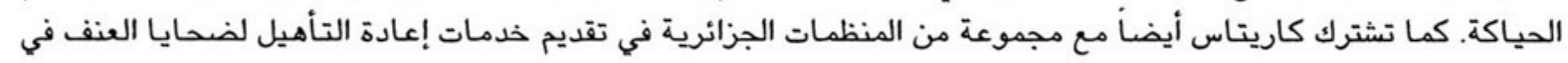
الجزائر.

السفارة الكندية/ سيدا/ الجزائر:

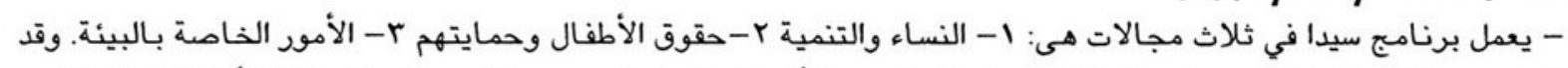
قدمت سيدا الدعم المالى للبدء في هذه المشروعات كما قدمت الأجهزة والمواد للعديد من الجمعيات النسائية الأهلية في الجزائر.

- فريدريش ناومان، الرياط:

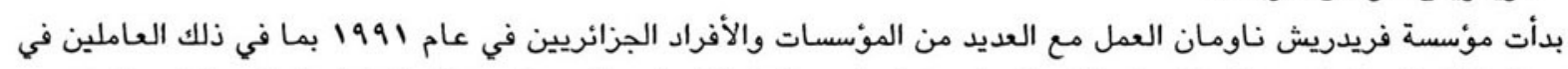

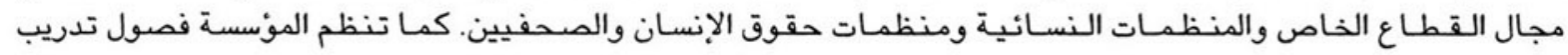
للمحفيين الشباب من الجزائر وتونس وأورويا. وتقوم المفوضية الأورويية بتقديم الدعم المالى لهذان الهات المشروع.

مؤسسة فريدريش اييرت: تونس

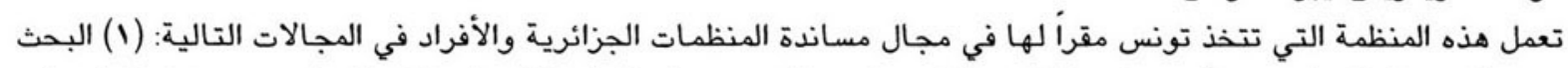

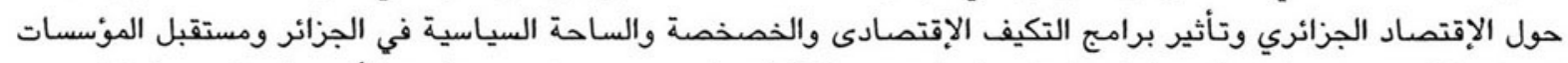

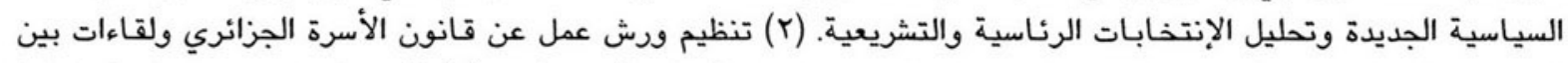

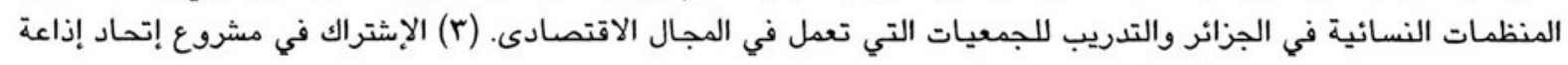
الدول العربية لتطوير الإتصالات والمشروعات والتريب الإذاعية في العالم العربى. في التئ.

\section{كندوق الأمم التحدة للانشطة السكانية: تونس/ الجزانر}

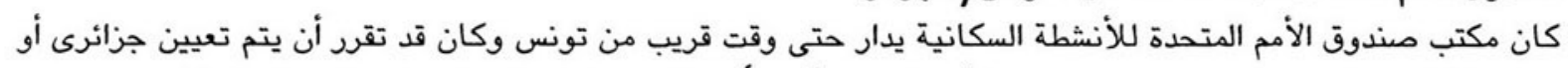

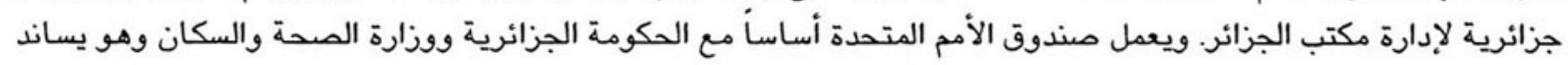

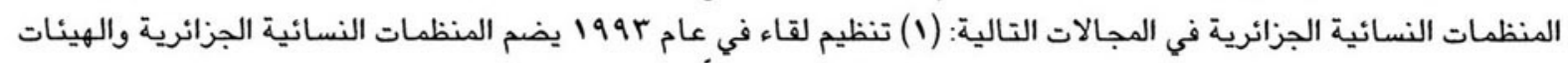
الدولية والجهات المانحة الثنائية التي تتخذ من الجزائر العاصمة مقرأ لها.

11 ا يقدم هذا الملحق مثالأ لما تقوم بـ بعض المؤسات لمساعدة الجمعيات الأهلية الجزانرية وهو لا يشمل كافة هذه الأنشطة. 


\section{مزٔسسة الإنسان: فرنسا}

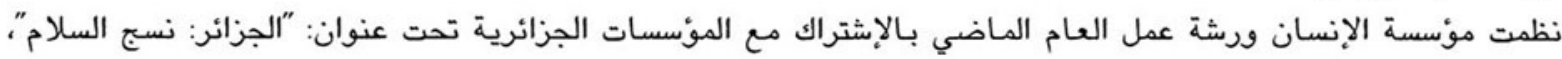

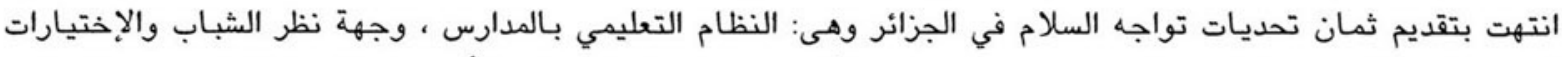

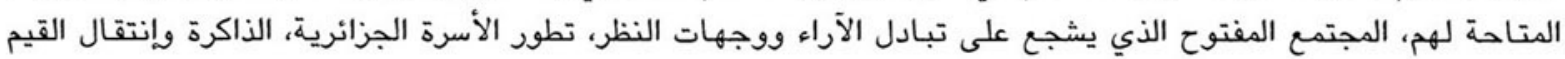
واعادة تعريف الدولة الجزائرية، ويناء المجتمع المدني وتكوين النخب.

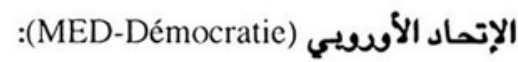
يساند برنـامج (MED-Démocratic) المشروعات في المجال السيـاسي والمدني ومجال الحقوق الإجتمـاعية والإقتصـادية وحماية الأفراد المهمشين. 